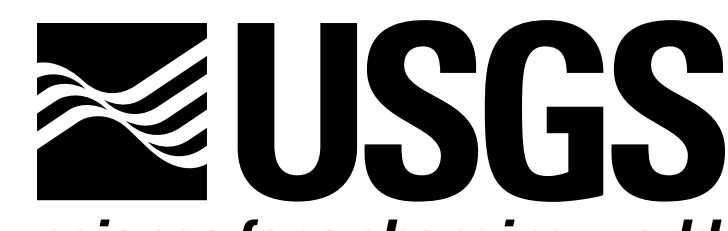

science for a changing world

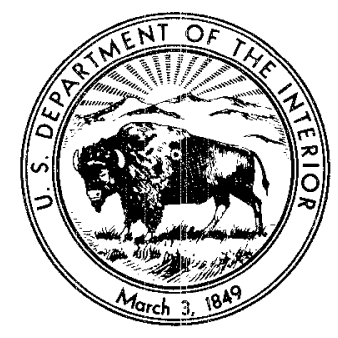

Techniques of Water-Resources Investigations of the United States Geological Survey

Chapter A8

DISCHARGE MEASUREMENTS AT

GAGING STATIONS

By Thomas J. Buchanan and William P. Somers

Book 3

APPLICATIONS OF HYDRAULICS 


\section{UNITED STATES DEPARTMENT OF THE INTERIOR}

THOMAS S. KLEPPE, Secretary

\section{GEOLOGICAL SURVEY}

V. E. McKelvey, Director 


\section{PREFACE}

The series of manuals on techniques describes procedures for planning and executing specialized work in water-resources investigations. The material is grouped under major subject headings called books and further subdivided into sections and chapters; section $\boldsymbol{\Lambda}$ of book 3 is on surface-water techniques.

Provisional drafts of chapters are distributed to field offices of the U.S. Geological Survey for their use. These drafts are subject to revision because of experience in use or because of advancement in knowledge, techniques, or equipment. After the technique described in a chapter is sufficiently developed, the chapter is published and is sold by the U.S. Geological Survey, 1200 South Eads Street, Arlington, VA 22202 , (authorized agent of Superintendent of Documents, Government Printing Office). 


\section{CONTENTS}

Preface

Abstract.

Introduction

Current-meter measurements. . . . . . . . . . .

Instruments and equipment

Current meters

Vertical-axis current meters

Horizontal-axis current meters

Optical current meter

Care of the vertical-axis current meter.

Rating of current meters $\ldots \ldots$.

Sounding equipment $\ldots \ldots \ldots \ldots$

Wading rods ..................

Sounding weights and accessories.

Sounding reels

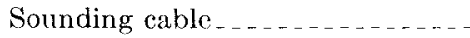

Connectors .......................

Depth indicators......................

Power unit ......................

Handlines

Width-measuring equipment . . . .....

Equipment assemblies ...............

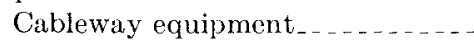

Bridge equipment .............

Boat equipment . . . . . . . . . . .

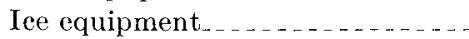

Velocity-azimuth-depth-assembly

Miscellaneous equipment .......

Measurement of velocity . . . . . . . . . . . .

Vertical-velocity curve method.......

Two-point method ..............

Six-tenths-depth method...........

Two-tenths-depth method ..........

Three-point method...............

Subsurface method

\begin{tabular}{r|} 
Page \\
III \\
1 \\
1 \\
1 \\
4 \\
4 \\
4 \\
7 \\
7 \\
\\
7 \\
8 \\
9 \\
9 \\
11 \\
13 \\
14 \\
14 \\
14 \\
15 \\
15 \\
16 \\
17 \\
18 \\
18 \\
20 \\
24 \\
27 \\
27 \\
30 \\
31 \\
31 \\
32 \\
32 \\
33 \\
37 \\
37
\end{tabular}

Current-meter measurements-Continued

Current-meter measurement procedure... -

Current-meter measurements by wading. .............................

Current-meter measurements from cableways _.............................

Current-meter measurements from bridges...........................

Current-meter measurements from ice cover..............................

Current-meter measurements from

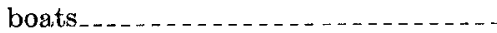

Moving-boat measurements of discharge _... . . . . . . . . . . . . . .

Networks of current meters . ........

Measurement of deep, swift streams . Possible to sound; weight and meter drift downstream.....--

Not possible to sound; standard cross section available

Not possible to sound; standard cross section not available....

Not possible to put meter in water

Measurements during rapidly changing stage . . . . . ....................

Series of measurements during a peak of short duration..................

Mean gage height of discharge measurements.........................

Portable weir plates Portable Parshall flumes, description and theory Volumetric measurements.

Indirect discharge measurements....... 64 Dye-dilution method of measuring discharge $\ldots \quad 6.4$

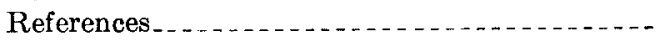

Pagre

\section{FIGURES}

1. Definition sketch of midsection method of computing cross-section area for

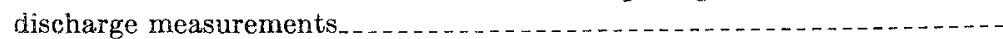

2. Computation notes of a current-meter measurement by the midsection

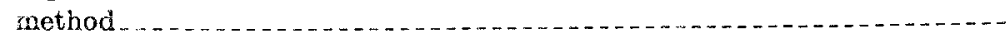

3. Assembly drawing of small Price type AA current meter.

Page 
4. Price type AA and Price pygmy meters

5. Vane ice meter, and vane meter with cable suspension yoke.........

6. Magnetic switch contact chamber, shaft, and adapter bushing, and

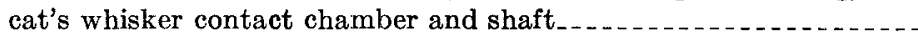

7. Ott current meter

8. Velocity components measured by Ott and Price current meters..........

9. Photograph of Hoff current meter.

10. Photograph of optical current meter

11. Current-meter rating table

12-55. Photographs:

12. Top-setting wading rod with meter attached $\ldots \ldots \ldots$

13. Closeup view of setting scale on handle of top-setting rod........

14. Parts for round wading rod

15. Round wading rod with meter attached .

16. Lower section of ice rod for use with vane ice meter

17. Lower section of ice rod for use with Price meter

18. Columbus sounding weights

19. Sounding-weight hangers and hanger pins

20. A-pack reel

21. Canfield reel $\ldots \ldots$

22. B-56 reel $\ldots \ldots$

23. E-53 reel

24. Connectors

25. Computing depth indicator

26. Power unit for sounding reel .

27. Handline $\ldots \ldots \ldots$

28. Lee- $\mathrm{Au}$ and Morgan handline reels...

29. Handline in use from a bridge

30. Sonic-sounding recorder

31. Sounding weight with compass and sonic transducer...............

32. Sonic measuring assembly ........

33. Pakron, Lee-Au and Columbus type $\mathrm{A}$ tag-line reels

34. Sitdown cable car.......

35. Standup cable car $\ldots \ldots$

36. Portable reel seat on sitdown type cable car.......

37. Cable-car pullers

38. Battery-powered cable car

39. Gasoline-powered cable car $\ldots$

40. Sitdown cable car with Canfield reel clamped to side of car........

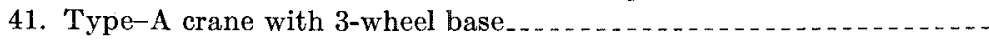

42. Type-A crane with 4-wheel base

43. Bridge board in use

44. Truck-mounted crane used on the Mississippi River-..............

45. Horizontal-axis boat tag-line reel without a brake

46. Horizontal-axis boat tag-line rool with a brake

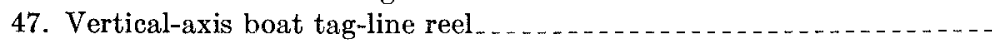

48. Boom and crosspiece for use on boats

49. Measuring equipment set up in a boat

50. Gasoline-powered ice drill.

51. Collapsible reel support and ice-weight assembly

52. Velocity-azimuth-depth assembly

53. Stopwatch $\ldots$

54. Automatic counter and headphone

55. Ice creapers for boots and wagers.

56. Tpyical verical-velocity curve.... 
58. Photograph showing wading measurement using top-setting rod

59. Photograph showing ice rod being used to support current meter for a discharge measurement and ice drill being used to cut holes.

60. Diagram showing method of computing meter settings for measurements under ice.

61. Typical vertical-velocity curve under ice cover

62. Sample sheet of part of notes for discharge measurement under ice cover.... 63-65. Diagrams:

63. Determining position in the cross section section, stadia method....

64. Determining position in the cross section, angular method.....

65. Position of sounding weight and line in deep, swift water.

66. Sketch of geometry of relationship of actual to measured vertical angle when

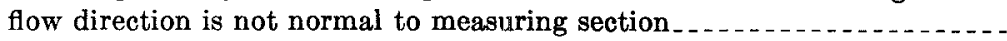

67-69. Charts:

67. Computation of weighted mean gage height

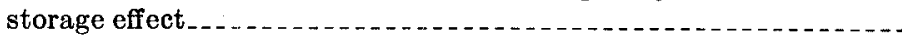

69. Discharge measurement notes with mean gage height adjusted for time-of-travel of flood wave.

70. Expanded plot of gage-height graph during measurement 264 at Big Creek near Dogwood, Va

71. Sketch showing portable weir plate sizess.

72. Photograph of modified 3-inch Parshall flume made of sheet iron . . . . .

73. Working drawing of modified 3-inch Parshall flume.

\section{TABLES}

1. Sounding reel data

2. Current-meter and velocity-measurement method for various depths.

3. Velocity-measurement method for various suspensions and depths

4. Air-correction table, giving difference, in feet, between vertical length and slant length of sounding line above water surface for selected vertical angles.........

5. Wet-line table, giving difference, in feet, between wet-line length and vertical depth for selected vertical angles.

6. Degrees to be added to observed angles to obtain actual vertical angles.

7. Summary table for setting the meter at 0.8-depth position in deep, swift streams .

8. Rating table for 3-inch modified Parshall flume 


\title{
DISCHARGE MEASUREMENTS AT GAGING STATIONS
}

\author{
By Thomas J. Buchanan and William P. Somers
}

\begin{abstract}
The techniques used in making discharge measurements at gaging stations are described in this report. Most of the report deals with the current-meter method of measuring discharge, because this is the principal method used in gaging streams. The use of portable weirs and flumes, floats, and volumetric tanks in measuring discharge are briefly described.
\end{abstract}

\section{Introduction}

The U.S. Geological Survey makes thousands of streamflow measurements each year. Discharges measured range from a trickle in a ditch to a flood on the Amazon. Several methods are used, but the Geological Survey makes most streamflow measurements by current meter. The purpose of this report is to describe in detail the procedures used by the Geological Survey for making currentmeter measurements and to describe briefly several of the other methods of measuring streamflow.

Streamflow, or discharge, is defined as the volume rate of flow of the water including any sediment or other solids that may be dissolved or mixed with it. Dimensions are usually expressed in cubic feet per second. Other common units are million gallons per day and acre-feet per day.

\section{Current-Meter Measurements}

A current-meter measurement is the summation of the products of the partial areas of the stream cross section and their respective average velocities. The formula

$$
Q=\Sigma(a v)
$$

represents the computation where $Q$ is total discharge, $a$ is an individual partial crosssection area, and $v$ is the corresponding mean velocity of the flow normal to the partial area.

In the midsection method of making a current-meter measurement it is assumed that the velocity sample at each location represents the mean velocity in a partial rectangular area. The area extends laterally from half the distance from the preceding meter location to half the distance to the next and vertically, from the water surface to the sounded depth. (See fig. 1.)

The cross section is defined by depths at locations $1,2,3,4, \ldots n$. At each location the velocities are sampled by current meter to obtain the mean of the vertical distribution of velocity. The partial discharge is now computed for any partial section at location $x$ as

$$
\begin{gathered}
q_{x}=v_{x}\left[\frac{\left(b_{x}-b_{(x-1)}\right)}{2}+\frac{\left(b_{(x+1)}-b_{x}\right)}{2}\right] d_{x} \\
=v_{x}\left[\frac{b_{(x+1)}-b_{(x-1)}}{2}\right] d_{x},
\end{gathered}
$$

where

$q_{x}=$ discharge through partial section $x$,

$v_{x}=$ mean velocity at location $x$,

$b_{x}=$ distance from initial point to location $x$,

$b_{(x-1)}=$ distance from initial point to preceding location,

$b_{(x+1)}=$ distance from initial point to next location,

$d_{x}=$ depth of water at location $x$. 


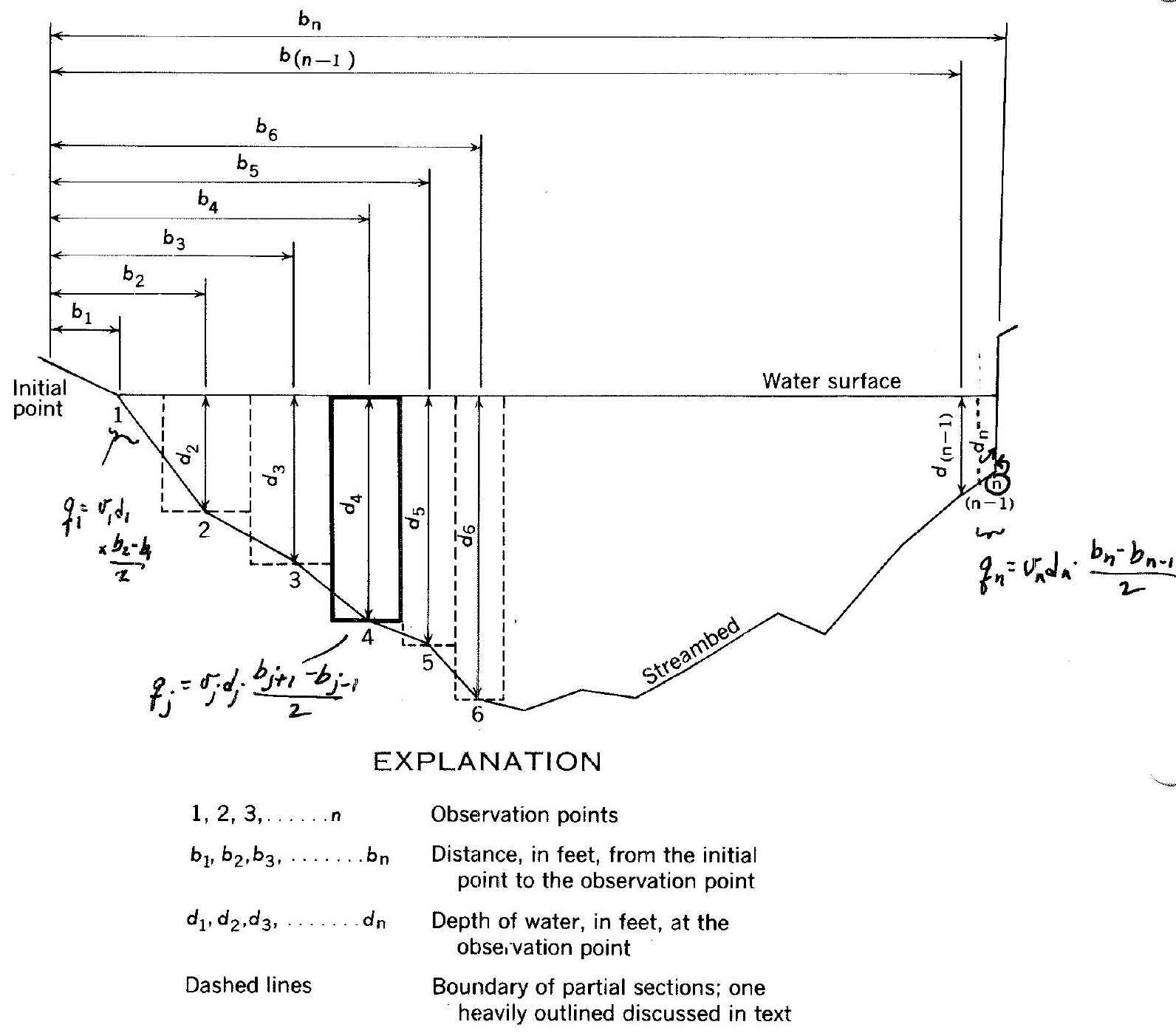

Figure 1.-Definition sketch of midsection method of computing cross-section area for discharge measurements.

Thus, for example, the discharge through partial section 4 (heavily outlined in fig. 1) is

$$
q_{4}=v_{4}\left[\frac{b_{5}-b_{3}}{2}\right] d_{4} .=0 d_{2}
$$

The procedure is similar when $x$ is at an end section. The "preceding location" at the beginning of the cross section is considered coincident with location 1 ; the "next location" at the end of the cross section is considered coincident with location $n$. Thus,

$$
\begin{aligned}
& q_{1}=v_{1}\left[\frac{b_{2}-b_{1}}{2}\right] d_{1}, \text { and } \\
& q_{n}=v_{n}\left[\frac{b_{n}-b_{(n-1)}}{2}\right] d_{n} .
\end{aligned}
$$

For the example shown in figure $1, q_{1}$ is zero because the depth at observation point 1 is zero. However, when the cross-section boundary is a vertical line at the edge of the water as at location $n$, the depth is not zero and velocity at the end section may or may not be zero. The formula for $q_{1}$ or $q_{n}$ is used whenever there is water only on one side of an observation point such as at piers, abutments, and islands. It usually is necessary to estimate the velocity at an end section as some percentage of the adjacent section because it normally is impossible to measure the velocity accurately with the current meter close to a boundary. There also 
is the possibility of damage to the equipment if the flow is turbulent.

The summation of the discharges for all the partial sections is the total discharge of the stream. An example of the measurement notes is shown in figure 2 .
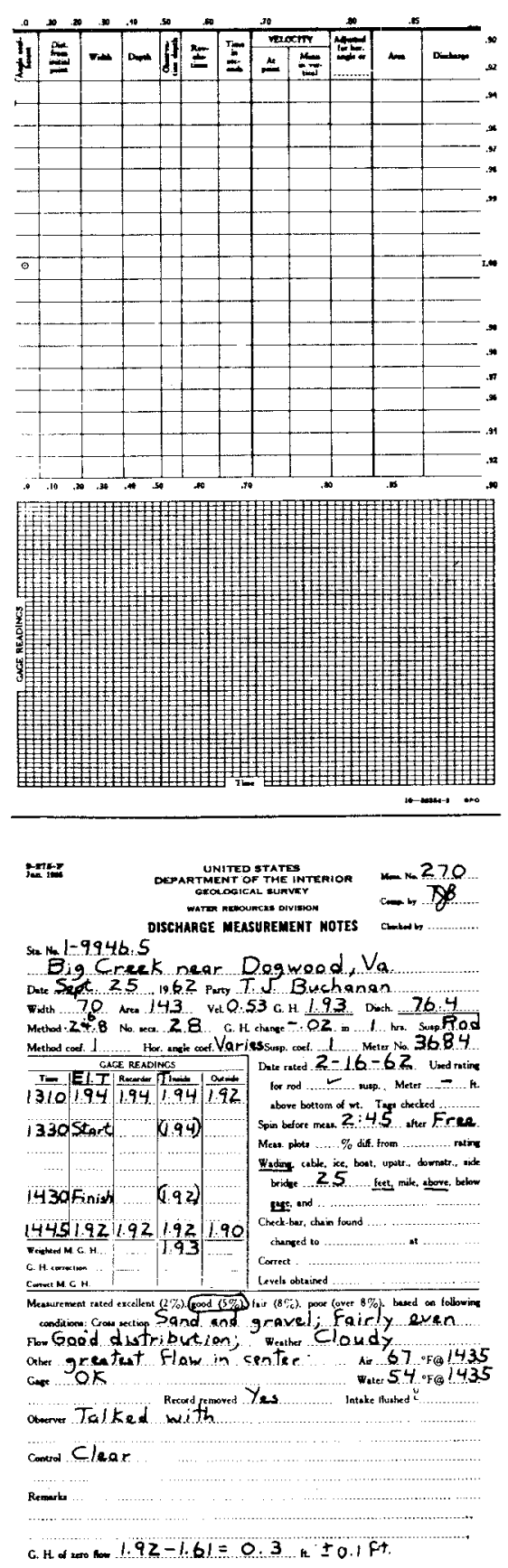

The mean-section method used by the Survey prior to 1950 differs from the midsection method in computation procedure. Partial discharges are computed for partial sections between successive locations. The velocities and depths a.t successive locations are each averaged, and

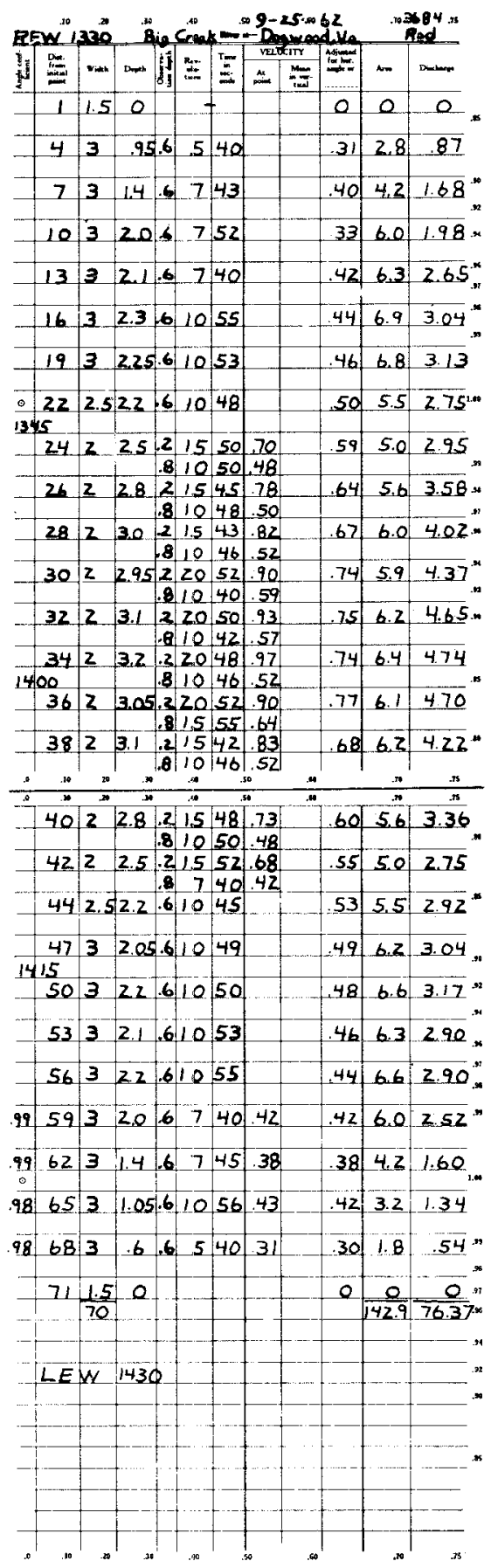

Figure 2.-Computation notes of a current-meter measurement by the midsection method. 
the section extends laterally from one observation point to the next. Discharge is the product of the average of two mean velocities, the average of two depths, and the distance between locations. A study by Young (1950) concluded that the midsection method is simpler to compute and is a slightly more accurate procedure than the mean-section method.

Current-meter measurements usually are classified in terms of the means used to cross the stream during the measurement, such as wading, cableway, bridge, boat, or ice.

\section{Instruments and equipment}

Current meters, timers, and counting equipment are used when making conventional types of measurements. Additional equipment used depends on the type of measurements being made. Instruments and equipment used in making current-meter measurements are described in this section under the following categories: current meters, sounding equipment, width-measuring equipment, equipment assernblies, and miscellaneous equipment.

\section{Current meters}

A current meter is an instrument used to measure the velocity of flowing water. The principle of operation is based on the proportionality between the velocity of the water and the resulting angular velocity of the meter rotor. By placing a current meter at a point in a stream and counting the number of revolutions of the rotor during a measured interval of time, the velocity of water at that point is determined.

The number of revolutions of the rotor is obtained by an electrical circuit through the contact chamber. Contact points in the chamber are designed to complete an electrical circuit at selected frequencies of revolution. Contact chambers can be selected having contact points that will complete the circuit twice per revolution, once per revolution, or once per five revolutions. The electrical impulse produces an audible click in a headphone or registers a unit on a counting device.

The counting intervals are measured by a stopwatch.
Current meters generally can be classified into two main types, those meters having vertical-axis rotors and those having horizontalaxis rotors. The comparative characteristics of these two types are summarized below:

1. Vertical-axis rotor with cups or vanes.

a. Operates in lower velocities than do horizontal-axis meters.

b. Bearings are well-protected from silty water.

c. Rotor is repairable in the field without adversely affecting the rating.

d. Single rotor serves for the entire range of velocities.

2. Horizontal-axis rotor with vanes.

a. Rotor disturbs flow less than do vertical-axis rotors because of axial symmetry with flow direction.

b. Rotor is less likely to be entangled by debris than are vertical-axis rotors.

c. Bearing friction is less than for verticalaxis rotors because bending moments on the rotor are eliminated.

Vertical-axis current meters

The most common type of vertical-axis current meter is the Price meter, type AA. (See fig. 3.) This meter is used extensively by the Geological Survey. The standard Price meter has a rotor 5 inches in diameter and 2 inches high with six cone-shaped cups mounted on a stainless-steel shaft. A pivot bearing supports the rotor shaft. The contact chamber houses the upper part of the shaft and an an eccentric contact that wipes a bead of solder on a slender bronze wire (cat's whisker) attached to the binding post. A separate reduction gear (pentagear), wire, and binding post provide a contact each time the rotor makes five revolutions. A tailpiece keeps the meter pointing into the current.

In addition to the standard type $\mathrm{AA}$ meter for general use there is a type AA meter for low velocities. No pentagear is provided. This modification reduces friction. The shaft usually has two eccentrics making two contacts per revolution. The low-velocity meter normally is rated from 0.2 to 2.5 fps (feet per second) and is recommended when the mean velocity at a cross section is less than $1 \mathrm{fps}$.

In addition to the type $\mathrm{AA}$ meters, the Geological Survey uses a Price pygmy meter 


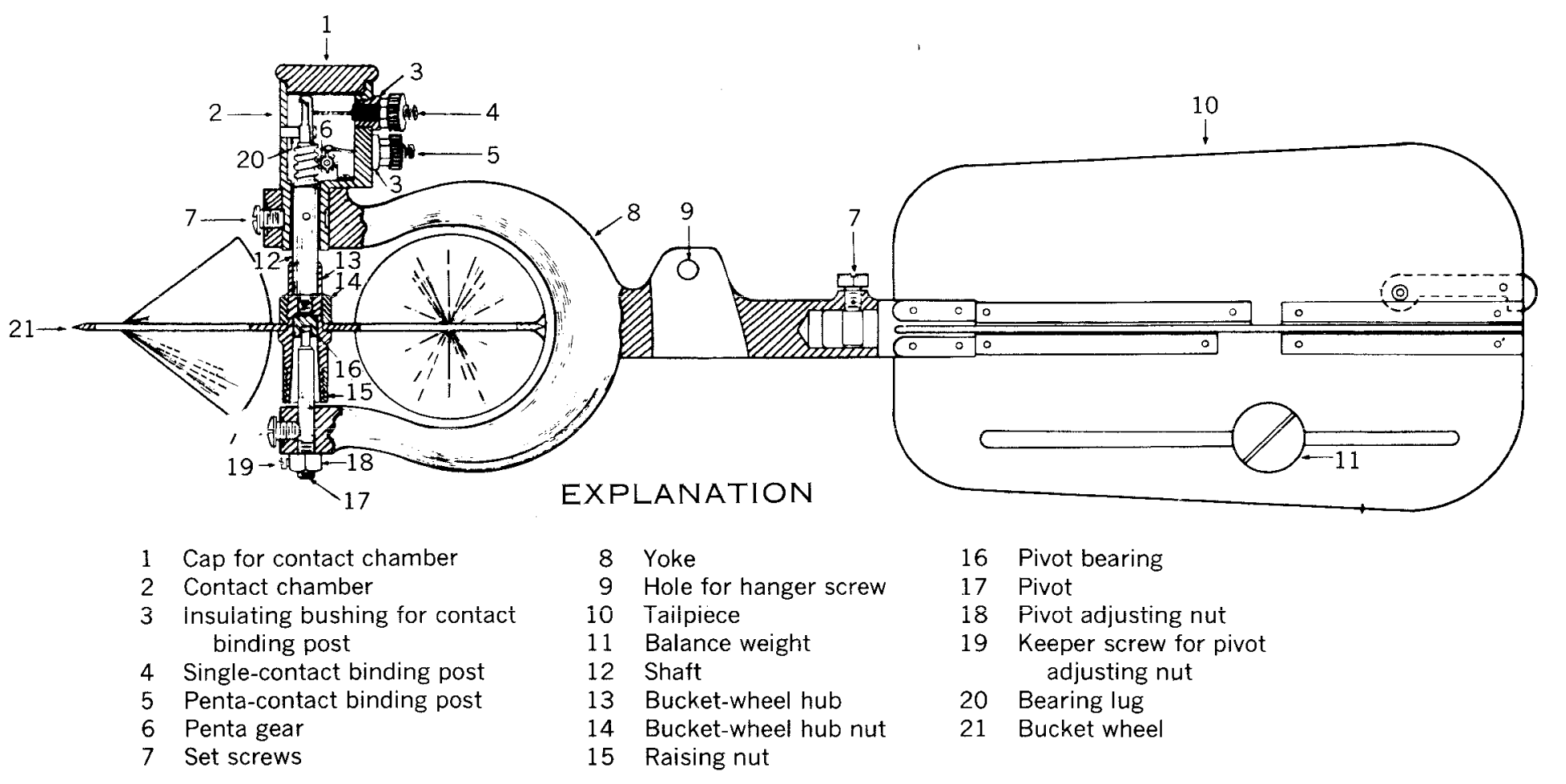

Figure 3.-Assembly drawing of small Price type AA current meter. 
in shallow depths. (See fig. 4.) The pygmy meter is scaled two-fifths as large as the standard meter and has neither a tailpiece nor a pentagear. The contact chamber is an integral part of the yoke of the meter. The pygmy meter makes one contact each revolution and is used only for rod suspension.

The Geological Survey has recently developed a four-vane vertical-axis meter. (See fig. 5.) This meter is useful for measurements under ice cover because the vanes are less likely to fill with slush ice, and because it requires a much smaller hole to pass through the ice. One yoke of the vane meter is made to be suspended at the end of a rod and will fit holes made by an ice drill. Another yoke is made for regular suspensions. (See fig. 5.) The vane meter has a disadvantage of not responding as well as the Price type AA meter at velocities below $0.5 \mathrm{fps}$.

A new contact chamber has been designed by the Geological Survey to replace the wiper

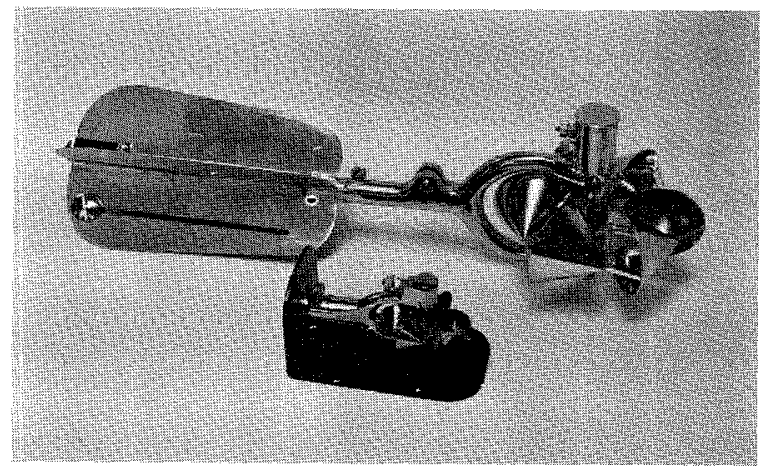

Figure 4.-Price type AA meter, top; and Price pygmy meter, bottom

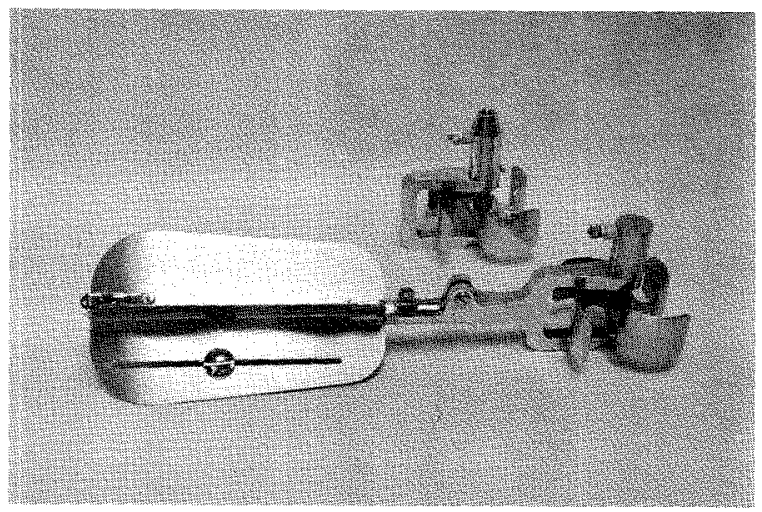

Figure 5-Vane ice meter, top; and vane meter with cable suspension yoke, bottom. contact of the type AA and vane meters. The new contact chamber contains a magnetic switch, glass enclosed in a hydrogen atmosphere and hermetically sealed. The switch assembly is rigidly fixed in the top of the meter head just above the tip of the shaft. The switch is operated by a small permanent magnet rigidly fastened to the shaft. The switch quickly closes when the magnet is alined with it, and then promptly opens when the magnet moves away. The magnet is properly balanced on the shaft. Any type AA meter can have a magnetic switch added by replacing the shaft and the contact chamber. (See fig. 6.) The magnetic switch is placed in the special contact chamber through the tapped hole for the binding post. The rating of the meter is not altered by the change. An automatic counter (see p. 31) is used with the magnetic-switch contact chamber. If a headphone is used, arcing can weld the contacts.

A Price meter accessory that indicates the direction of flow is described on page 27 .

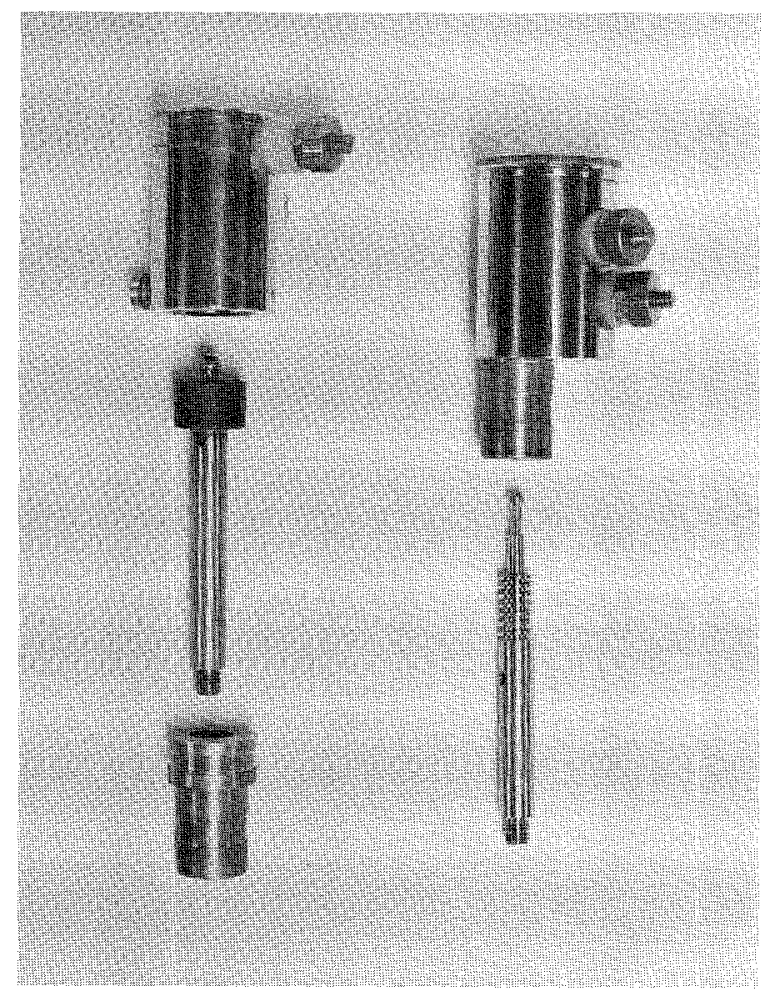

Figure 6-Magnetic switch contact chamber, shaft, and adapter bushing, left; and cat's whisker contact chamber and shaft, right. 
The care and rating of vertical-axis meters is described below and by Smoot and Novak (1968).

\section{Horizontal-axis current meters}

The types of horizontal-axis meters in use are the Ott, Neyrpic, Haskell, and Hoff. The Ott meter is made in Germany, the Neyrpic meter in France, and both are used extensively in Europe. The Haskell and Hoff meters were developed in the United States where they are used to a limited extent.

The Ott meter is a precision instrument but is not used extensively in this country because it is not as durable as the Price meter under extreme conditions. (See fig. 7.) The makers of the Ott meter have developed a component propeller which in oblique currents automatically registers the velocity projection at right angles to the measuring section for angles as much as $45^{\circ}$ and velocities as much as $8 \mathrm{fps}$. For example, if this component propeller were held in the position $A B$ in figure 8 it would

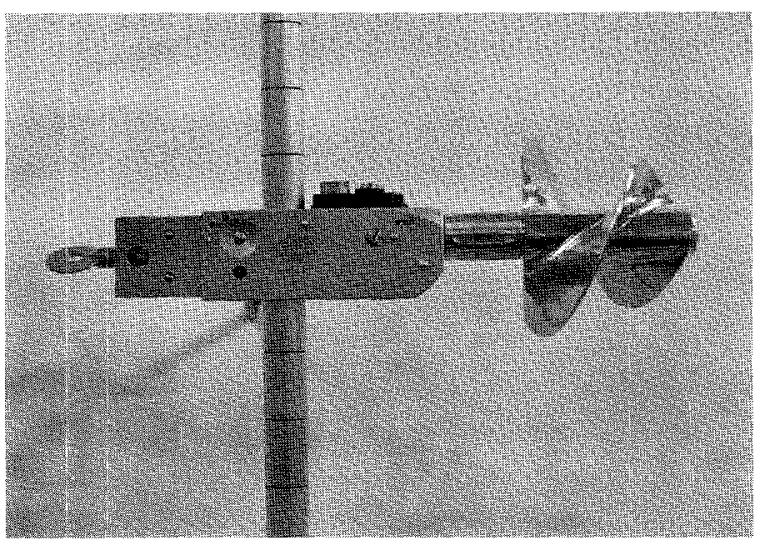

Figure 7.-Ott current meter.

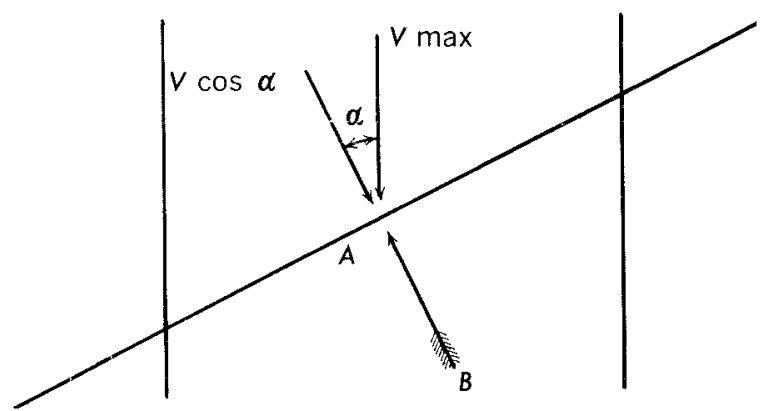

Figure 8.-Velocity components measured by Ott and Price current meters. register $V \cos \alpha$ rather than $V$, which the Price meter would register.

The Neyrpic meter is used rarely in this country because it has the same disadvantages as the Ott meter.

The Haskell meter has been used by the U.S. Lake Survey, Corps of Engineers, in streams that are deep, swift, and clear. By using propellers with a variety of screw pitches, a considerable range of velocity can be measured. The meter is durable, but has most of the other disadvantages of horizontal-axis meters.

The Hoff meter is used by the Geological Survey, the Department of Agriculture, and others, especially for measuring pipe flow. (See fig. 9.) The lightweight propeller has three or four vanes of hard rubber. The meter is suited to measurement of low velocities, but not for rugged use.

Optical current meter

The Geological Survey, in cooperation with the California Department of Water Resources, has developed an optical current meter. (See fig. 10.) This meter is a stroboscopic device designed to measure surface velocities in open channels without immersing equipment in the stream. The optical current meter will find its principal use in measurements of surface velocity during floods when it is impossible to use conventional stream-gaging equipment because of extremely high velocities and a high debris content in the stream.

Care of the vertical-axis current meter

The calibration and maintenance of verticalaxis type current meters is presented in detail

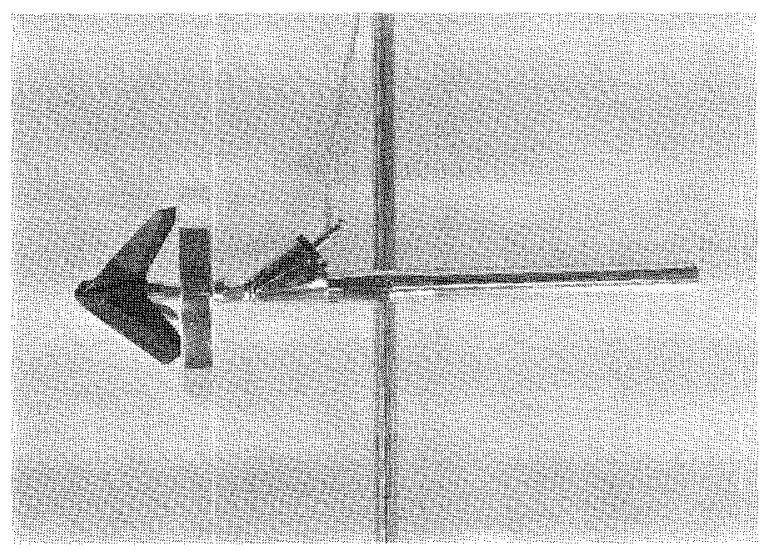

Figure 9.-Hoff current meter. 


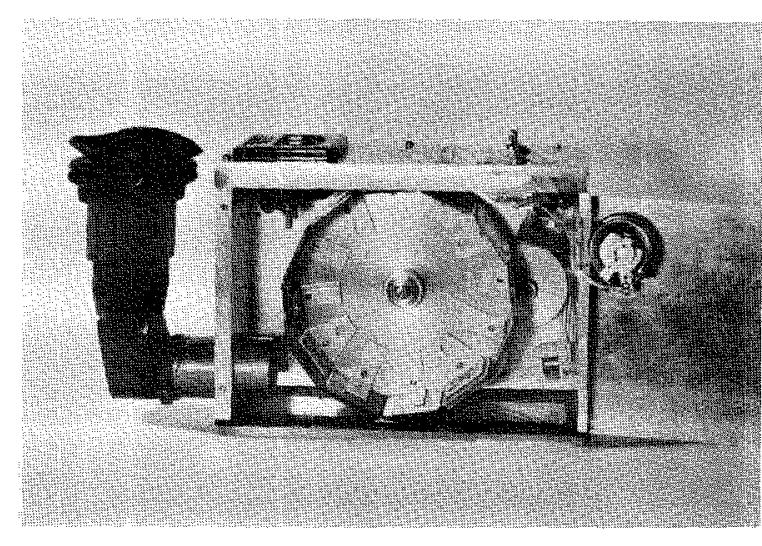

Figure 10.-Optical current meter.

by Smoot and Novak (1968). A brief description of the checks of the condition of a meter and the care and cleaning of it during daily field use is presented in the next few paragraphs.

Before and after each discharge measurement, examine the meter cups or vanes, pivot and bearing, and shaft for damage, wear, or faulty alinement. Before using the meter, check its balance if on a hanger, check the alinement of the rotor axis with a hanger or wading rod, and adjust the conductor wire to prevent interference with meter balance and rotor spin.

Clean and oil meters daily when in use. If measurements are made in water carrying noticeable suspended sediment, clean the meter immediately after each measurement. Surfaces to be cleaned and oiled are the pivot bearing, pentagear teeth and shaft, cylindrical shaft bearing, and thrust bearing at the cap.

After oiling, spin the rotor to make certain it operates freely. If the rotor stops abruptly, find the cause and correct the trouble before using the meter. On notes for each measurement, record the duration of spin. Obvious decrease in spin duration indicates need for attention to the bearings.

The pivot needs replacement more often than other meter parts. Examine the pivot after each measurement. Replace a fractured, rough, or worn pivot.

Keep the pivot and pivot bearing separated except during measurements. Use the raising nut if provided, or, for pygmy meters, replace the pivot by the brass plug.

Most minor repairs can be made in the field. Repair attempts, however, should be limited only to minor damages. This is particularly true of the rotor because minor dents in the bucket wheel or cups can have a large influence on the meter rating. Unless minor dents in the cups can be straightened out to "like new" condition, the entire rotor should be replaced with a new one. Badly sprung yokes, bent yoke stems, misalined bearings and tailpieces, should be reconditioned in shops equipped with the specialized facilities needed.

\section{Rating of current meters}

In order to determine the velocity of the water from the revolutions of the rotor of a current meter, a relation must be established between the angular velocity of the rotor and the velocity of the water turning it. The establishment of this relation, known as "rating the current meter," is done for the Geological Survey by the National Bureau of Standards.

Because there is rigid control in the manufacture of the small Price meter, virtually identical meters are produced and, for all practical purposes, their rating equations are identical. Therefore there is no need to calibrate the meters individually. Instead, a standard rating is established by calibrating a large number of meters that have been constructed according to Survey specifications and this rating is then supplied with each meter. Identicalness of meters is insured by supplying the dies and fixtures for the construction of small Price meters to the manufacturer who makes the successful bid.

Meters which have been rated by means of rod suspension, and then by means of cable suspension using Columbus-type weights and hangers, have not shown significant differences in rating. Therefore, no suspension coefficients are needed, and none should be used, if weights and hangers are properly used.

The current-meter rating station operated by the National Bureau of Standards in Washington, D.C., has a sheltered reinforced concrete basin 400 feet long, 6 feet wide, and 6 feet deep. An electrically driven car rides on rails extending the length of the basin. The car carries the current meter at a constant rate through the still water in the basin. Although the rate of travel can be accurately adjusted by means of a hydraulic regulating gear, the average velocity 
of the moving car is determined for each run by making an independent measurement of the distance it travels during the time that the revolutions of the rotor are electrically counted. A scale graduated in feet and tenths of a foot is used for this purpose. Eight pairs of runs are usually made for each current meter. A pair of runs consists of two traverses of the basin, one in each direction, at approximately the same speed. Practical considerations usually limit the ratings to velocities ranging from $0.1 \mathrm{fps}$ to about $15 \mathrm{fps}$, although the rating car can be operated at lower speeds. Unless a special request is made for a more extensive rating, the lowest velocity used in the rating is about $0.2 \mathrm{fps}$, and the highest is about $8.0 \mathrm{fps}$.

For convenience in field use, the data from the current-meter ratings are reproduced in tables, a sample of which is shown in figure 11. The velocities corresponding to a range of 3 to 350 revolutions of the rotor within a period of 40 to 70 seconds are listed in the tables. This range in revolution and time has been found to cover general field requirements. To provide the necessary information for extending a table for the few instances where extensions are required, the equations of the rating table are shown in the spaces provided in the heading. The equation to the left of the figure in parentheses (2.28 in fig. 11) is the equation for velocities less than $2.28 \mathrm{fps}$ and the equation to the right is for velocities greater than $2.28 \mathrm{fps}$. The 2.28 fps is the velocity common to both equations.

It should be noted that the equations given are those of the rating table, and not necessarily those of the actual rating. If a rating table already on file matches a rating within tolerances, that table is selected in preference to preparing a new one. Those tolerances are listed below.

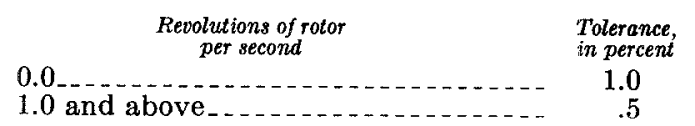

Sounding equipment

Sounding (determination of depth) is commonly done mechanically, the equipment used depending on the type of measurement being made. Depth and position in the vertical are messured by a rigid rod or by a sounding weight suspended from a cable. The cable is controlled either by a reel or by a handline. A sonic sounder is also available, but it is usually used in conjunction with a reel and a sounding weight.

Sounding equipment used by the Geological Survey is described in the following categories: wading rods, sounding weights, sounding reels, handlines, and sonic sounder.

\section{Wading rods}

The two types of wading rods commonly used are the top-setting rod and the round rod. The top-setting rod is preferred because of the convenience in setting the meter at the proper depth and because the hydrographer can keep his hands dry. The round rod can be used in making ice measurements as well as wading measurements, and has the advantage that it can be taken down to 1-foot lengths for storing and transporting.

The top-setting wading rod has a $1 / 2$-inch hexagonal main rod for measuring depth and a 3/8-inch diameter round rod for setting the position of the current meter. (See fig. 12.)

The rod is placed in the stream so the base plate rests on the streambed, and the depth of water is read on the graduated main rod. When the setting rod is adjusted to read the depth of water, the meter is positioned automatically for the 0.6-depth method. (See fig. 13 and p. 32.) The 0.6-depth setting might also be described as the 0.4-depth position up from the streambed. When the depth of water is divided by 2 and this new value is set, the meter would be at the 0.2-depth position up from the streambed. When the depth of water is multiplied by 2 and this value is set, the meter would be at the 0.8 depth position up from the streambed. These two positions represent the conventional $0.2-$ and 0.8-depth positions in reverse. (See p. 32.)

The round wading rod consists of a base plate, lower section, three or four intermediate sections, sliding support, and a rod end (not essential). (See fig. 14.) The parts are assembled as shown in figure 15. The meter is mounted on the sliding support and is set at the desired position on the rod by sliding the support.

The round rod is also used in making ice measurements. Intermediate sections of the round rod are screwed together to make an ice rod of desired length. (See fig. 16.) The most convenient length for an ice rod is about 3 feet 


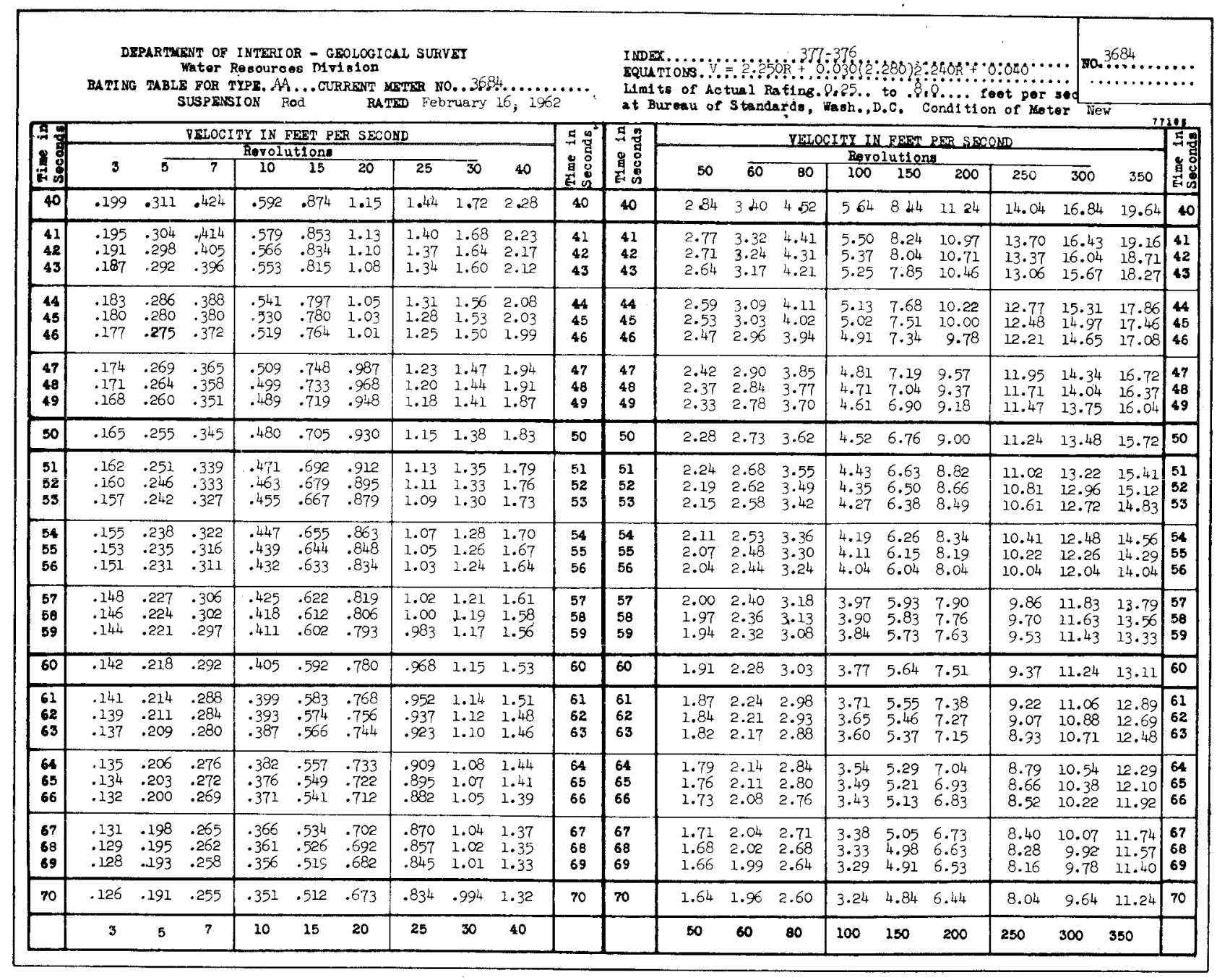

Figure 11.-Current-meter rating table. 


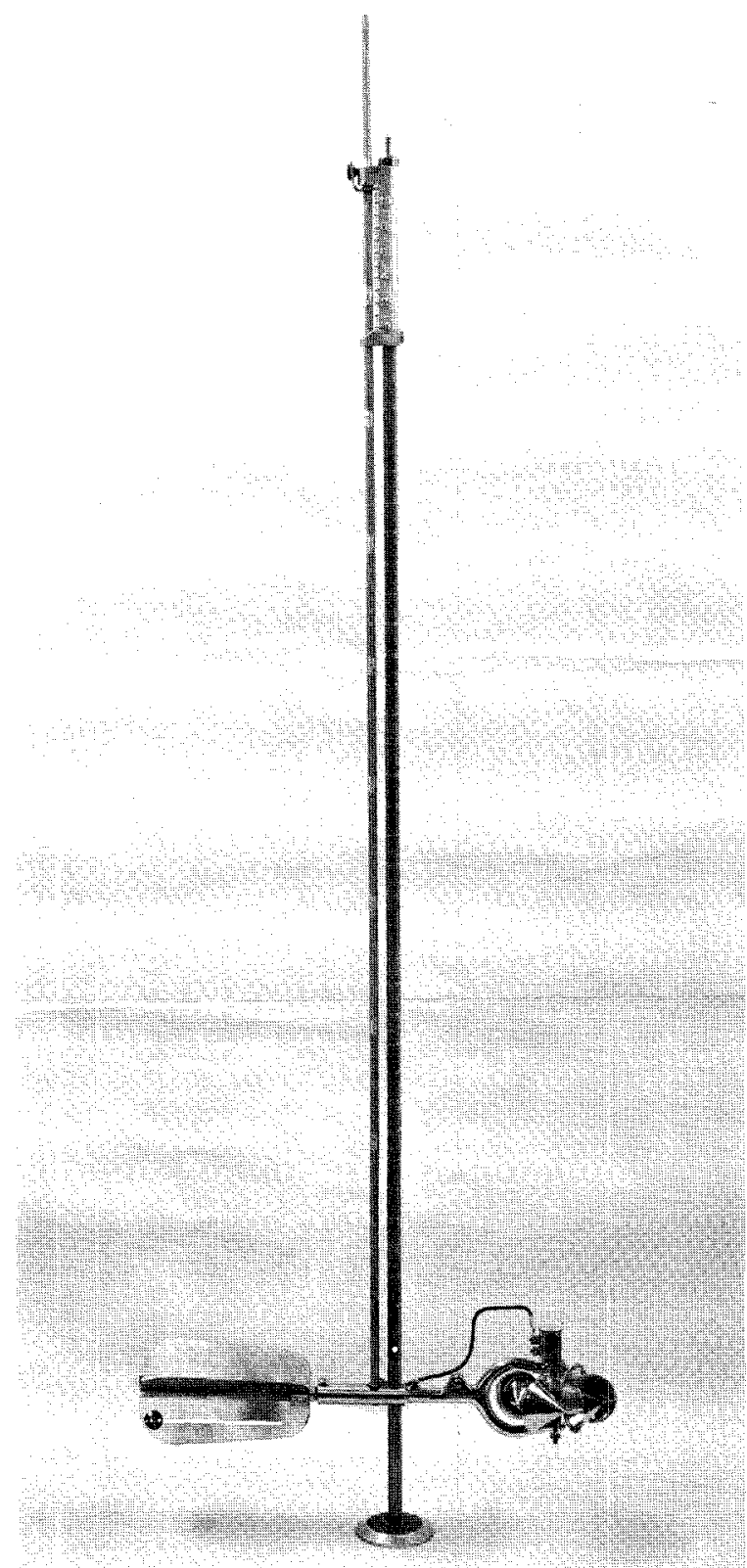

Figure 12.-Top-setting wading rod with meter aftached.

longer than the maximum depth of water to be found in a cross section. About 12 feet is the maximum practical length for an ice rod; depths greater than 10 feet are usually measured with a sounding weight and reel. The base plate, sliding support, and lower section are not used on an ice rod. Instead a special lower section is screwed directly into the top of the contact chamber of the vane ice meter. (See fig. 16.) If a Price meter is used under ice cover,

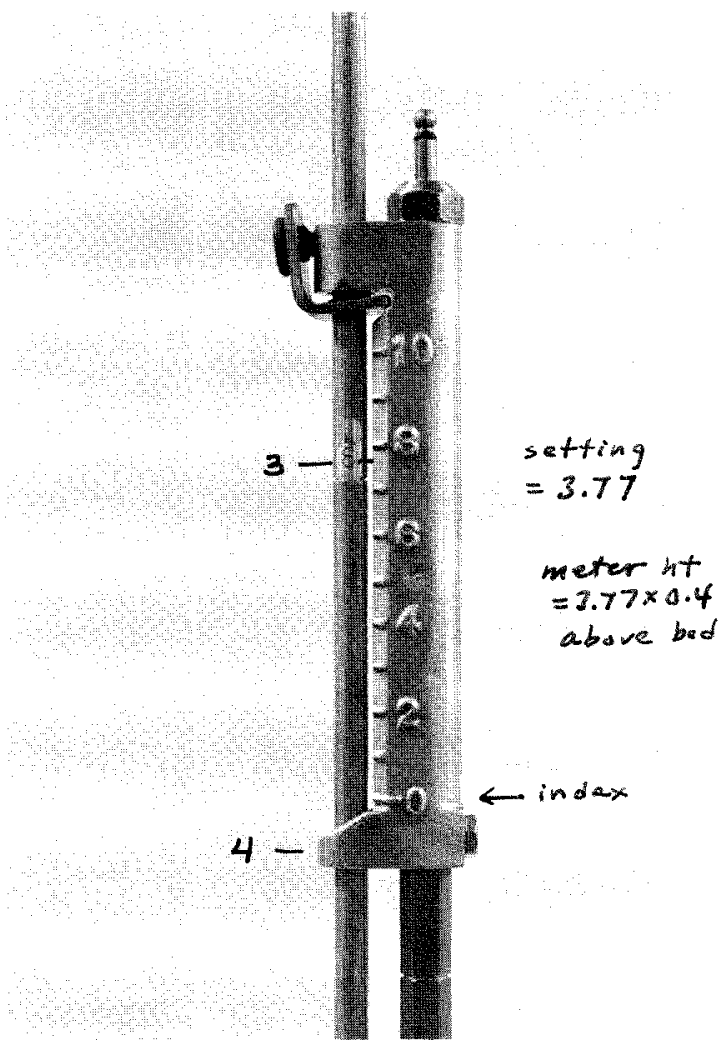

Figure 13.-Closeup view of setting scale on handle of top-setting rod.

another special lower section is used to hold the meter by means of the hanger screw. (See fig. 17.) All lower sections for ice rods now are made so that the center of the vanes or cups is at the 0 -foot point on the rod.

\section{Sounding weighits and accessories}

If a stream is too deep or too swift to wade, the current meter is suspended in the water from a boat, bridge, or cableway. A sounding weight is suspended below the current meter to keep it stationary in the water. The weight also prevents damage to the meter when the assembly is lowered to the streambed.

The sounding weights now used are the Columbus weights, commonly called the $\mathrm{C}$ type. (See fig. 18.) The weights are streamlined to offer minimum resistance to flowing water. Each weight has a vertical slot and a drilled horizontal hole to accommodate a weight hanger and securing pin.

The weight hanger is attached to the end of the sounding line by a connector. The current 


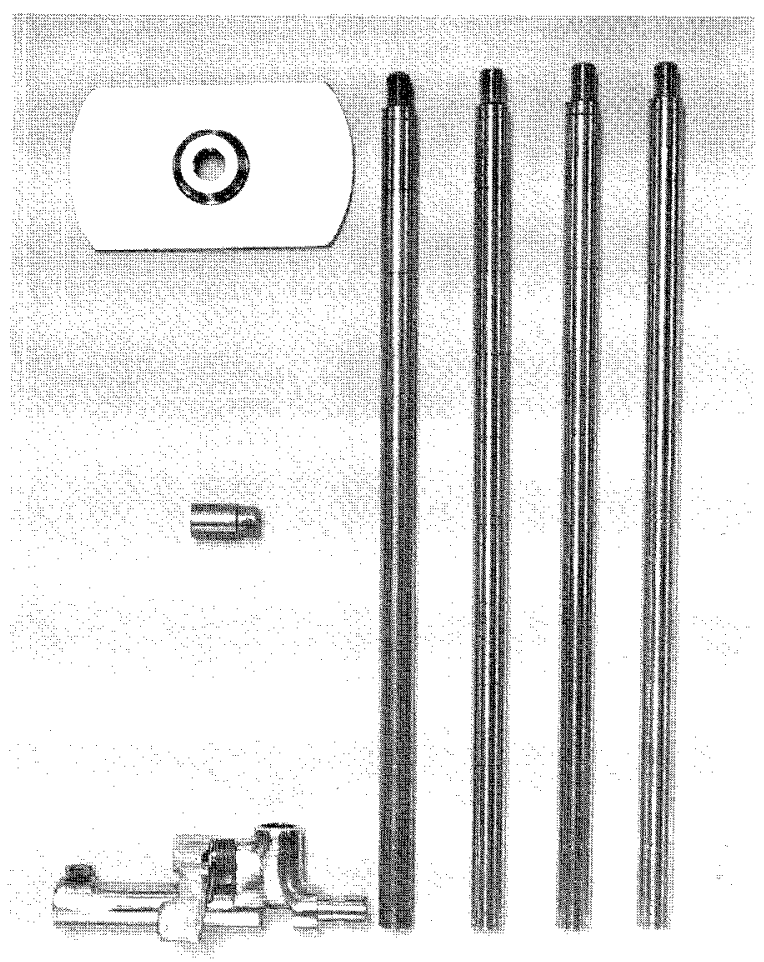

Figure 14.-Parts for round wading rod.

meter is attached beneath the connector, and the sounding weight is attached to the lower end of the hanger.

There are three types of weight hangers (fig. 19):

1. The Columbus or $\mathrm{C}$ type, $1 / 8$ by $3 / 4$ by 12 inches (for weights up to 150 pounds).

2. Heavy weight, $1 / 8$ by $3 / 4$ by 18 inches (for 200 - and 300 -pound weights).

3. Heavy weight, $1 / 8$ by $13 / 2$ by 18 inches (for 200 - and 300-pound sounding weights which have the slots properly extended to accommodate a 13/2-in. hanger).

The Columbus hanger has three holes in it in order to properly position the meter. The hanger screw of the current-meter yoke is placed through the bottom hole to support the meter when a 30-pound sounding weight is used. The center of the meter cups is then 0.5 foot above the bottom of the weight. This arrangement is designated as $30 \mathrm{C} .5$, which means that a 30-pound Columbus weight is being used and the center of the meter cups is

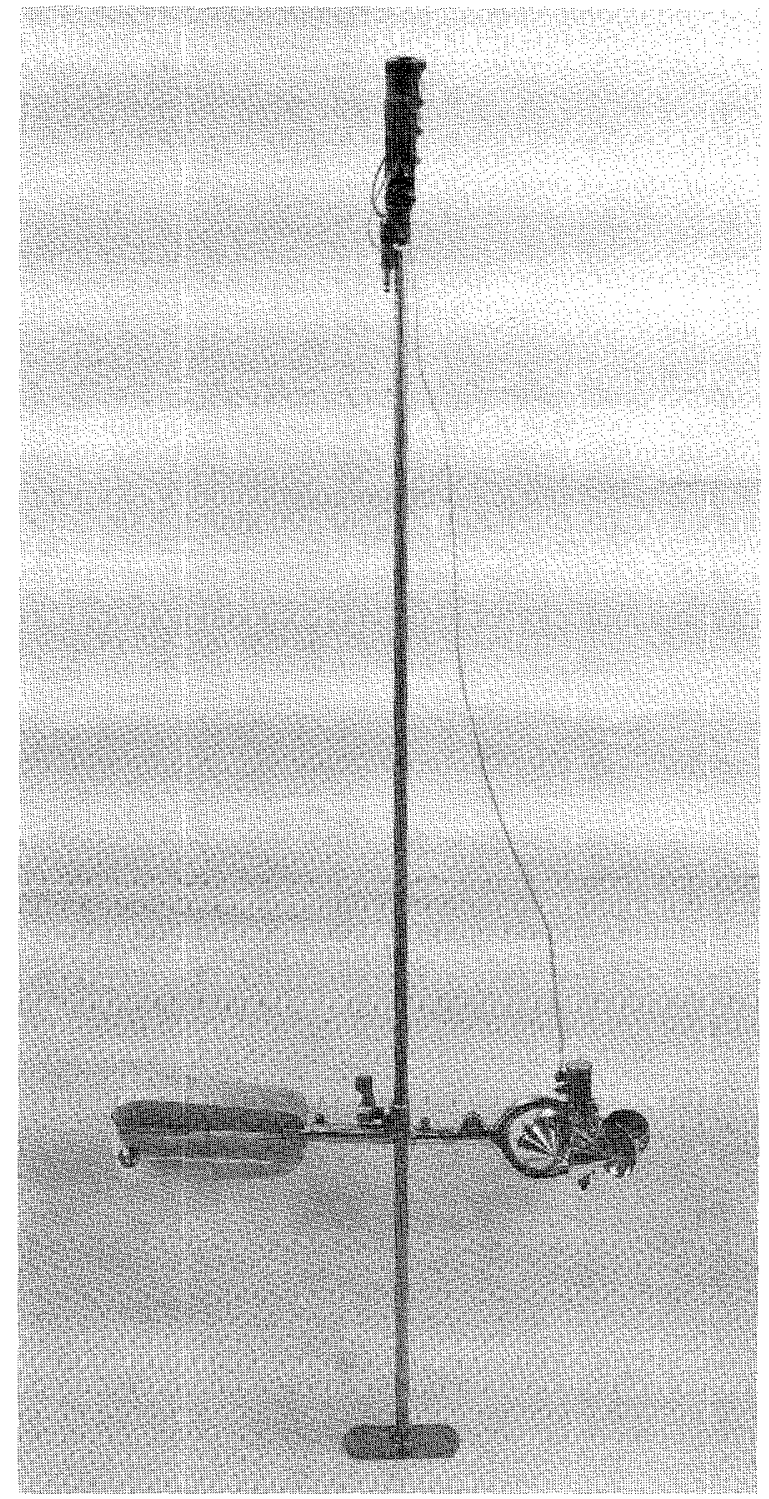

Figure 15.-Round wading rod with meter attached.

0.5 foot above the bottom of the weight. The hanger screw goes through the middle hole when $15-$ or 50 -pound weights are used. The designations for these arrangements are $15 \mathrm{C} .5$ and $50 \mathrm{C} .55$. The hanger screw goes through the upper hole when 50-, 75-, 100-, and 150-pound weights are used. The designations for these arrangements are $50 \mathrm{C} .9,75 \mathrm{C} 1.0,100 \mathrm{C} 1.0$, and $150 \mathrm{C}$ 1.0. Each of the two heavy-weight hangers has only one hole for the hanger screw of the meter. The designations for these arrangements are $200 \mathrm{C} 1.5$ and $300 \mathrm{C} 1.5$. 


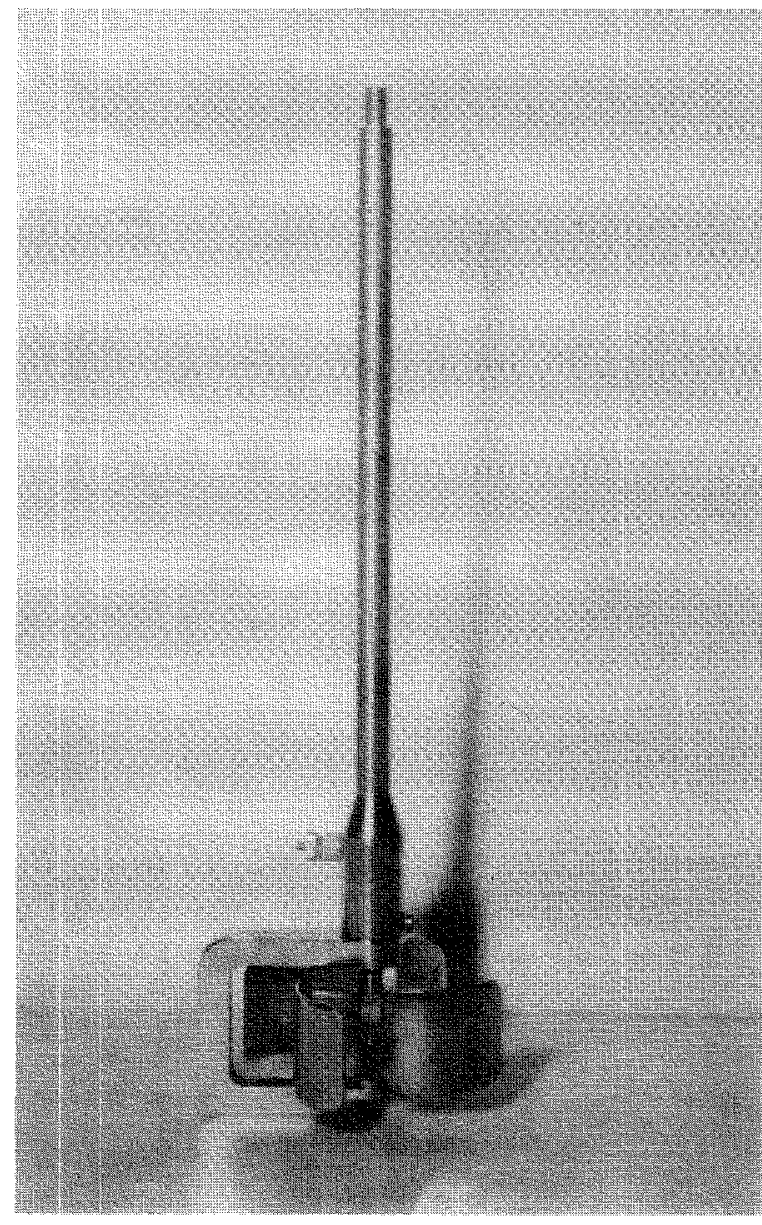

Figure 16.-Lower section of ice rod for use with vane ice meter.

Weight-hanger pins of various lengths are available for attaching the sounding weight to the weight hanger. (See fig. 19.) The stainless steel pins are threaded on one end to screw into the weight hanger and slotted on the other.

Sounding reels

A sounding reel has a drum for winding the sounding cable, a crank and ratchet assembly for raising and lowering the weight or holding it in any desired position, and a depth indicator. Table 1 contains detailed information on each of the five reels most commonly used.

The A-pack reel is light, compact, and ideal for use at cableway sites a considerable distance from the highway. (See fig. 20.) It can also be used on cranes, bridge boards, and boat booms.

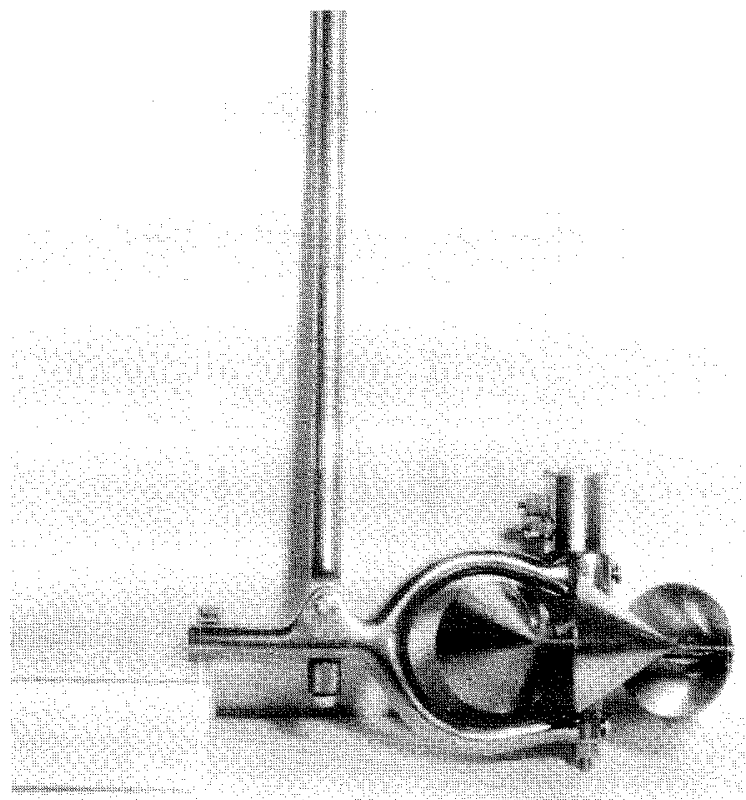

Figure 17.-Lower section of ice rod for use with Price meter.

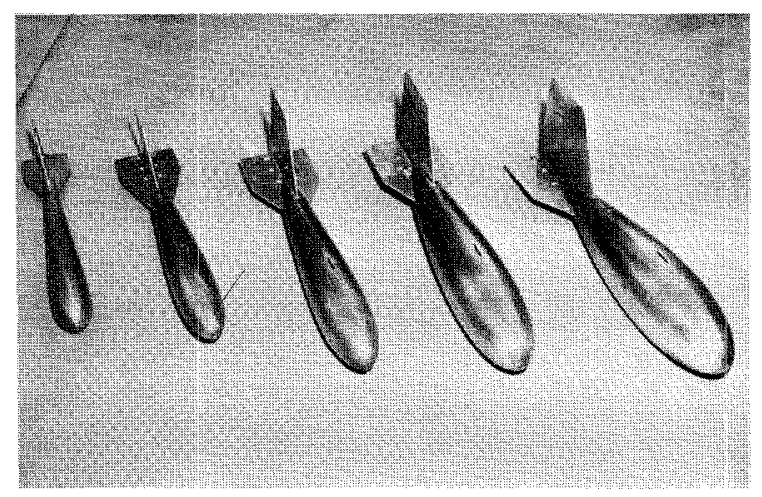

Figure 18.-15-, 30-, 50-, 75-, and 100-pound Columbus sounding weights.

The Canfield reel is also compact with uses similar to that of the A-pack reel. (See fig. 21.)

The A-55 reel is for general purpose use with the lighter sounding weights.

The B-56 reel (a major modification of the $\mathrm{B}-50$ reel) can handle all but the heaviest sounding weights and has the advantage that it can be used with a handcrank or power equipment. (See fig. 22.) 


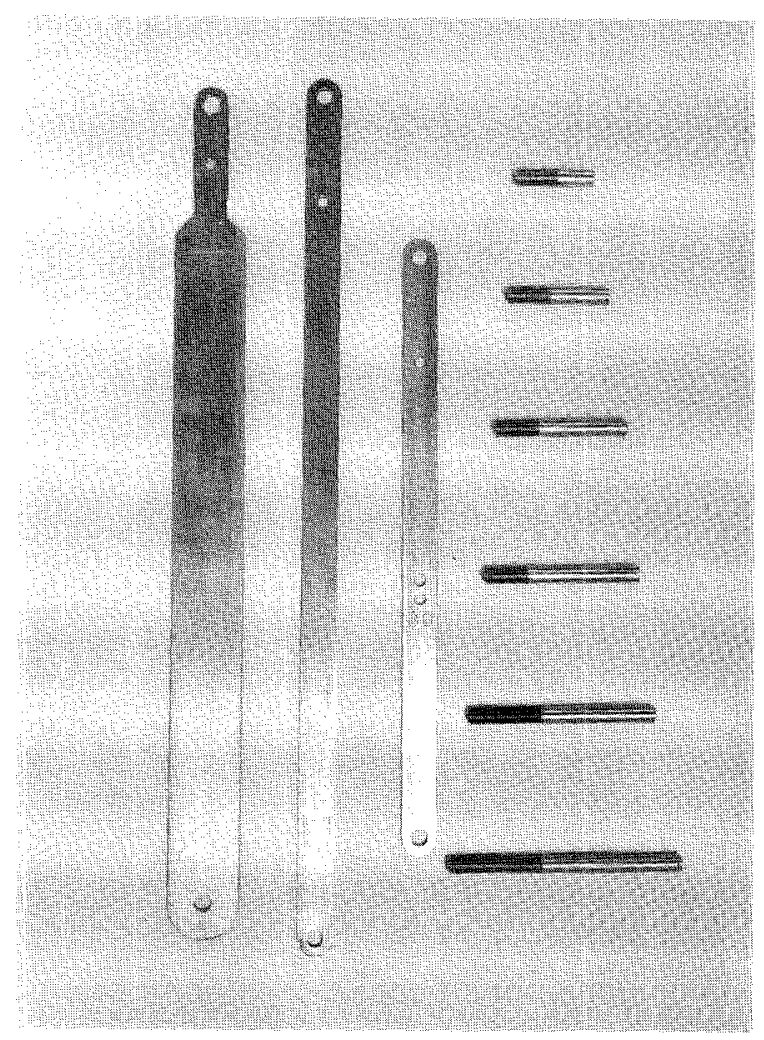

Figure 19.-Sounding-weight hangers and hanger pins.

The E-53 reel is the largest reel commonly used for current-meter measurements. This reel. will handle the heaviest sounding weights and is designed exclusively for use with power equipment. It has a handerank for emergency use. (See fig. 23.)

\section{Sounding cable}

Ellsworth reverse-lay two-conductor cable is normally used on all sounding reels except the

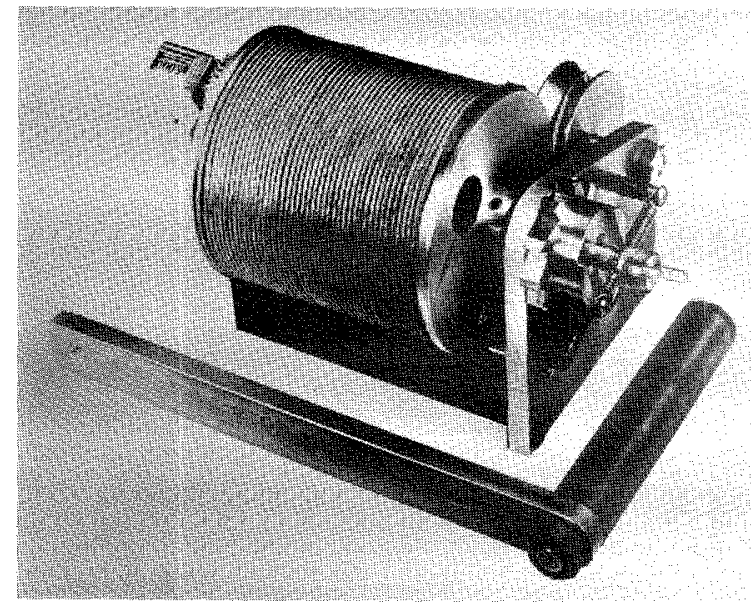

Figure 20.-A-pack reel.

single-conductor Canfield reel which uses galvanized steel aircraft cord. It is important that the appropriate size cable-laying sheave be used on the reels.

\section{Connectors}

A connector is used to join the end of the reel cable to the sounding-weight hanger. The three types of connectors generally used are types B, Au, and pressed sleeve. (See fig. 24.) The type-B connector is used with $A-55, B-56$, and $\mathrm{E}-53$ reels. The $\mathrm{Au}$ connector is used with the A-pack and Canfield reels although the pressed-sleeve connector can be used on these reels. The pressed-sleeve connector is used mainly on handlines. (See p. 15.)

Depth indicators

A computing depth indicator is used on the $\mathrm{A}-55, \mathrm{~B}-56$, and $\mathrm{E}-53$ reels. (See fig. 25.) The

Table 1.-Sounding reel data

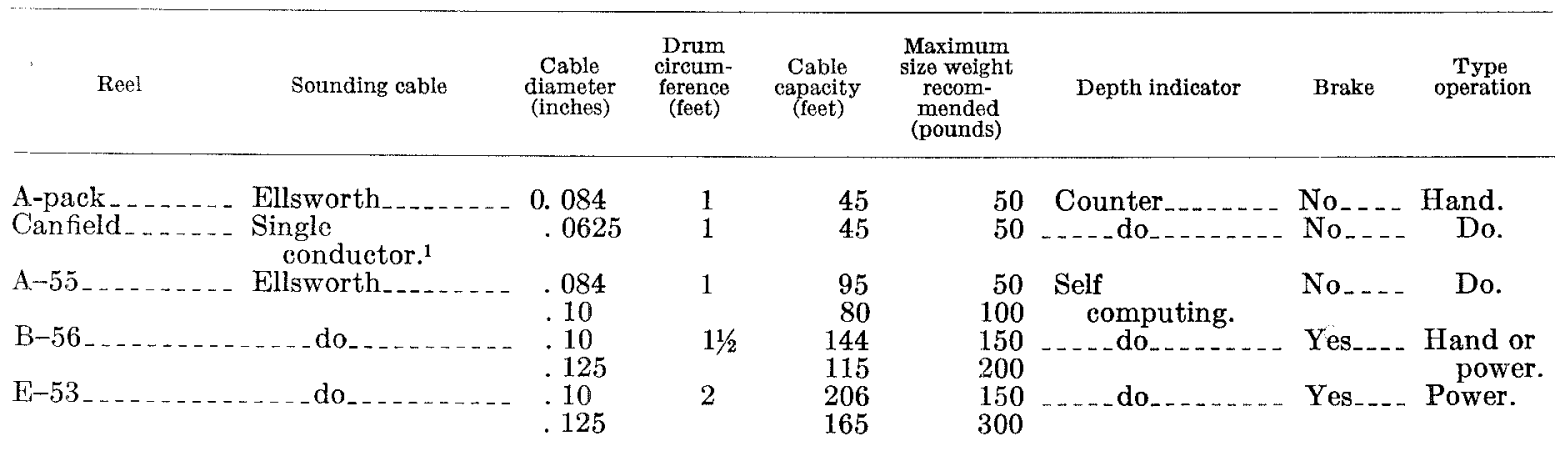

1 Some Canfield reels have been converted to double-conductor cable but most, of them are still used as single-conductor reels. 


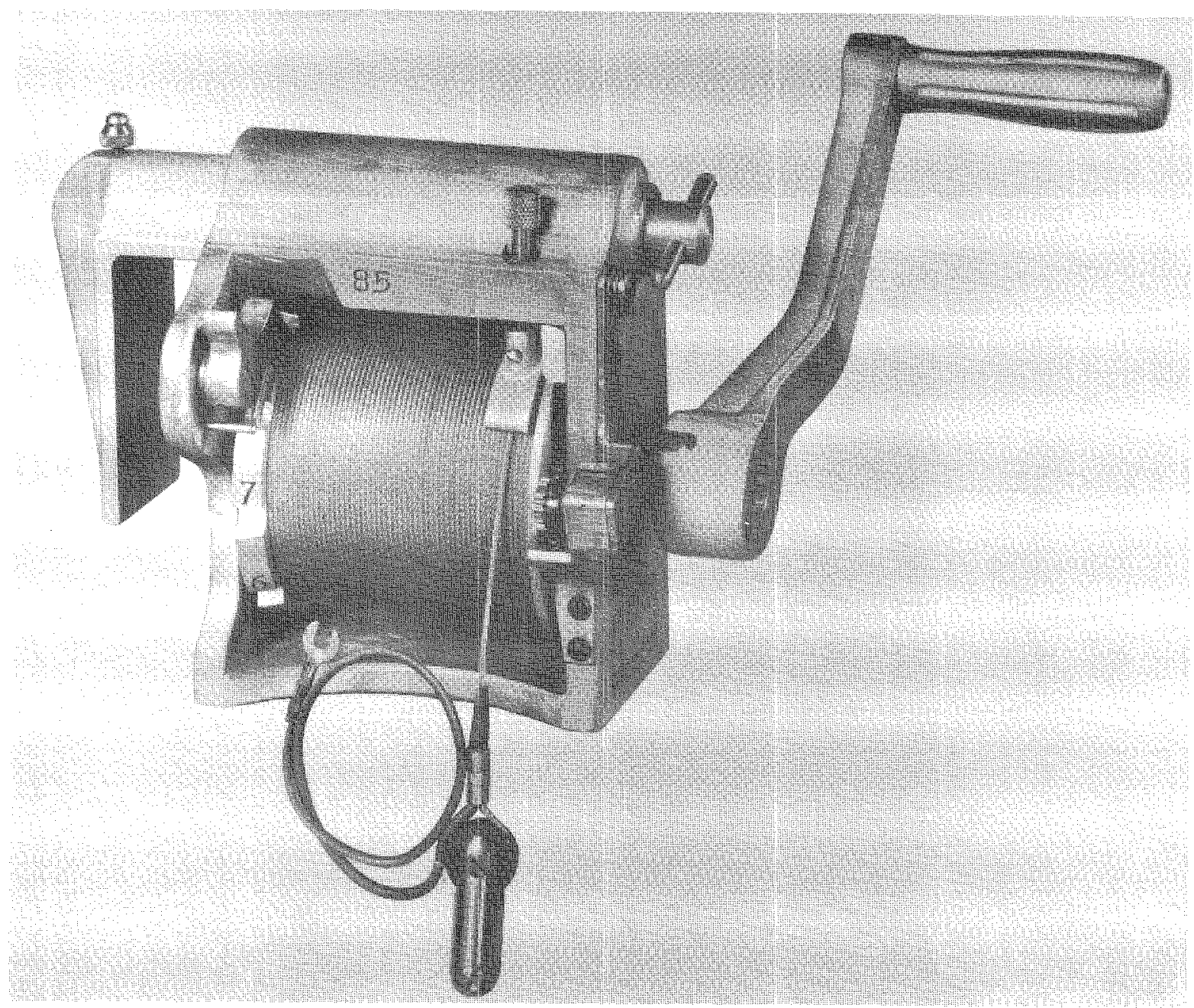

Figure 21.-Canfield reel. Photograph by permission of Leupold and Stevens Instruments, Inc.

stainless-steel indicator is less than 3 inches in diameter and has nylon bushings which do not require oil. The main dial is graduated in feet and tenths of a foot from 0 to 10 feet. The depth is indicated by a pointer. Tens of feet are read on a numbered inner dial through an aperture near the top of the main dial.

The main dial has a graduated spiral to indicate directly the 0.8-depth position (see p. 32) for depths up to 30 feet.

The A-pack and Canfield reels are equipped with counters for indicating depths. (See figs. 20 and 21.)

\section{Power unif}

A. power unit is available for the B-56 and E-53 reels to raise and lower the sounding weight and meter. (See fig. 26.) The power unit can be used with 6-, 12-, 18-, or 24-volt batteries.

Handlines

Handlines are devices used for making discharge measurements from bridges using a 15or 30-pound sounding weight. (See fig. 27.) The advantages of the handline are that it is easily set up, that it eliminates the use of a sounding reel and supporting equipment, and that it reduces the difficulty in making measurements from bridges which have interfering members. The disadvantages of the handline are that there is a greater possibility of making errors in determining depth because of slippage of the handline or measuring scale or tape and that it requires more physical exertion especi-. ally in deep streams. Handlines can be used 


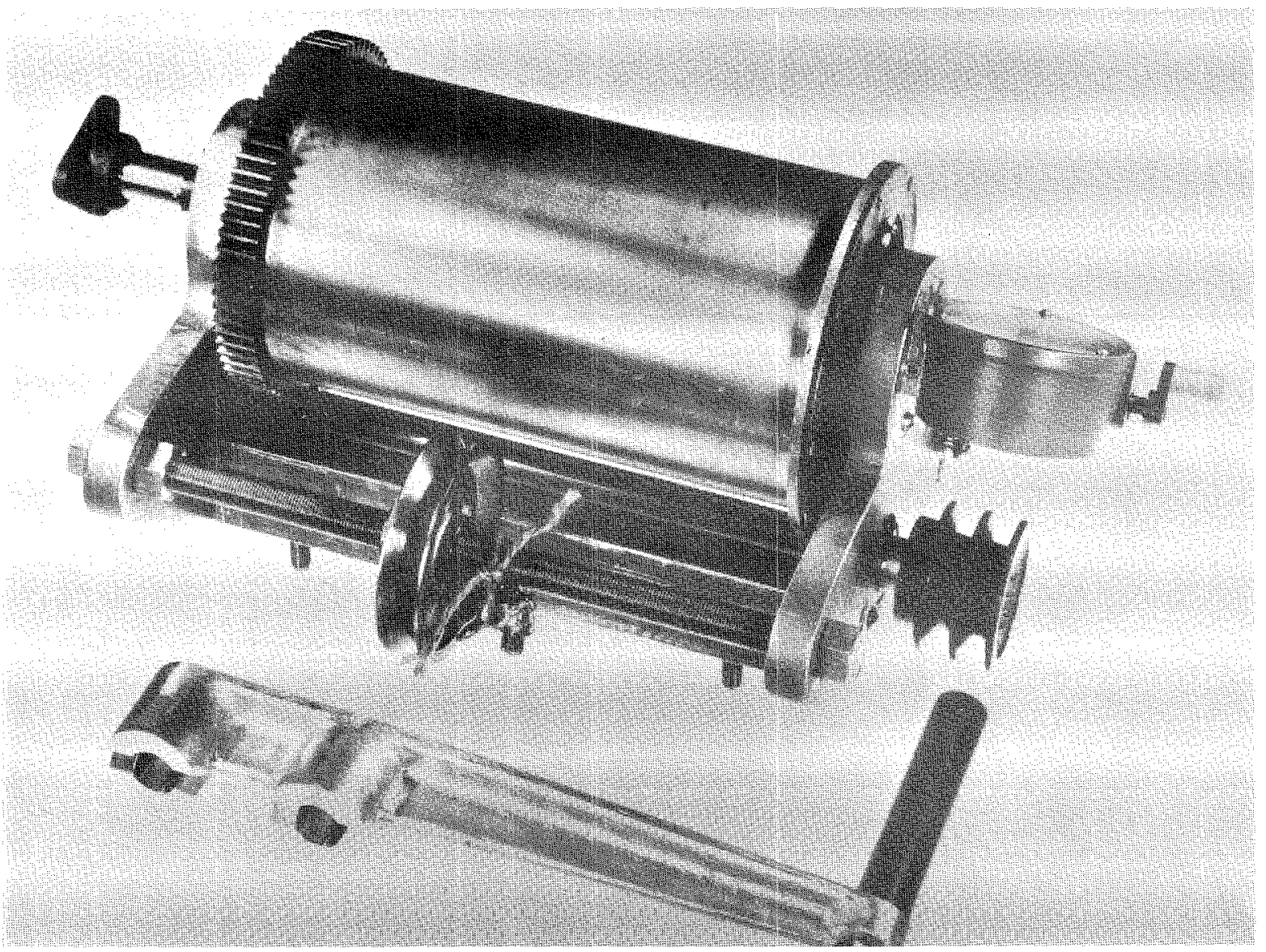

Figure 22.-B-56 reel.

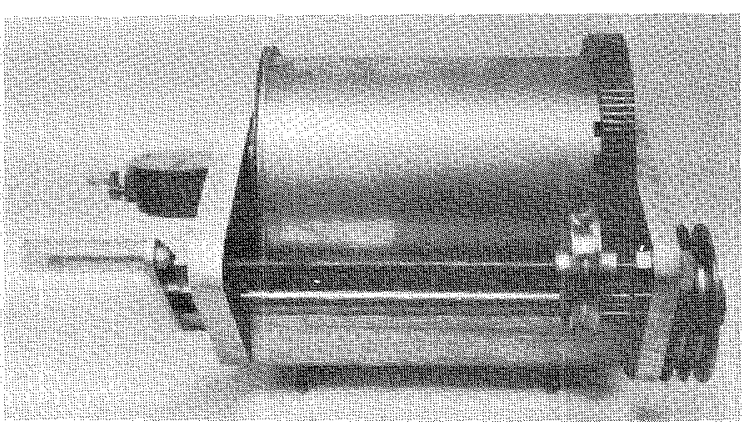

Figure 23.-E-53 reel.

from cable cars, but this is not recommended because of the disadvantages mentioned above.

Two types of handline reels are the Lee-Au and the Morgan. (See fig. 28.)

Ellsworth cable is recommended for handlines because of its flexibility and durability.
The pressed-sleeve connector or the Au connector are used on handlines because they are lighter in weight than the type-B connector, yet strong enough for the sounding weights used with handlines.

Figure 29 shows a handline in use from a bridge.

\section{Sonic sounder}

A commercial, compact, portable sonic sounder has been adapted to measure stream depth. (See figs. 30, 31, and 32.)

The sounder is powered by either a 6 - or 12 volt storage battery and will operate continuously for 10 hours on a single battery charge. Three recording speeds are available, 36,90 , or 180 inches per hour. Four operating ranges, $0-60,60-120,120-180$, and 180-240 feet allow intervals of 60 feet of depth. The sounder is portable, weighing only 46 pounds. The depth 


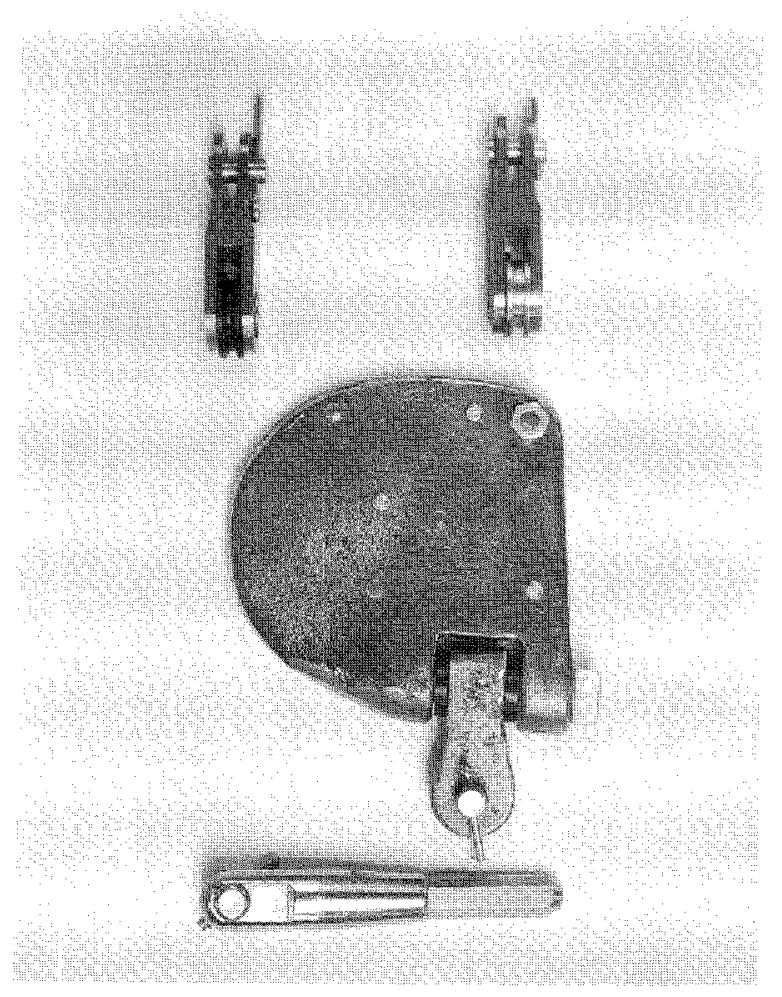

Figure 24.-Connectors: top left, Au connector with plastic sheave; top right, $A u$ connector with mefal sheave; middle, type-B connector; and bottom, pressed-sleeve connector.

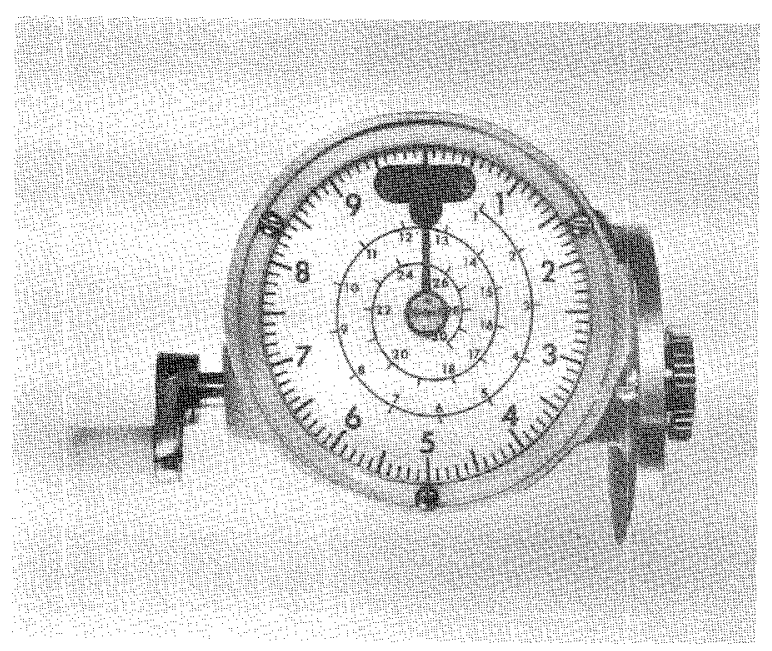

Figure 25.-Computing depth indicator.

recorded is that to the streambed. The transducer has a narrow beam angle of $6^{\circ}$ which minimizes errors on inclined streambeds and allows the hydrographer to work close to piers or other obstructions.
Measurements can be made with this equipment without lowering the meter and weight to the streambed. As soon as the weight is in the water, the depth will be recorded. The meter can then be set at the 0.2 depth (see p. 31) or just below the water surface (see p. 37) where a velocity reading is obtained. Then a coefficient is applied to convert measured velocity to the mean in the vertical. (See p. 37.)

Temperature change affects the sound propagation velocity, but this error is limited to about \pm 2 percent in fresh water. This error can be eliminated completely by adjusting the sounder to read correctly at a particular average depth determined by other means.

\section{Width-measuring equipment}

The distance to any point in a cross section is measured from an initial point on the bank. Cableways and bridges used regularly for making discharge measurements are commonly marked at 2-, 5-, 10-, or 20-foot intervals by paint marks. Distance between markings is estimated, or measured with a rule or pocket tape.

For measurements made by wading, from boats, or from unmarked bridges, steel or metallic tapes or tag lines are used.

Tag lines are made of $1 / 32^{-}, 1 / 16^{-}, 3 / 32^{-}$, or $1 / 8$-inch diameter galvanized steel aircraft cord with solder beads at measured intervals to indicate distances. The standard arrangement of solder beads or tags is:

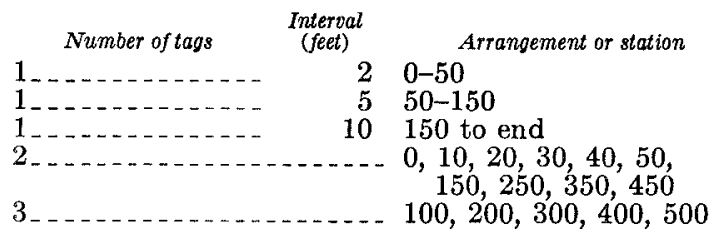

The standard lengths of tag line are 300,400 , and 500 feet, but other sizes are available.

Three types of tag-line reels in use (fig. 33) are Lee-Au, Pakron, and Columbus type A.

Larger reels designed particularly for use with boats are described on page 24 .

It is practically impossible to string a tag line for discharge measurements from a boat when the width of the stream is greater than 2,500 feet. The methods used to determine width at such places are described on page 44 . 


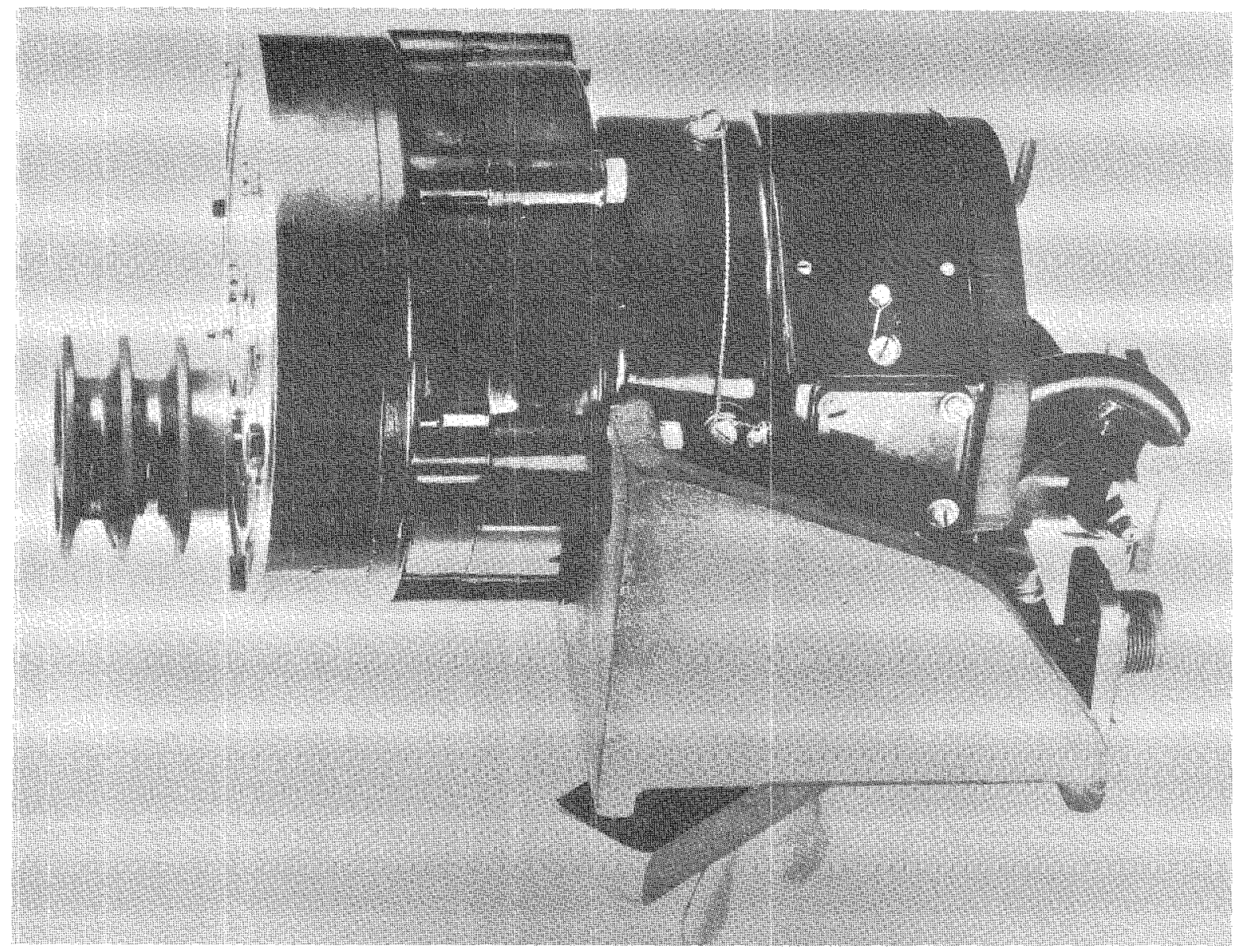

Figure 26.-Power unit for sounding reel.

Equipment assemblies

Special equipment is necessary for each type of current-meter measurement. The meters, weights, and reels used have already been described. The additional equipment needed is described in this section.

The special equipment assemblies have been divided into five basic groups: cableway, bridge, boat, ice, and velocity-azimuth-depth-assembly (VADA) equipment.

\section{Cableway equipmen}

The cableway provides a track for the operation of a cable car from which the hydrog.rapher makes a current-meter measurement. Cable cars also support the sounding reel and other necessary equipment. Both sitdown and standup types of cable cars are used in stream gaging. (See figs. 34-36.) Pierce (1947) describes plans for both types. Normally, sitdown cars are used for cableway spans less than 400 feet and where lighter sounding weights are used. The standup car is used on the longer spans and where heavy sounding weights are needed.

The cars are moved from one point to another on the cableway by means of cable-car pullers. (See fig. 37.) The standard car puller is a cast aluminum piece with a snub attached. The snub, usually four-ply belting, is placed between one of the car sheaves and the cable to prevent movement of the car along the cable. A second-type puller is used when a car is equipped with a follower brake. (See fig. 37.) A third type, the Colorado River cable-car puller, is the same in principle as the puller used on cars equipped with a follower brake.

Power-operated cable cars are available for extremely long spans or other special situations. (See figs. 38-39.) 


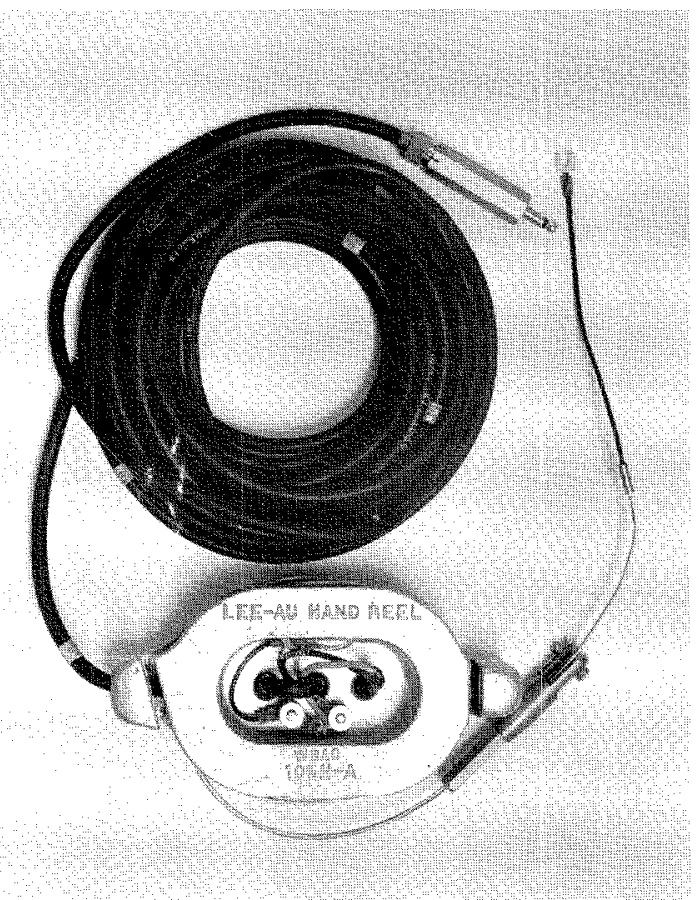

Figure 27.-Handline.

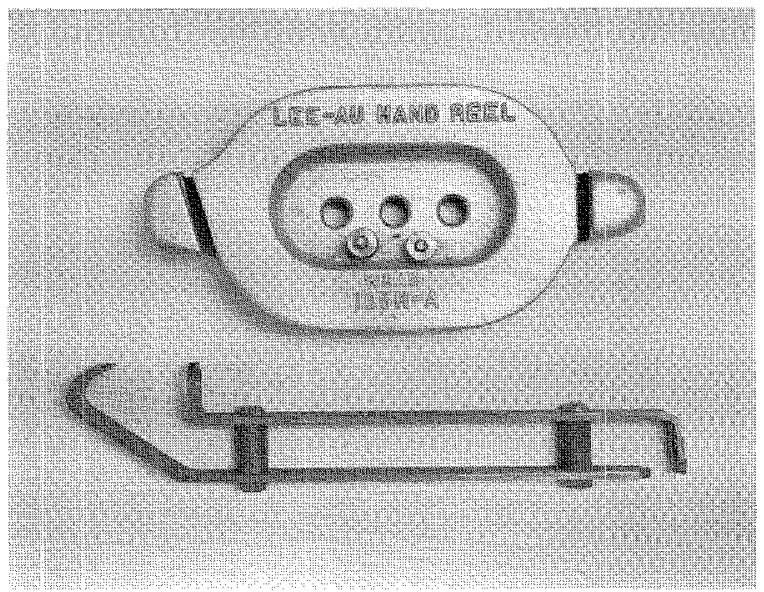

Figgure 28.-Handline reels, Lee-Au (top) and Morgan (bottom).

Sitdown cable cars have a variety of means of supporting the sounding reel. A-pack and Canfield reels are designed to clamp on the side of the car. (See fig. 40.) Permanent or portable reel seats are attached to the cable cars for larger reels. (See figs. 34 and 36.)

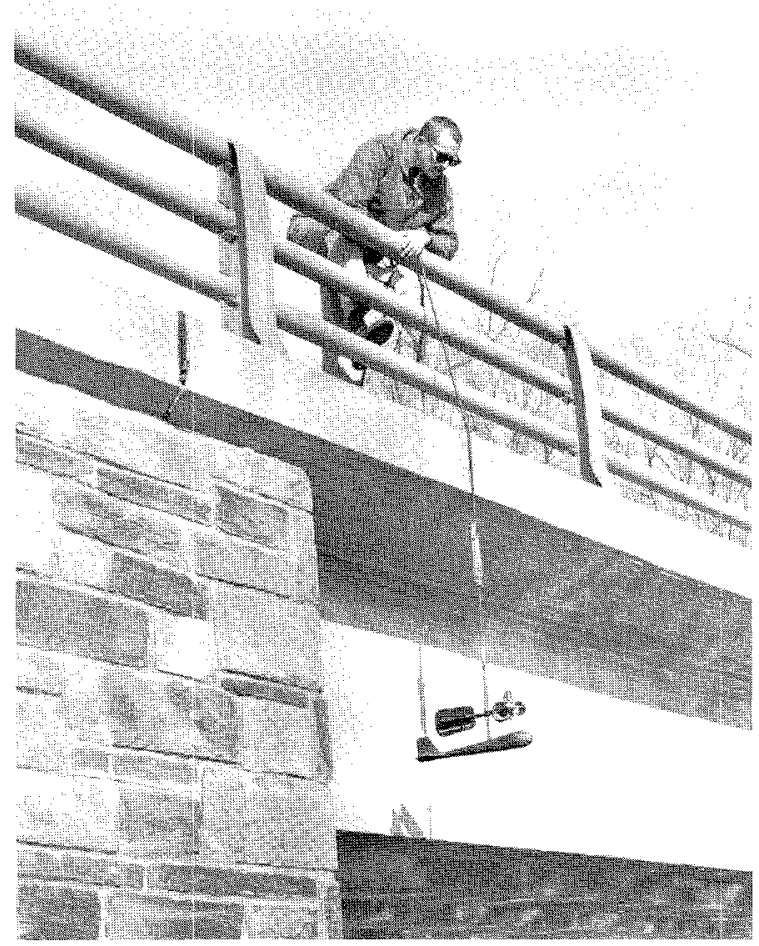

Figure 29.-Handline in use from a bridge.

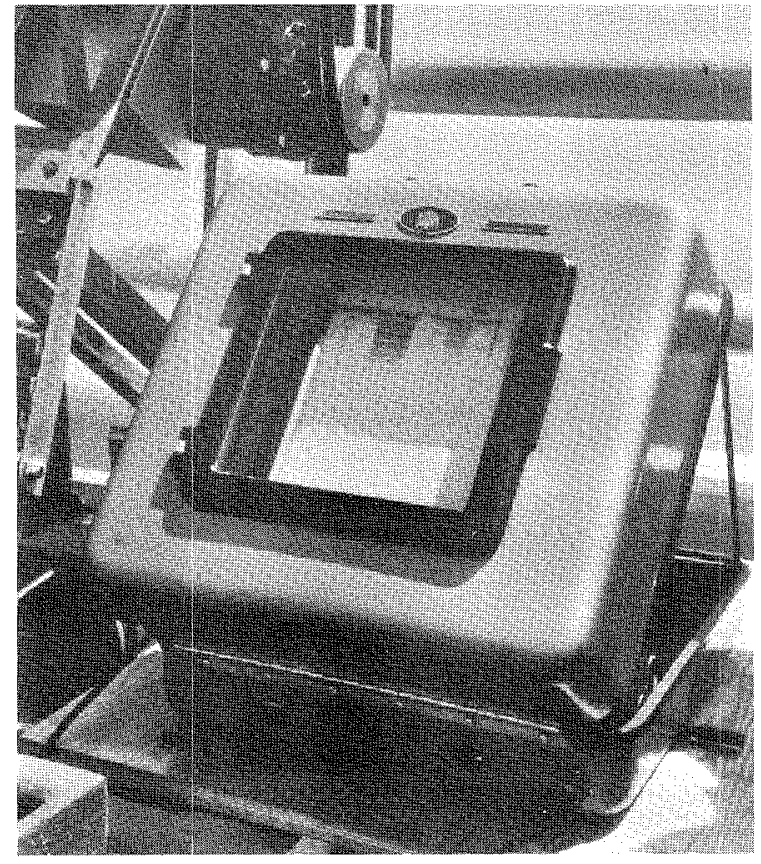

Figure 30.-Sonic-sounding recorder. 


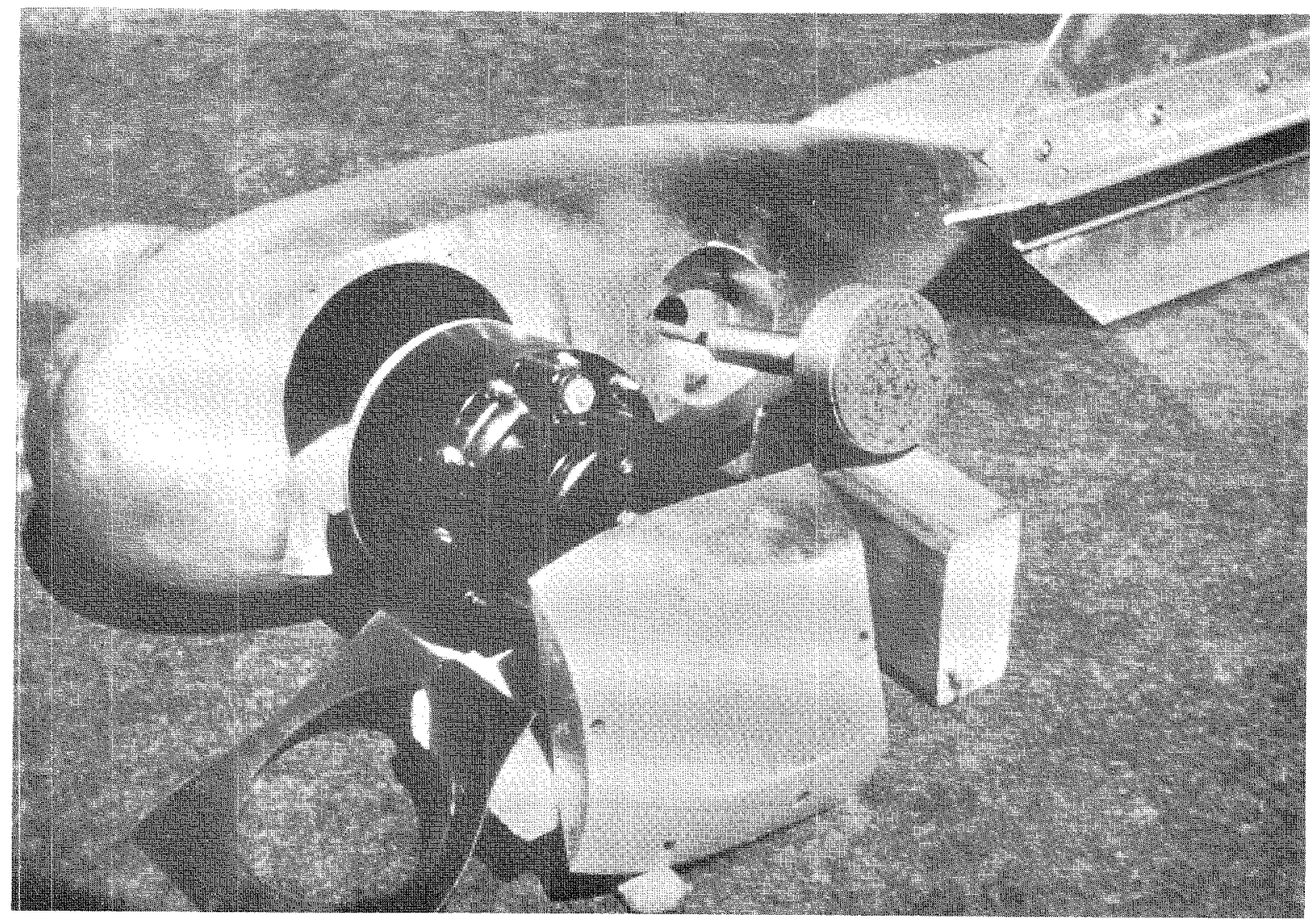

Figure 31 -Sounding weight with compass and sonic transducer ready for assembly.

Standup cable cars have reel seats attached to the structural members of the car. (See fig. 35.) A sheave attached to the structural members carries the sounding line so that the sound.ing weight and current meter will clear the bottom of the car. Power reels can also be used. on standup cable cars.

Carrier cables are being used on deep, narrow streams for measuring as well as for sediment sampling. They are used in areas where it is impossible to wade, where no bridges are available, and where it has been impractical to build a complete cableway. The assembly is operated from the shore.

\section{Bridge equipment}

When one measures from a bridge, the meter and sounding weight can be supported by a handline or by a sounding reel mounted on a crane or bridge board. The handline has been described on page 15 .

Two types of hand-operated portable cranes are the type $A$ (see figs. 41, 42) for weights up to 100 pounds, and the type $\mathrm{E}$ for heavier weights.

All cranes are designed so that the superstructure can be tilted forward over the bridge rail far enough for the meter and weight to clear most rails. Where bridge members are found along the bridge, the weight and meter can be brought up, and the superstructure can be tilted back to pass by the obstruction. (See fig. 41.)

Cast-iron counterweights weighing 60 pounds each are used with four-wheel base cranes. (See fig. 42.) The number of such weights needed depends upon the size of sounding weight being supported, the depth and velocity of the stream, and the amount of debris being carried by the stream.

A protractor is used on cranes to measure the angle the sounding line makes with the vertical when the weight and meter are dragged downstream by the water. The protractor is a graduated circle clamped to an aluminum 


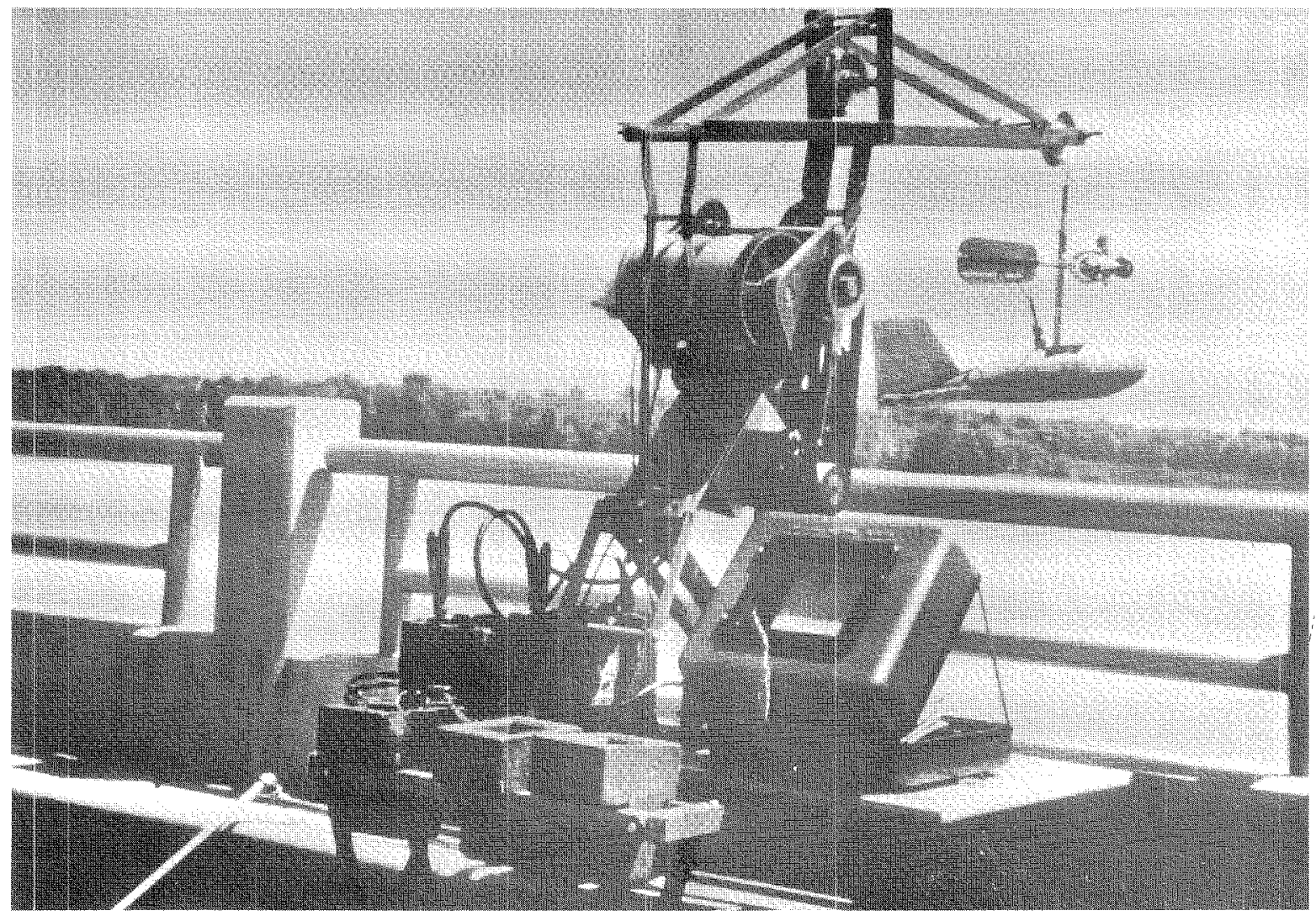

Figure 32.-Sonic measuring assembly.

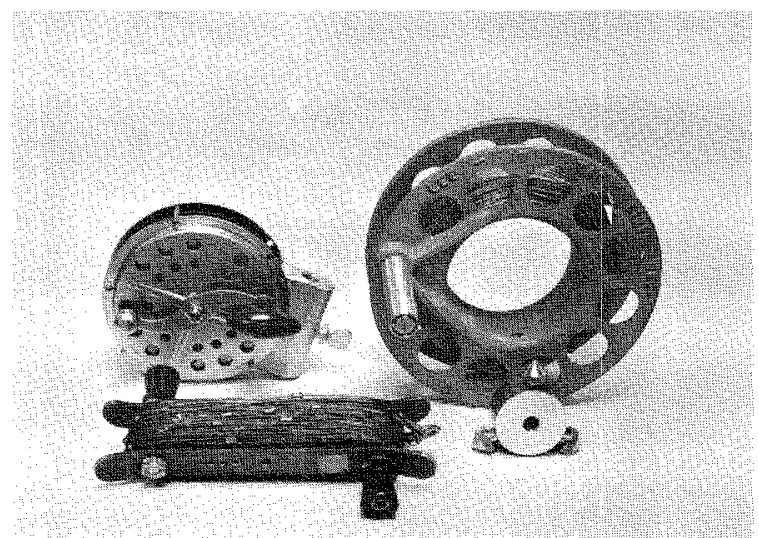

Figure 33.-Tag-line reels: top left, Pakron; top right, Lee-Au with removable hub in front; and bottom, Columbus type $A$.

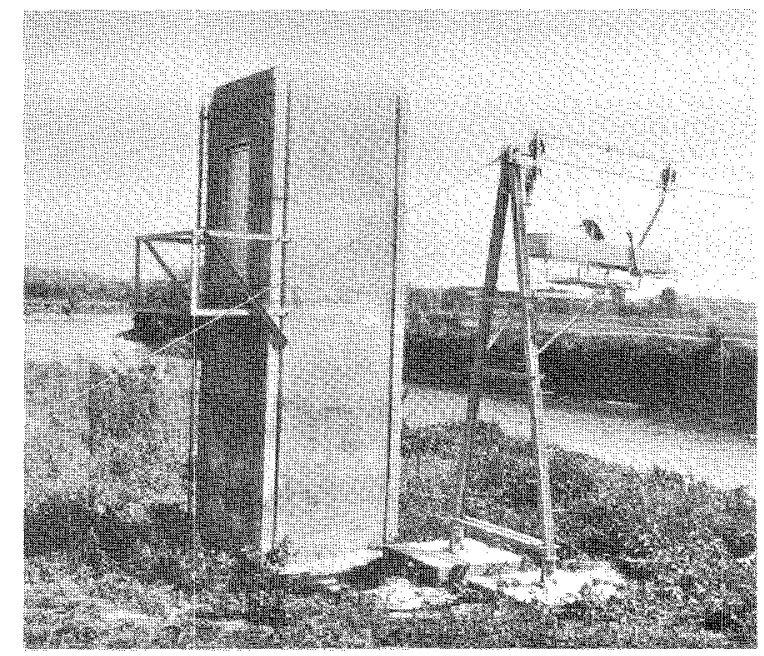

Figure 34.-Sitdown cable car. 


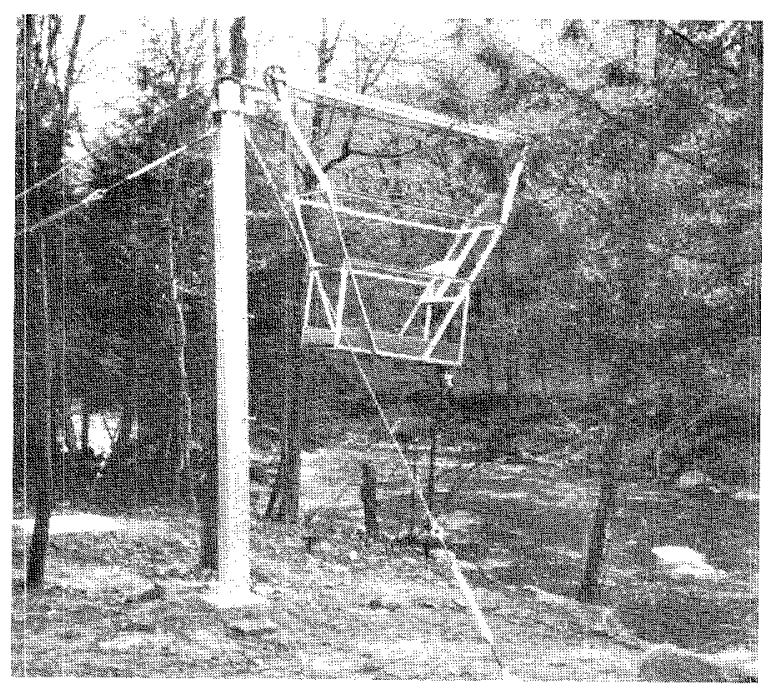

Figure 35.-Standup cable car.

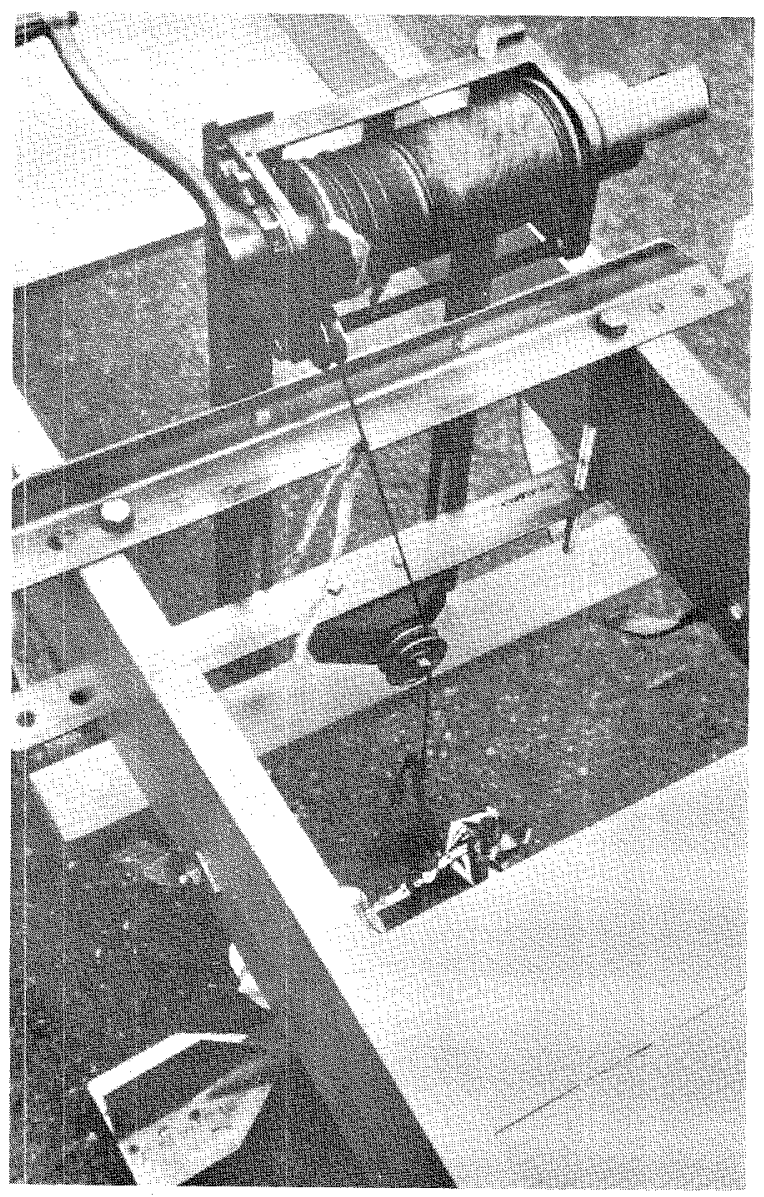

Figure 36.-Porfable reel seat on sitdown-type cable car. Note tags on sounding cable.

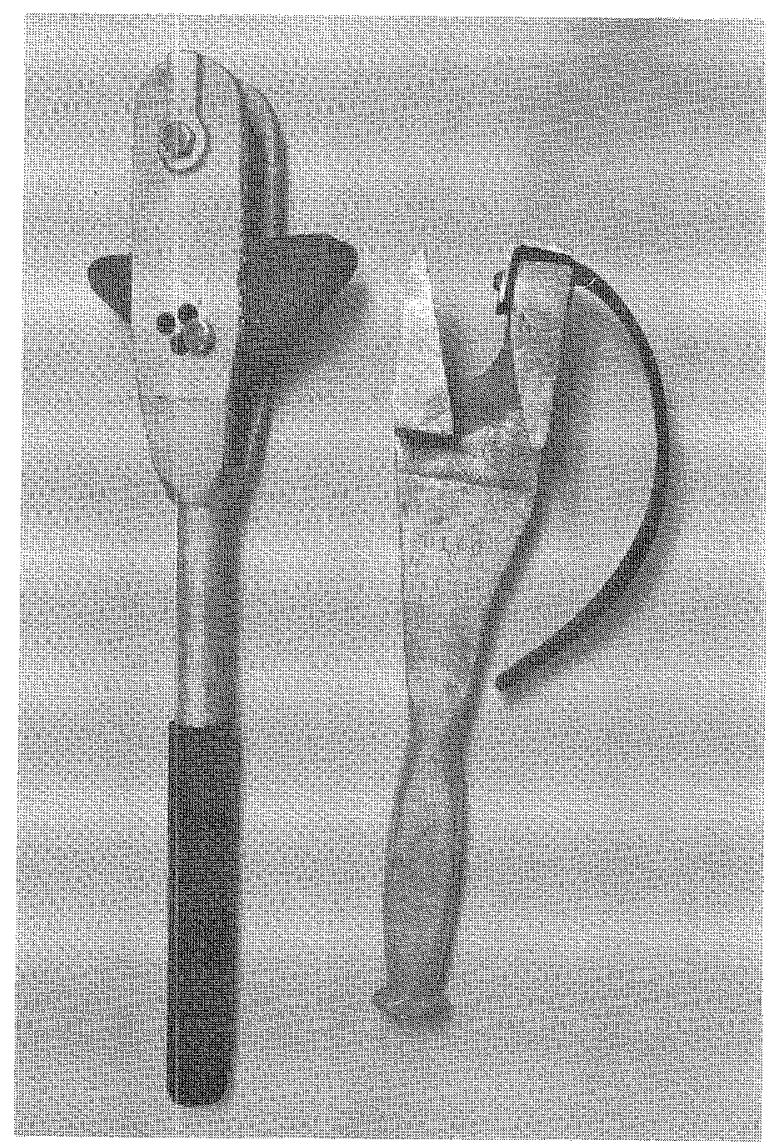

Figure 37.-Cable-car pullers for follower brake cable cars, left; and standard cars, right.

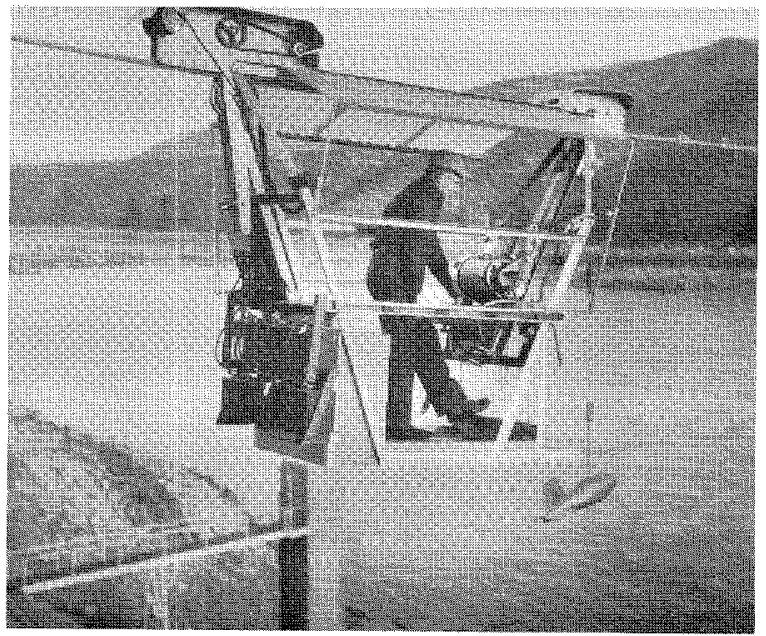

Figure 38.-Battery-powered cable car. 


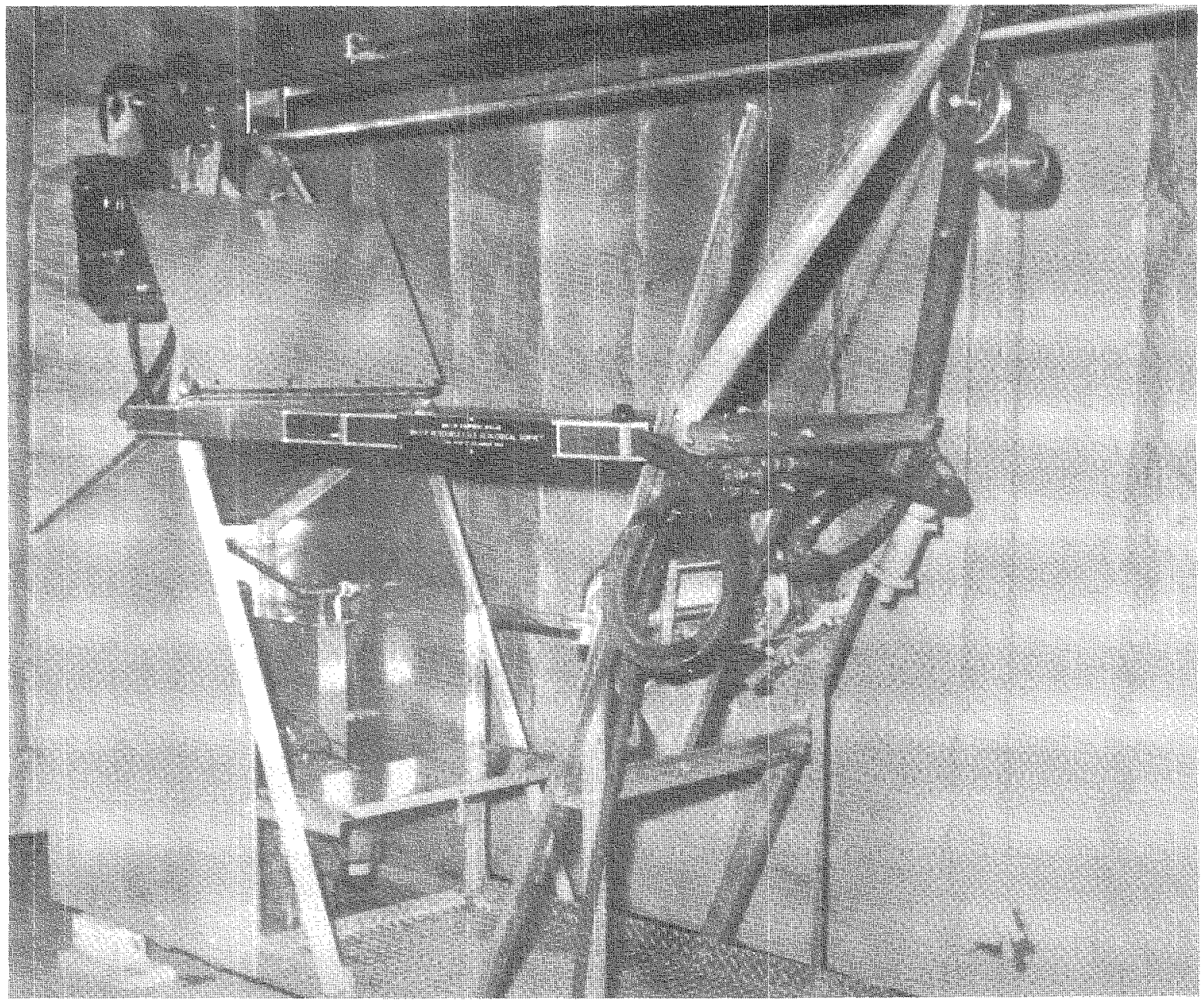

Figure 39.-Gasoline-powered cable car.

plate. A plastic tube partly filled with colored antifreeze fitted in a groove between the graduated circle and the plate is the protractor index. A stainless-steel rod is attached to the lower end of the plate to ride against the downstream side of the sounding cable. The protractor will measure vertical angles from $-25^{\circ}$ to $+90^{\circ}$. The cranes shown in figures 41,42 are equipped with protractors at the outer end of the boom.

Bridge boards may be used with an A-pack or A-55 sounding reel and weights up to 50 pounds. A bridge board is usually a plank about 6-8 feet long with a sheave at one end over which the meter cable passes and a reel seat near the other end. The board is placed on the bridge rail so that the force exerted by the sounding weight suspended from the reel cable is counterbalanced by the weight of the sounding reel. (See fig. 43.) The bridge board may be hinged near the middle to let one end be placed on the sidewalk or roadway.

Many special arrangements for measuring from bridges have been devised to suit a porticular purpose. Truck-mounted cranes are often used for measuring from bridges over larger rivers (see fig. 44). Monorail streamgaging cars have been developed for large rivers. The car is suspended from the substructure of bridges by means of I-beams. The car is attached to the I-beam tracks by trolleys and is propelled by a forklift motor having a wheel in contact with the bottom of the beam. The drive mechanism and sounding equipment 


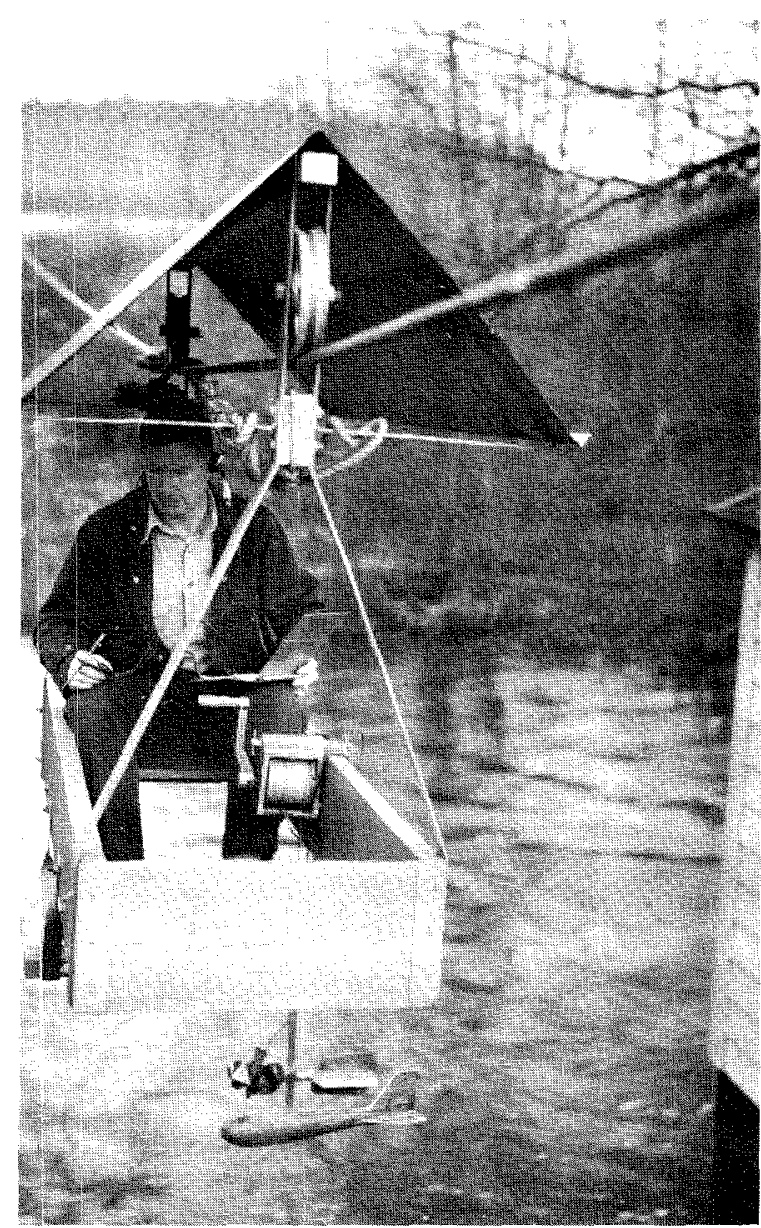

Figure 40.-Sitdown cable car with Canfield reel clamped to side of car.

are powered by a 430 -ampere-hour, 450 -pound, 12-volt battery.

\section{Boat equipment}

Measurements made from boats require special equipment not used for other types of measurements.

Extra large tag-line reels are used on wide streams. 'Three different tag-line reels are available for boat measurements:

1. A heavy-duty, horizontal-axis reel without a brake and with a capacity of 2,000 feet of $1 / 8$-inch diameter cable. (See fig. 45.)

2. A heavy-duty, horizontal-axis reel with a brake and with a capacity of 3,000 feet of $1 / 8$-inch diameter cable. (See fig. 46.)

3. A vertical-axis reel without a brake and with a capacity of 800 feet of $1 / 8$-inch diameter cable. (See fig. 47.)
A utility line consisting of 30 feet of $3 / 32$-inch diameter cable with a harness snap at one end and a pelican hook at the other is connected to the free end of the boat tag line and fastened around a tree or post, thereby preventing damage to the tag line. After the tag line is strung across the stream, the reel is usually bolted to a plank and chained to a tree. The tag line is stationed at appropriate intervals.

Special equipment is necessary to suspend the meter from the boat when the depths are such that rod suspension cannot be used. A crosspiece reaching across the boat is clamped to the sides of the boat and a boom attached to the center of the crosspiece extends out over the bow. (See fig. 48.) The crosspiece is equipped with a guide sheave and clamp arrangement at each end to attach the boat to the tag line and make it possible to slide the boat along the tag line from one station to the next. A small rope can be attached to these clamps so that in an emergency a tug on the rope will release the boat from the tag line. The crosspiece also has a clamp that prevents lateral movement of the boat along the tag line when readings are being made. The boom consists of two structural aluminum channels, one telescoped within the other to permit adjustments in length. The boom is equipped with a reel plate on one end and a sheave over which the meter cable passes on the other. The sheave end of the boom is designed so that by adding a cable clip to the sounding cable, a short distance above the connector, the sheave end of the boom can be retracted when the meter is to be raised out of the water. The raised meter is easy to clean and is in a convenient position when not being operated.

All sounding reels fit the boat boom except the A-pack and the Canfield, which can be made to fit by drilling additional holes in the reel plate on the boom.

In addition to the equipment already mentioned, the following items are needed when making boat measurements:

1. A stable boat big enough to support the hydrographers and equipment.

2. A motor that can move the boat with ease against the maximum current in the stream.

3. A pair of oars for standby use. 


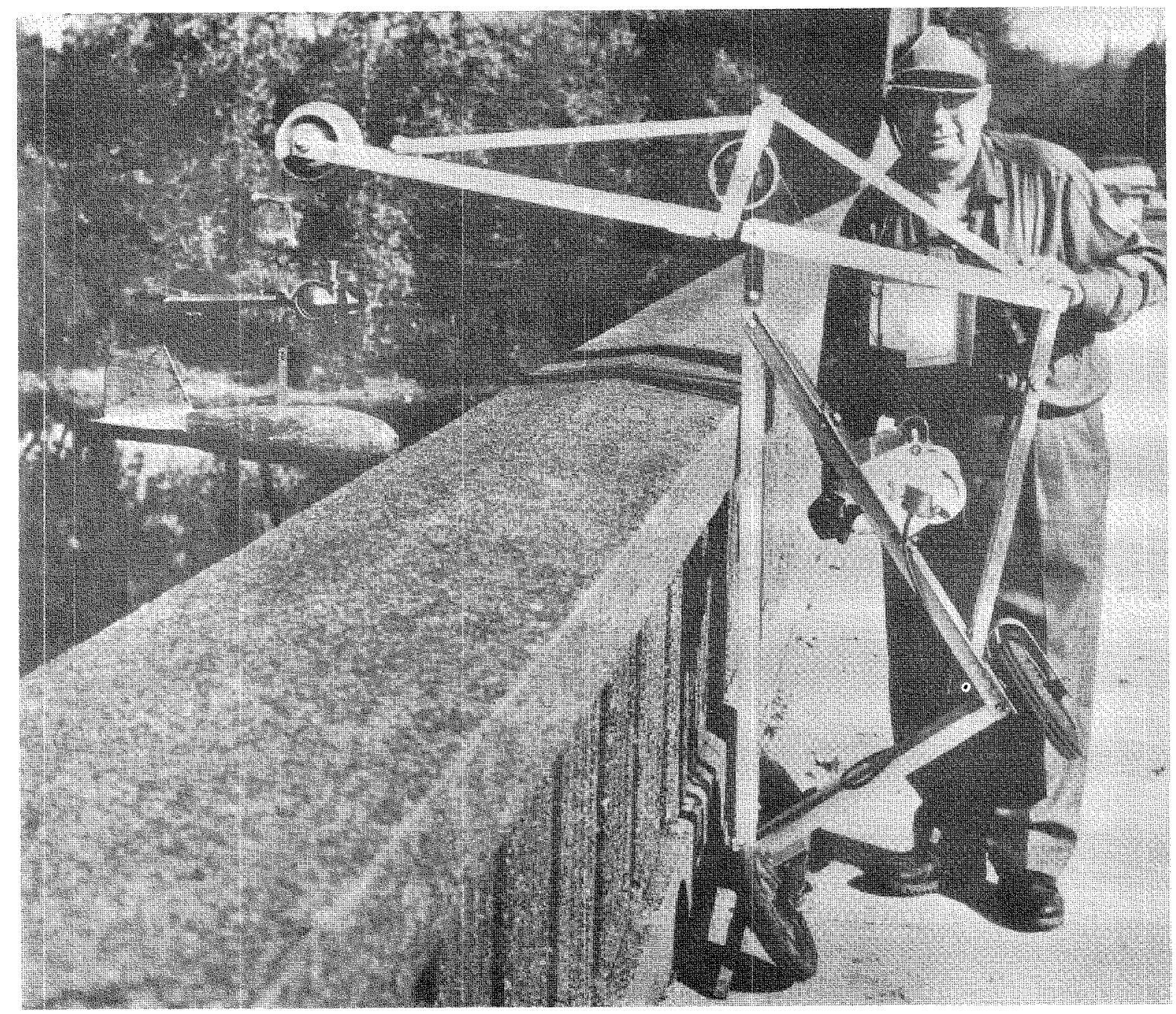

Figure 41.-Type-A crane with 3-wheel base. During soundings and velocity observations the crane is tilted against the bridge rail. An A-55 real is mounted on the crane. 


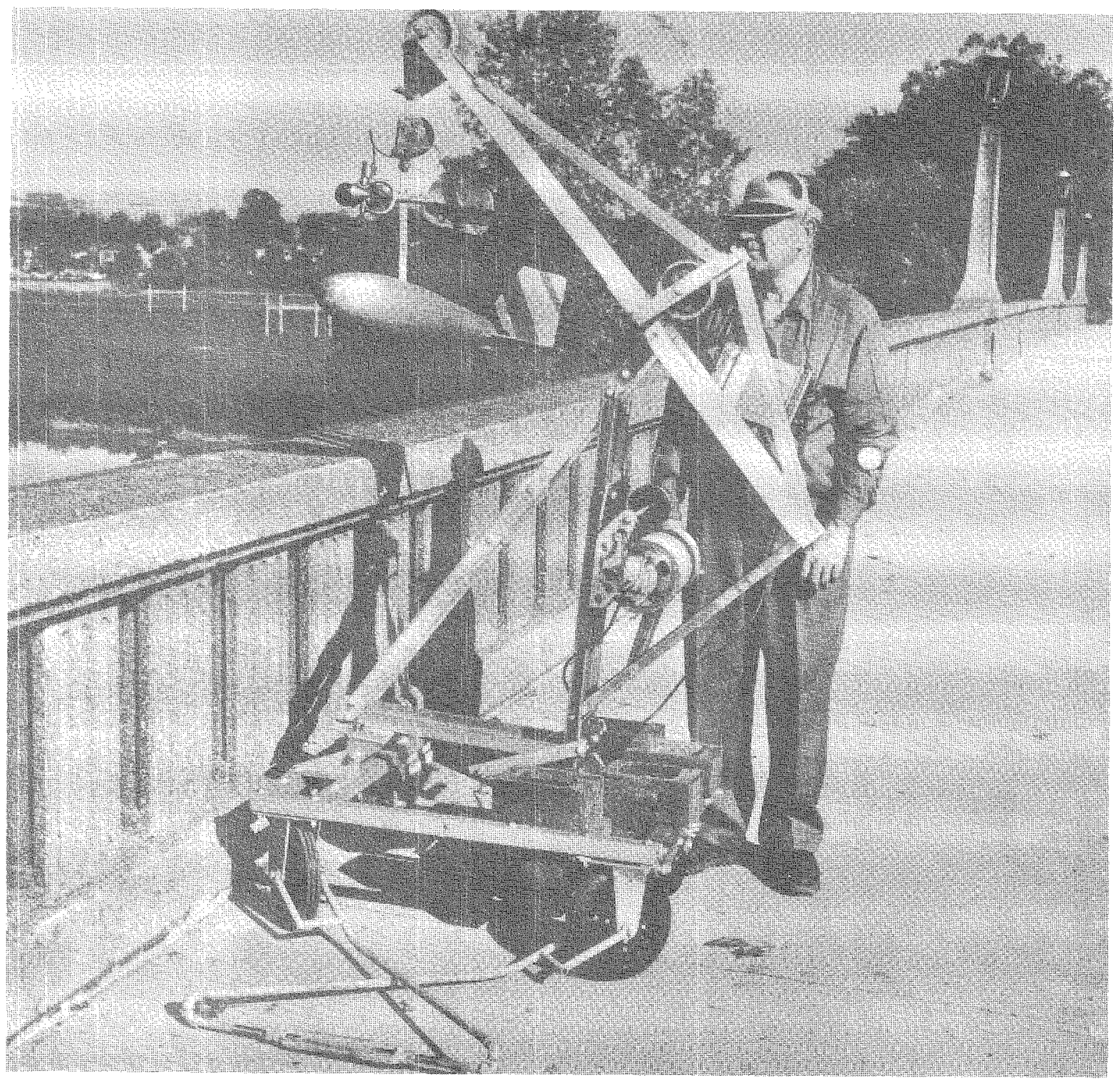

Figure 42.-Type-A crane with 4-wheel base with boom in refracted position. A B-56 reel is mounted on crane. Note fluid protractor on outer end of boom. 


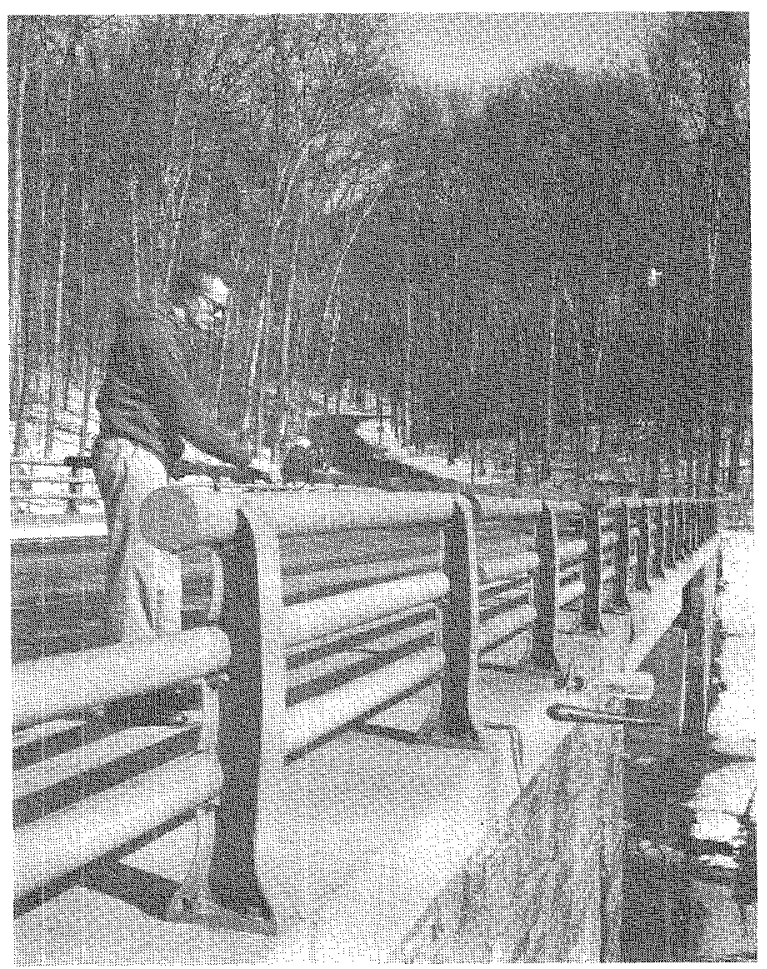

Figure 43.-Bridge board in use.

4. A life preserver for each hydrographer.

5. A bailing device.

Figure 49 shows the equipment assembled in a boat.

Ice: equipment

Current-meter measurements under ice cover require special equipment for cutting holes in the ice through which to suspend the meter.

Cutting holes through the ice on streams to make discharge measurements has long been a laborious and time-consuming job. The development of power ice drills, however, has eliminated many of the difficulties and has reduced considerably the time required to cut the holes.

Holes are often cut with a commercial ice drill that cuts a 6-inch-diameter hole. (See fig. 50.) The drill weighs about 30 pounds and under good conditions will cut through 2 feet of ice in about a minute.

Where it is impractical to use the ice drill, ice chisels are used to cut the holes. Ice chisels used are usually 4 or $4 \frac{1}{2}$ feet long and weigh about 12 pounds. The ice chisel is used when first crossing an ice-covered stream to determine whether the ice is strong enough to support the hydrographer. If a solid blow of the chisel blade does not penetrate the ice, it is safe to walk on, providing the ice is in contact with the water.

Some hydrographers supplement the ice chisel with a Swedish ice auger. The cutting blade of this auger is a spadelike tool of hardened steel which cuts a hole 6-8 inches in diameter, by turning a bracelike arrangement on top of the shaft.

When holes in the ice are cut, the water is usually under pressure owing to the weight of the ice, and it comes up in the hole. In order to determine the effective depth of the stream (see p. 42), ice-measuring sticks are used to measure the distance from the water surface to the bottom of the ice. This is done with a bar about 4 feet long, made of strap steel or wood, graduated in feet and tenths of a foot and having an $L$-shaped projection at the lower end. The horizontal part of the $L$ is held on the underside of the ice and the depth to that point is read at the water surface on the graduated part of the stick. The horizontal part of the $L$ is at least 4 inches long so that it may extend beyond any irregularities on the underside of the ice.

When the total depth of water under ice cover is greater than 10 or 12 feet, a sounding reel or handline is usually used. The sounding reel is mounted on a collapsible support set on runners. (See fig. 51.)

A special ice-weight assembly is used for sounding under ice because a regular sounding weight will not fit through the hole cut by the ice drill. (See fig. 51.) The weights and meter are placed in a framework that will fit through the drilled hole.

\section{Velocity-azimuth-depth-assembly}

The velocity-azimuth-depth-assembly, commonly called VADA, combines a sonic sounder with a remote-indicating compass and Price current meter to record depth, indicate the direction of flow, and permit observations of velocity at any point.

In figure 52, the azimuth-indicating unit is shown mounted on the four-wheel crane. Incorporated within the remote-indicator box 


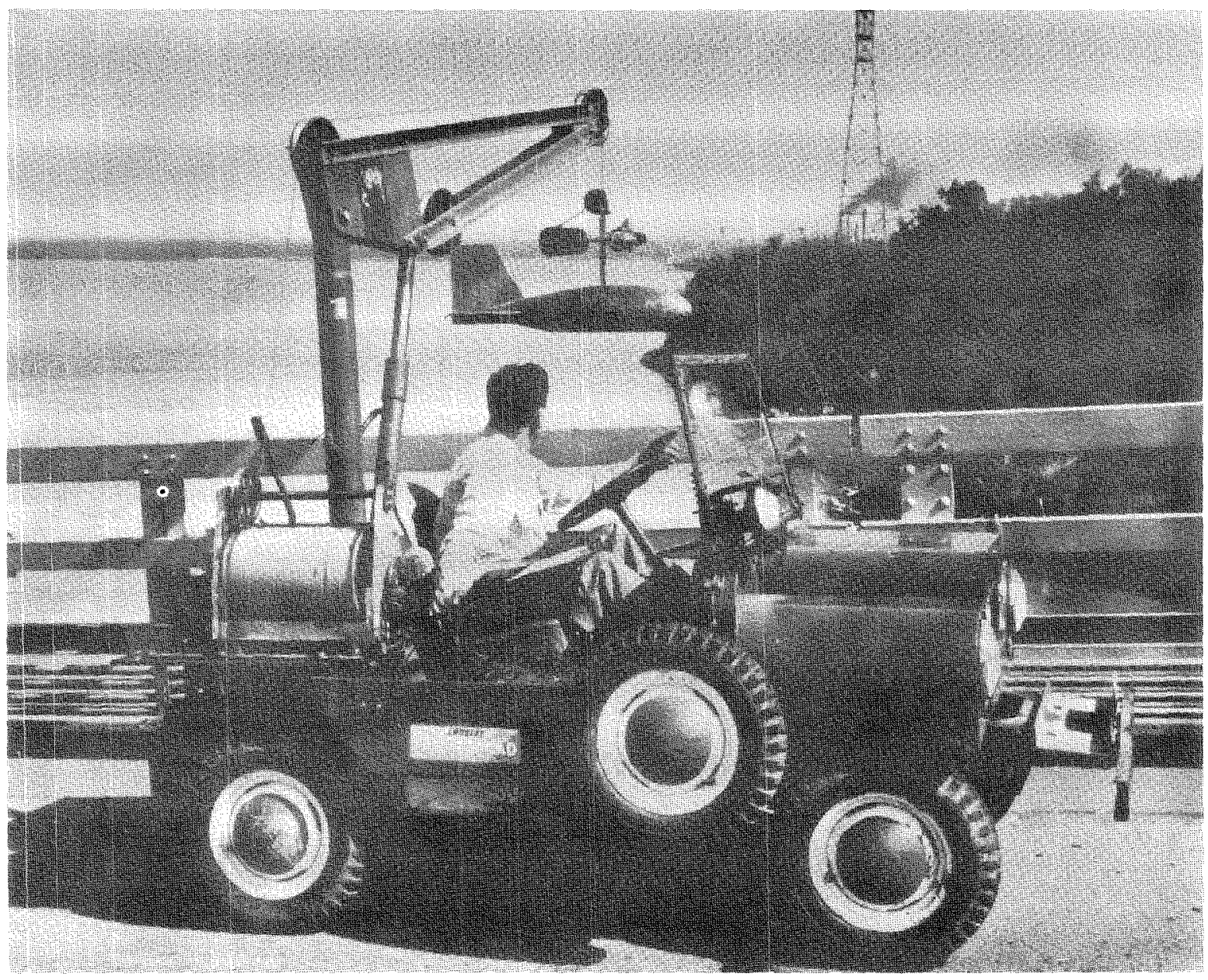

Figure 44.-Truck-mounted crane used on the Mississippi River. 


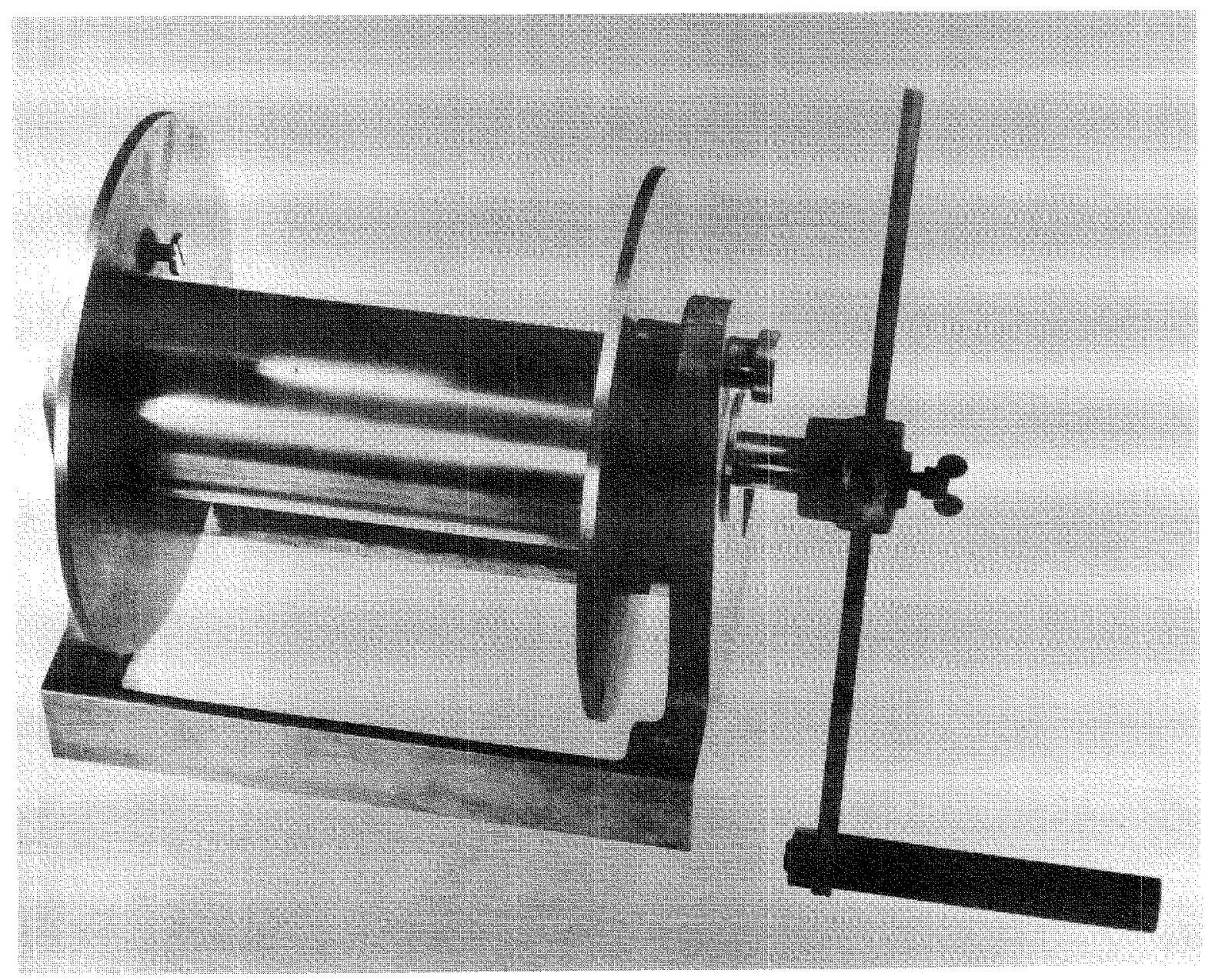

Figure 45.-Horizontal-axis boat tag-line reel without a brake. 


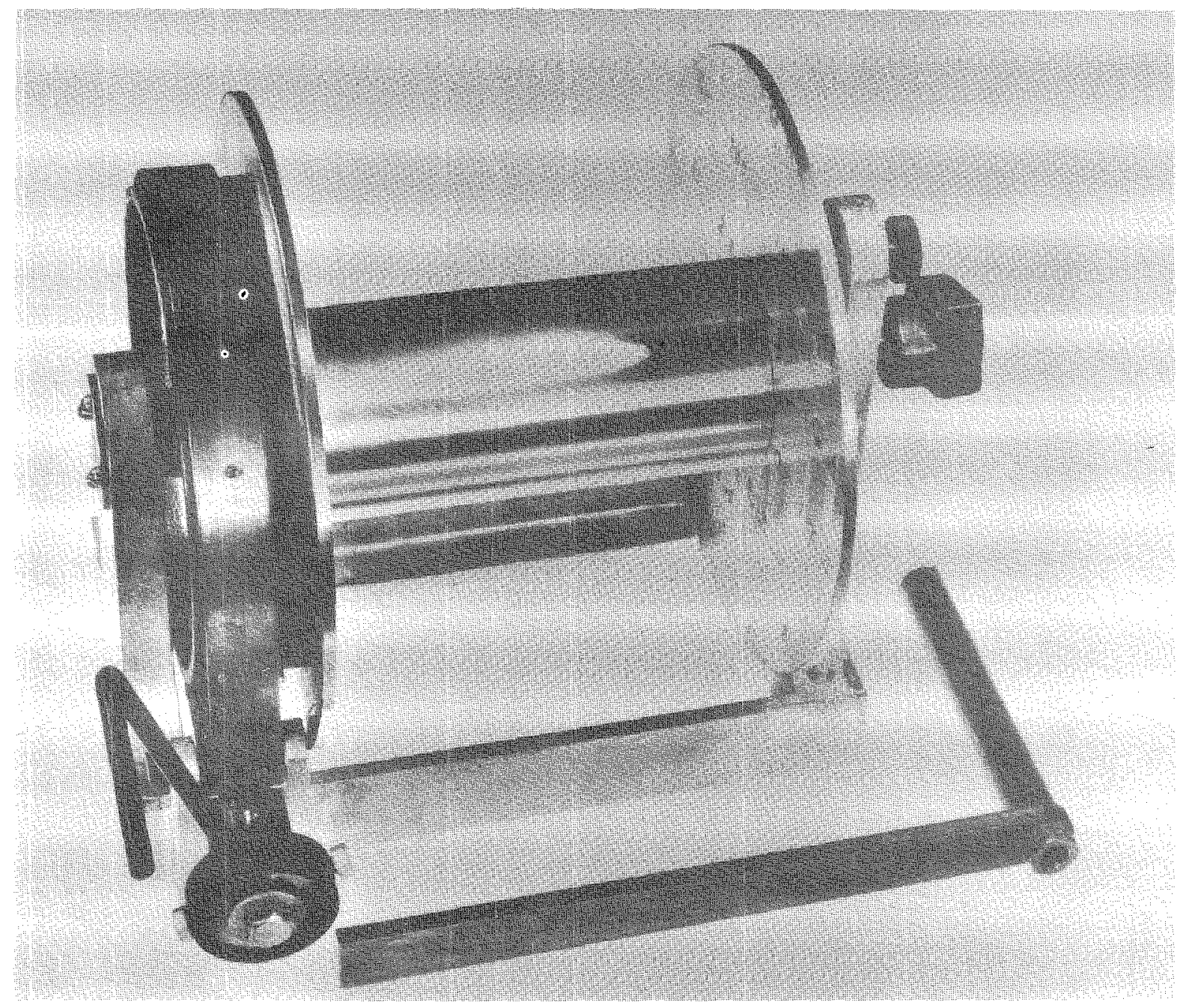

Figure 46.-Horizontal-axis boat tag-line reel with a brake.

is the battery for the current-meter circuit, the headphone jacks, and the two-conductor jack for the sonic sounder. A switch allows the remote-indicating unit to be used separately or in conjunction with the sonic sounder. The sonic sounder is mentioned on page 16 . This assembly is useful in tidal investigations and other special studies as well as at regular gaging stations, where it is desirable to determine the direction of flow beneath the surface when it may differ from that at the surface.

Miscellaneous equipment

Several miscellaneous items which have not been described are necessary when currentmeter measurements are made. Three classi- fications of this equipment are timers, counting equipment, and waders and boots.

In order to determine the velocity at a point with a current meter, it is necessary to count the revolutions of the rotor in a measured interval of time, usually $40-70$ seconds. The velocity is then obtained from the meter-rating table. (See fig. 11.) The time interval is measured to the nearest second with a stopwatch. (See fig. 53.)

The revolutions of the meter rotor during the observation of velocity are counted by an electric circuit that is closed each time the contact wire touches the single or penta eccentric of the current meter. A battery and headphone are 


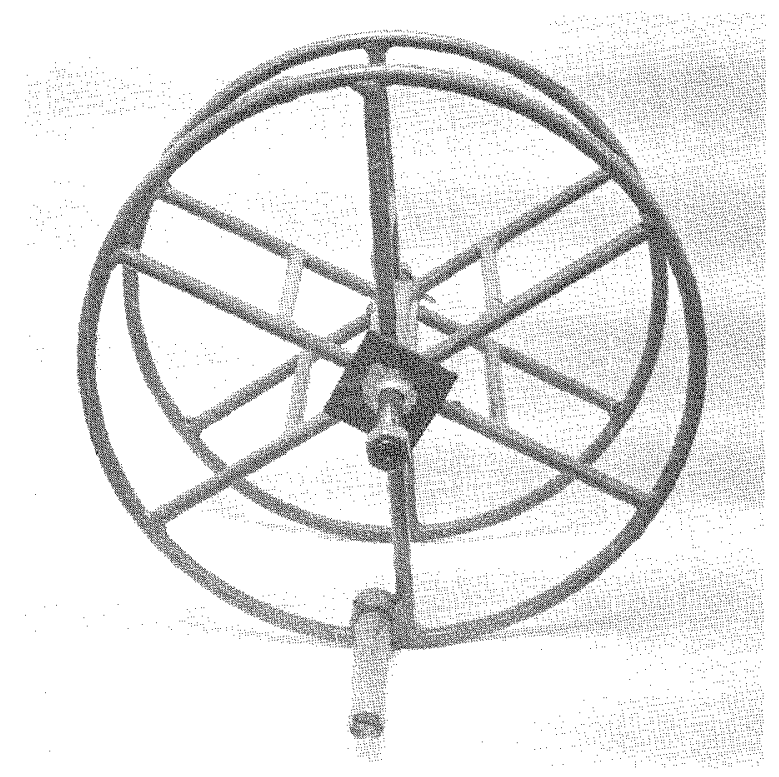

Figure 47.-Vertical-axis boat tag-line reel. When in use the axis of the reel is vertical.

parts of the electrical circuit, and a click is heard in the headphone each time the contact wire touches. (See fig. 54.) In many cases, compact, comfortable hearing-aid phones have been adapted to replace headphones.

A magnetic-switch contact chamber has been developed to replace the contact-wire chamber. (See p. 6.) An automatic electric counter has been developed for use with the magnetic contact chamber. (See fig. 54.) The counter can register up to 999 and has a reset button. A metal clip is attached to the counter so that it may be easily carried on the belt. The electric counter should not be used with the contact-wire chamber because at low velocities the contact wire wipes irregularly thereby sending several signals to the counter for each revolution.

Waders or boots are needed when wading measurements are made. Waders should be loose fitting even after allowance has been made for heavy winter clothing. Ice creepers strapped on the shoe of boots or waders should be used on steep or icy stream banks and on rocky or smooth and slippery streambeds. (See fig. 55.)

\section{Measurement of velocity}

The current meter measures velocity at a point. The method of making discharge meas- urements at a cross section requires determination of the mean velocity in each of the selected verticals. The mean velocity in a vertical is obtained from velocity observations at many points in that vertical. The mean can be approximated by making a few velocity observations and using a known relation between those velocities and the mean in the vertical. The various methods of measuring velocity are:

1. Vertical-velocity curve.

2. Two-point.

3. Six-tenths-depth.

4. Two-tenths-depth.

5. Three-point.

6. Subsurface.

\section{Vertical-velocity curve method}

In the vertical-velocity curve method a series of velocity observations at points well distributed between the water surface and the streambed are made at each of the verticals. If there is considerable curvature in the lower part of the vertical-velocity curve, it as advisable to space the observations more closely in that part of the depth. Normally, the observations are taken at 0.1-depth increments between 0.1 and 0.9 of the depth. Observations are always taken at $0.2,0.6$, and 0.8 of the depth so that the results obtained by the vertical-velocity curve method may be compared with the commonly used methods of velocity observation. Observations are made at least 0.5 foot from the water surface and from the streambed with the Price AA meter or the vane meter and are made at least 0.3 foot from these boundaries with the Price pygmy meter.

The vertical-velocity curve for each vertical is based on observed velocities plotted against depth. (See fig. 56.) In order that verticalvelocity curves at different verticals may be readily compared, it is customary to plot depths as proportional parts of the total depth. The mean velocity in the vertical is obtained by measuring the area between the curve and the ordinate axis with a planimeter, or by other means, and dividing the area by the length of the ordinate axis.

The vertical-velocity curve method is valuable in determining coefficients for application to the results obtained by other methods, 


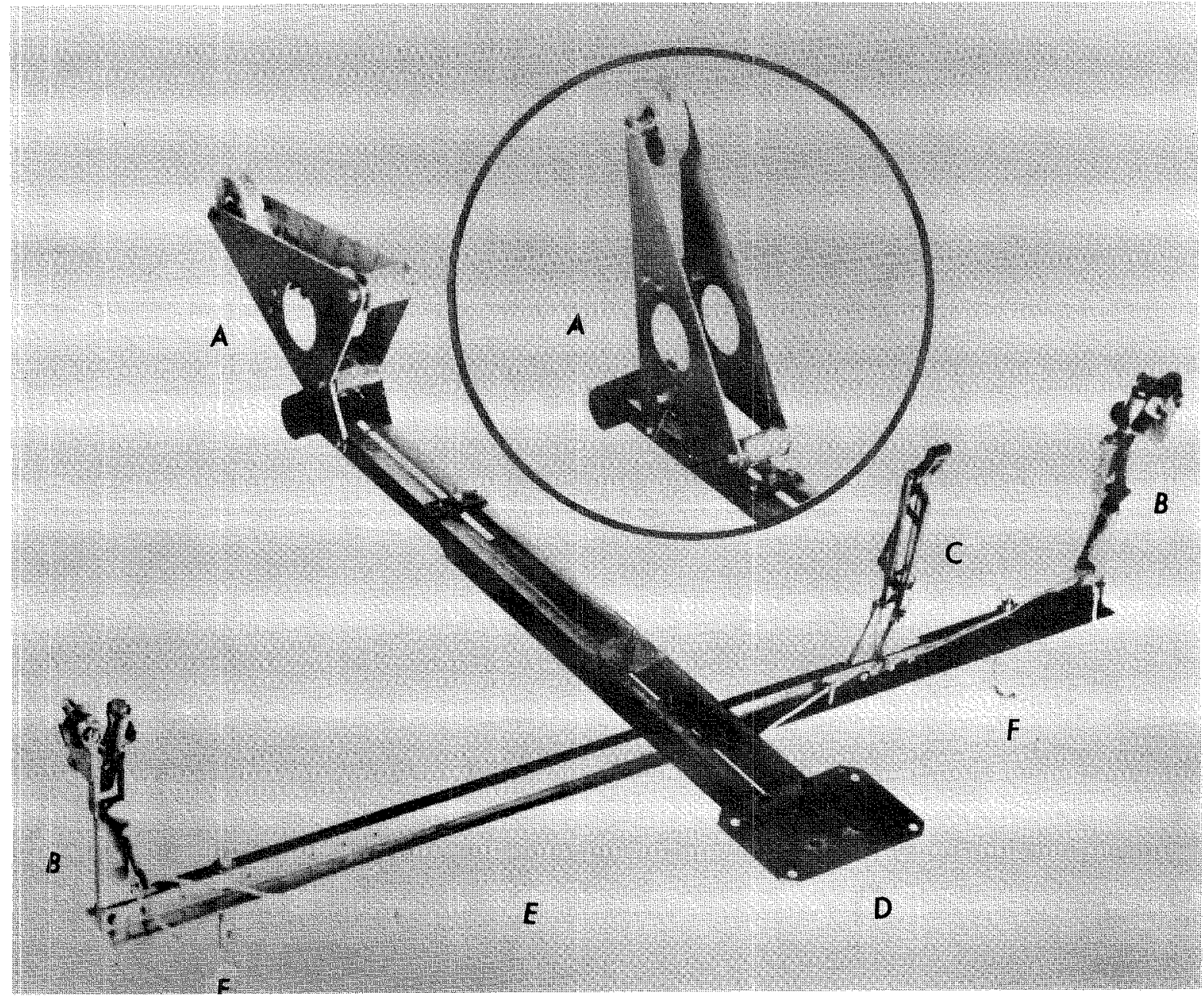

Figure 48.-Boom and crosspiece for use on boats. A, retrcictable end of boom; $\mathbf{B}$, guide sheave and clamp for attaching to tag line; $\mathbf{C}$, clamp to prevent movement of the boat along the tag line; $\mathbf{D}$, plate to accommodate reel, $\mathbf{E}$, rope to release clamps (B) to free boat from tag line; and F, clamps to attach crosspiece to boat.

but is not generally adapted to routine discharge measurements because of the extra time required to collect field data and to compute the mean velocity.

\section{Two-point method}

In the two-point method of measuring velocities, observations are made in each vertical at 0.2 and 0.8 of the depth below the surface. The average of these two observations is taken as the mean velocity in the vertical. This method is based on many studies of actual observation and on mathematical theory. Experience has shown that this method gives more consistent and accurate results than any of the other methods except the verticalvelocity curve method. (See p. 31.) The two-point method is the one generally used by the Geological Survey.

The two-point method is not used at depths less than 2.5 feet because the current meter would be too close to the water surface and to the streambed to give dependable results.

\section{Six-tenths-depth method}

In the 0.6-depth method, an observation of velocity made at 0.6 of the depth below the surface in the vertical is used as the mean velocity in the vertical. Actual observation and mathematical theory has shown that the 0.6- 


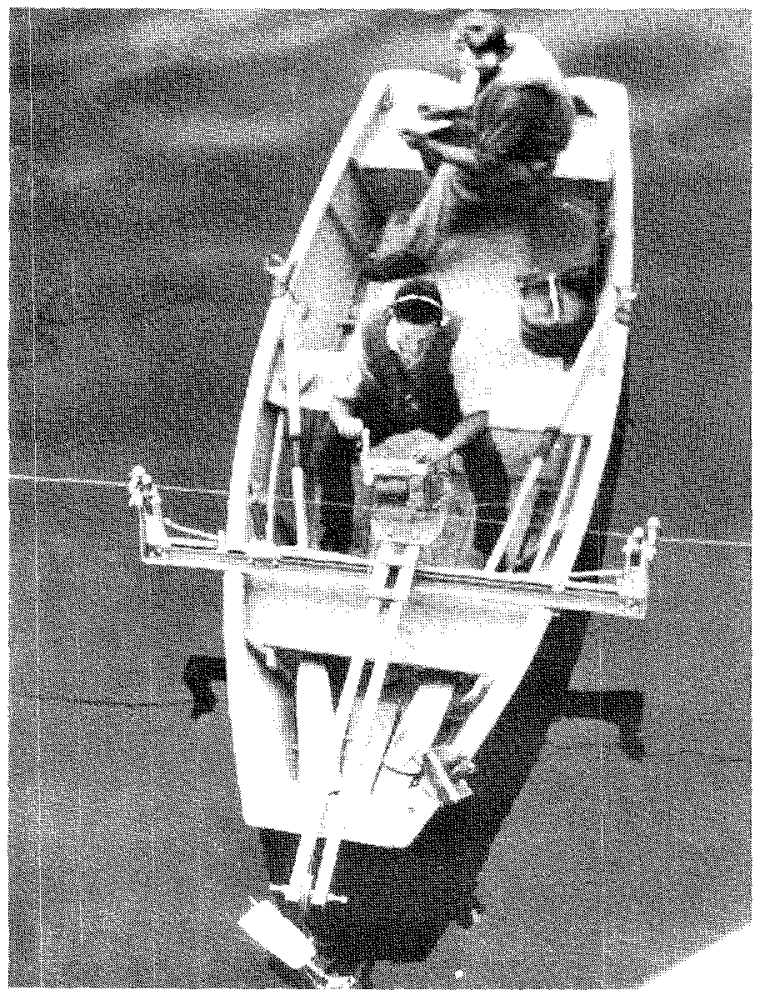

Figure 49.-Measuring equipment set up in a boat.

depth method gives reliable results and is used by the Geological Survey under the following conditions:

1. Whenever the depth is between 0.3 foot and and 2.5 feet.

2. When large amounts of slush ice or debris make it impossible to observe the velocity accurately at the 0.2 depth. This condition prevents the use of the two-point method.

3 . When the meter is placed a distance above the sounding weight which makes it impossible to place the meter at the 0.8 depth. This circumstance prevents the use of the two-point method.

4. When the stage in a stream is changing rapidly and a measurement must be made quickly.

\section{Two-tenths-depth method}

The two-tenths-depth method consists of observing the velocity at 0.2 of the depth below the surface and applying a coefficient to this observed velocity to obtain the mean in the vertical. It is used mainly during times of high

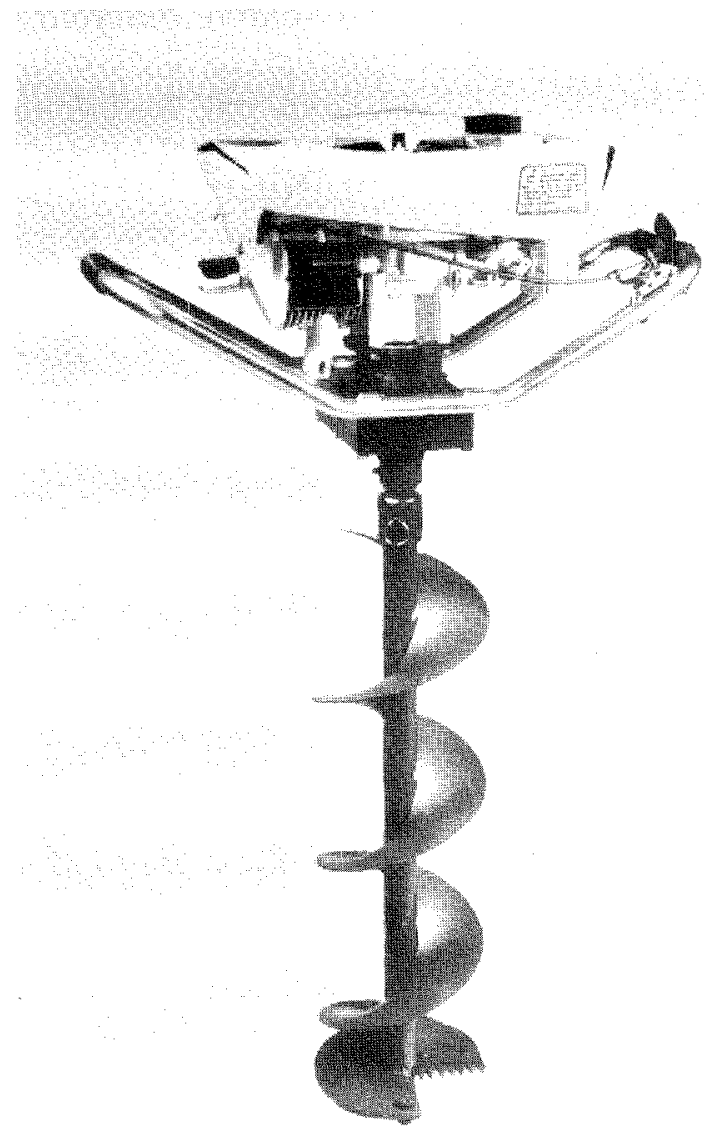

Figure 50,-Gasoline-powered ice drill. Photograph by perrnission of General Equipment $\mathrm{Co}$.

water when the velocities are great, making it impossible to obtain soundings or to place the meter at the 0.8 or the 0.6 depth.

A standard cross section or a general knowledge of the cross section at a site is used to compute the 0.2 depth when it is impossiblle to obtain soundings. A sizeable error in an assumed 0.2 depth is not critical because the slope of the vertical-velocity curve at this point is usually nearly vertical. (See fig. 56.) The 0.2 depth is also used in conjunction with the sonic sounder for flood measurements. (See p. 16.) The two-point method and the 0.6-depth method are preferred over the 0.2 -depth method because of their greater accuracy.

The measurement is normally computed by using the 0.2 -depth velocity observations without coefficients as though each were a mean in 


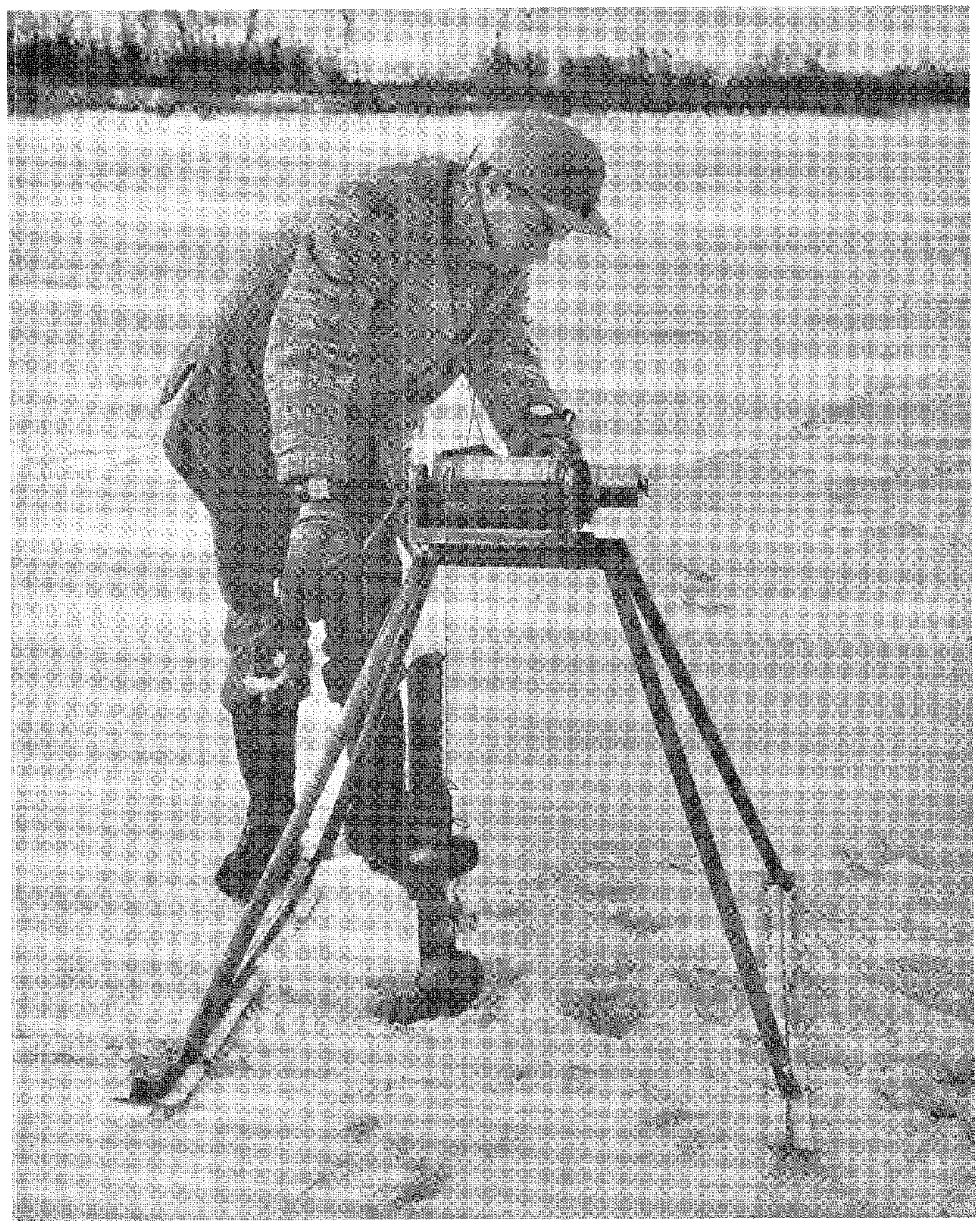

Figure 51.-Collapsible reel support and ice-weight assembly. 


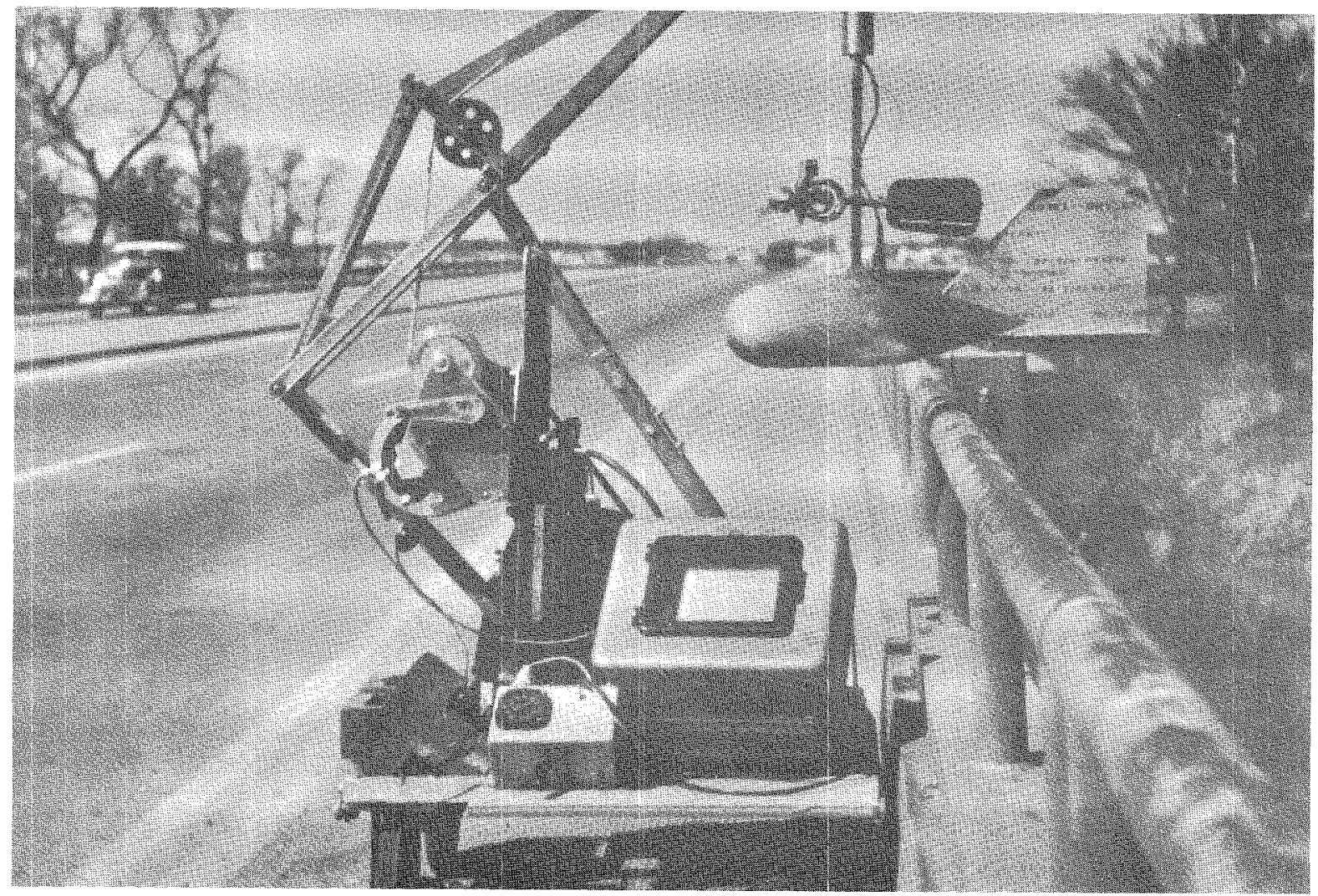

Figure 52.-Velocity-azimuth-depth assembly.

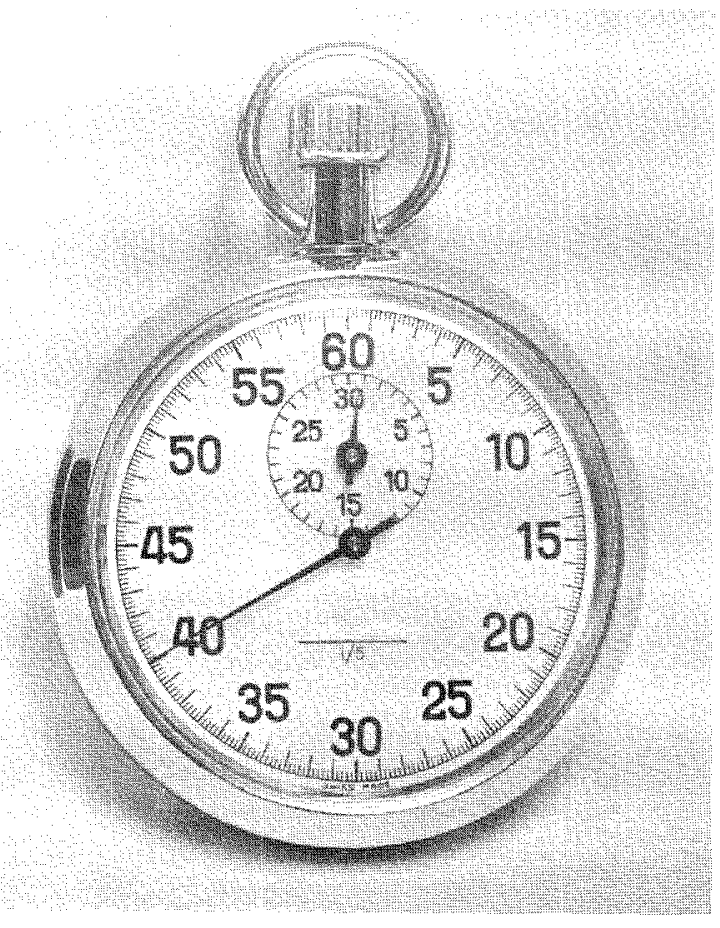

Figure 53.-Stopwatch.

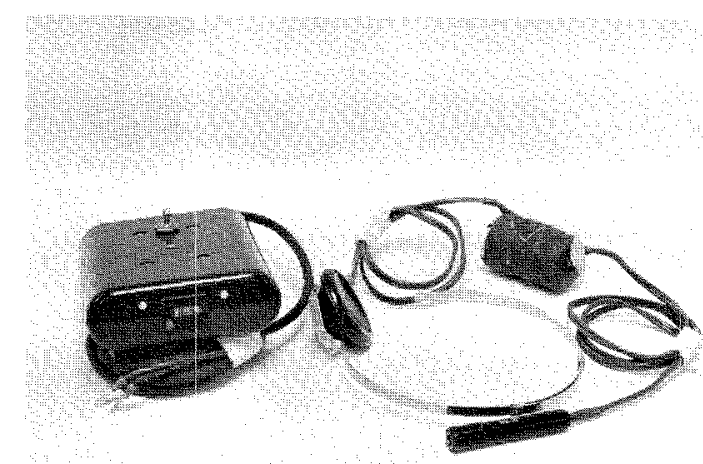

Figure 54.-A Automatic counter (left) and headphone (right).

the vertical. The approximate discharge thus obtained divided by the area of the measuring section gives the weighted mean value of the 0.2 -depth velocity. Studies of many measurements made by the two-point method show that for a given measuring section the relation 


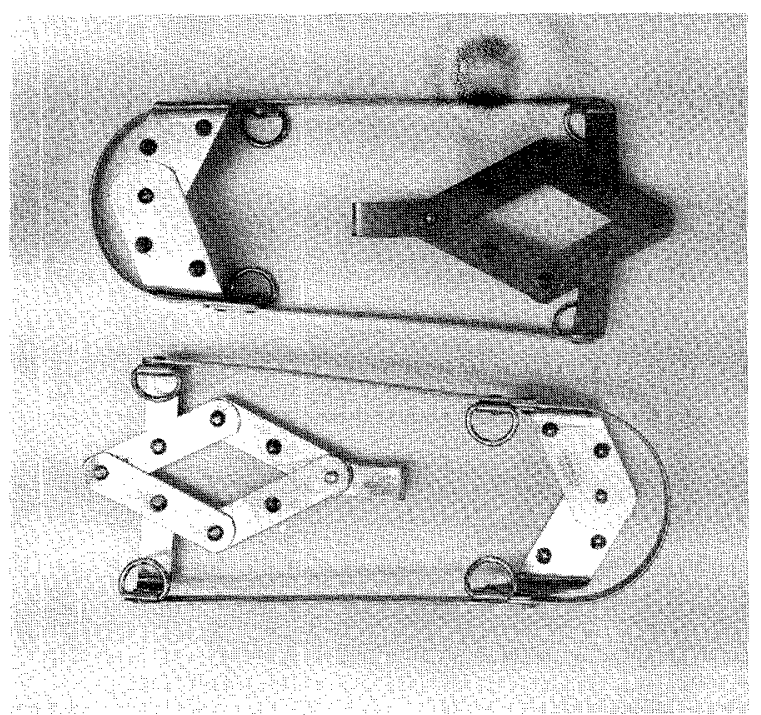

Figure 55.-Ice creepers for boots and waders. between the mean 0.2-depth velocity and the true mean velocity either remains constant or varies uniformly with stage. In either circumstance, this relation may be determined for a particular 0.2-depth measurement by recomputing measurements made at the site by the two-point method using only the 0.2-depth velocity observation as the mean in the vertical. The plotting of the true mean velocity versus the mean 0.2-depth velocity for each measurement will give a velocity-relation curve for use in adjusting the mean velocity for measurements made by the 0.2-depth method.

If at a site enough measurements have not been made by the two-point method to establish a velocity-relation curve, vertical-velocity curves are needed to establish a relationship between the mean velocity and the 0.2-depth

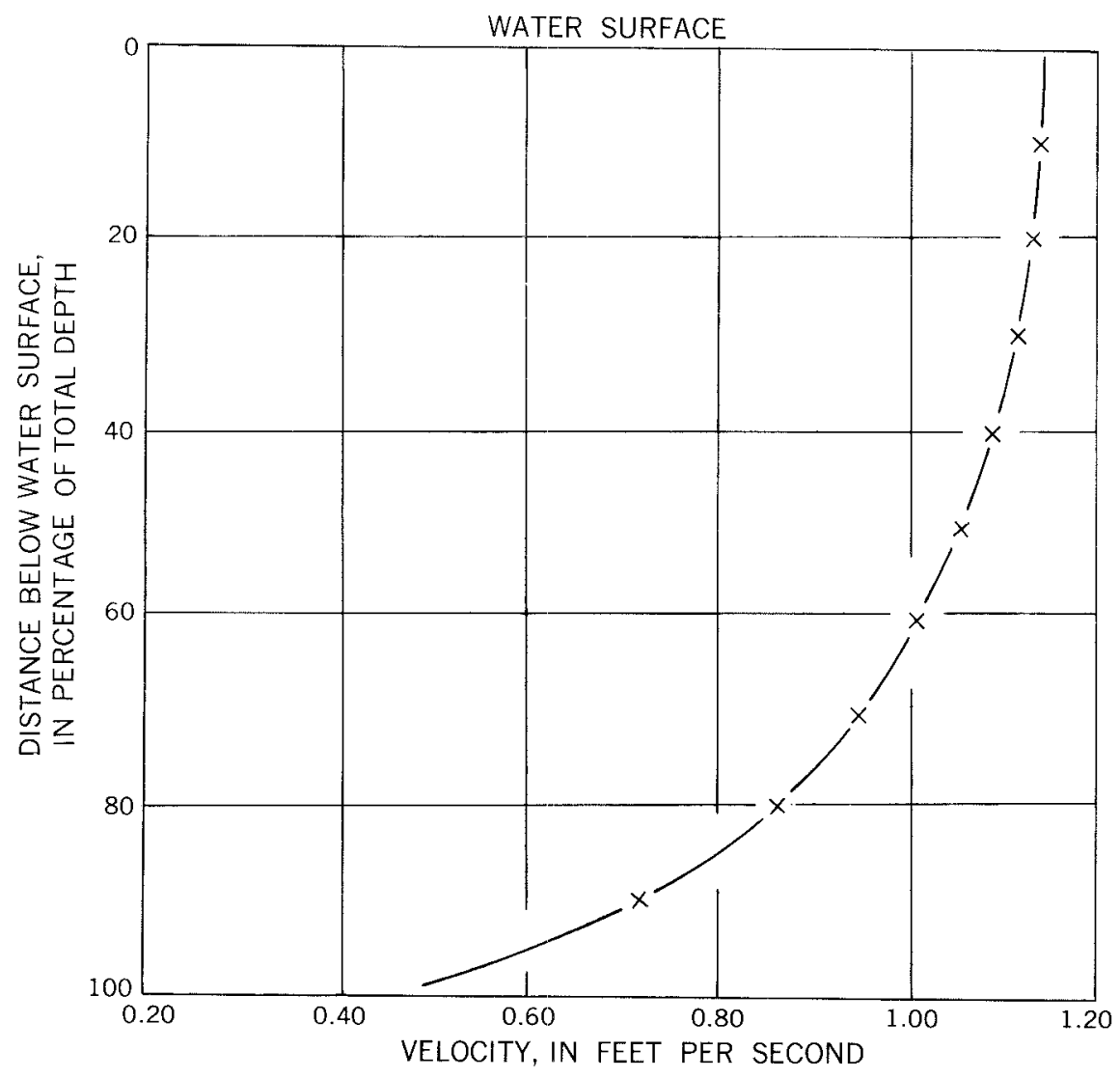

Figure 56.-Typical vertical-velocity curve. 
velocity. The usual coefficient to adjust the $0.2-$ depth velocity to the mean velocity is about 0.88 .

\section{Three-point method}

The three-point method consists of observing the velocity at $0.2,0.6$, and 0.8 of the depth, thereby combining the two-point and 0.6-depth methods. The mean velocity is computed by averaging the 0.2 - and 0.8 -depth observations and then averaging the result with the 0.6 -depth observation. When more weight to the $0.2-$ and 0.8-depth observations is desired, the arithmetical mean of the three observations may be used. The first procedure is usually followed, however.

The three-point method is used when the velocities in the vertical are abnormally distributed. It is also used when the 0.8-depth observation is made where the velocity is seriously affected by friction or by turbulance produced by the streambed or an obstruction in the stream. The depths must be greater than 2.5 feet before this method can be used.

\section{Subsurface method}

The subsurface method consists of observing the velocity at some distance below the water surface. This distance should be at least 2 feet and preferably more for deep swift streams to avoid the effect of surface disturbances.

The subsurface method is used when it is impossible to obtain soundings and the depths cannot be estimated with enough reliability to even approximate a 0.2-depth setting. Coefficients are necessary to convert the velocities observed by the subsurface method to the mean velocity in the vertical. Verticalvelocity curves obtained at the particular site are used to compute these coefficients. The coefficients are generally difficult to determine reliably because they may vary with stage, depth, and position in the measuring cross section.

\section{Current-meter measurement procedure}

The first step in making a current-meter measurement is to select a reach of stream containing the following characteristics:

1. A straight reach with the threads of velocity parallel to each other.
2. Stable streambed free of large rocks, weeds, and protruding obstructions such as piers, which would create turbulence.

3. A flat streambed profile to eliminate vertical components of velocity.

It is usually not possible to satisfy all of these conditions. Select the best possible reach using these criteria and then select a cross section.

After the cross section has been selected, determine the width of the stream. String a tag line or measuring tape for measurements made by wading, from a boat, from ice cover, or from an unmarked bridge. String the line at right angles to the direction of flow to avoid horizontal angles in the cross section. For cableway or bridge measurements, use the graduations painted on the cable or bridge rail as described on page 17. Next determine the spacing of the verticals, generally using about 25 to 30 partial sections. With a smooth cross section and good velocity distribution, fewer sections may be used. Space the partial sections so that no partial section has more than 10 percent of the total discharge in it. The ideal measurement is one in which no partial section has more than 5 percent of the total discharge in it, but this is very seldom accomplished when 25 partial sections are used. The discharge measurement shown in figure 2 had 6.2 percent of the total discharge in the partial section with the greatest discharge. Equal widths of partial sections across the entire cross section are not recommended unless the discharge is well distributed. Make the width of the partial sections less as depths and velocities become greater. Usually an approximate discharge can be obtained from the stage-discharge curve. Space the verticals so the discharge in each vertical is about 5 percent of the discharge from the rating curve.

After the cross section has been selected and the stationing determined, assemble the appropriate equipment for the current-meter measurement and prepare the measurement note sheets to record the observations. (See fig. 2.) For each discharge measurement record the following information:

1. Name of stream and location to correctly identify the established gaging station; or name of stream and exact location of site for a miscellaneous measurement. 
2. Date, party, type of meter suspension, and meter number.

3. Time measurement was started using military time.

4. Bank of stream that was the starting point.

5. Control conditions.

6. Gage heights and corresponding times.

7. Water temperature.

8. Other pertinent information regarding the accuracy of the discharge measurement and conditions which might affect the stage-discharge relation.

Identify the stream bank by either LEW or $\mathrm{REW}$ (left edge of water or right edge of water, respectively, when facing downstream). Record the time in the notes periodically, during the course of the measurement. This time usually should be synchronized with the time of punch on the digital recorder. (See fig. 2.) This is important because if there is any appreciable change in stage during the measurement, the time is needed to determine the mean gage height for the measurement. (See p. 53.) When the measurement is completed, record the time and the bank of the stream where the section ends.

After the equipment and the note sheet have been readied, begin the measurement. Indicate on the note sheet the distance from the initial point to the edge of the water. Measure and record the depth at the edge of water.

After the depth is known and recorded, determine the method of velocity measurement. Normally the two-point method or the 0.6-depth method is used. Compute the setting of the meter for the particular method to be used at that depth. Record the meter position (as $0.8,0.6,0.2, \ldots$ ). After the meter is placed at the proper depth, permit it to become adjusted to the current before starting the velocity observation. The time required for such adjustment is usually only a few seconds if the velocities are greater than $1 \mathrm{fps}$, but for lower velocities, particularly if the current meter is suspended by a cable, a long period of adjustment is needed. After the meter has become adjusted to the current, count the number of revolutions made by the rotor for a period of 40-70 seconds. Start the stopwatch simultaneously with the first signal or click, counting "zero," not "one." End the count on a convenient number given in the meter rating table column heading. Stop the stopwatch on that count and read the time to the nearest second, or to the nearest even second if the hand is on a half-second mark. Record the number of revolutions and the time interval.

If the velocity is to be observed at more than one point in the vertical, determine the meter setting for the additional observation, time the revolutions, and record the data. Move to each of the verticals and repeat this procedure; record the distance from initial point, depth, meter-position depth, revolutions, and time interval, until the entire cross section has been traversed. (See fig. 2.)

If the direction of flow is not at right angles to the cross section, find the velocity vector normal to the section. Measure the cosine of the horizontal angle (fig. 57) by holding the note sheet in a horizontal position with the point of origin ( 0$)$ on the left edge of the note sheet (fig. 2) over the tag line, bridge rail, or any other feature parallel to the cross section. With the long side of the note sheet parallel to the direction of flow, the tag line or bridge rail will intersect the value of the cosine of the angle $\alpha$ on the top, bottom, or right edge of the note sheet. Multiply the measured velocity by the cosine of the angle to determine the velocity component normal to the measuring section.

Details peculiar to specific types of currentmeter measurements are described in the following sections.

\section{Current-meter measurements by wading}

Current-meter measurements by wading are preferred, if conditions permit. (See fig. 58). Wading measurements offer the advantage over measurements from bridges and cableways in that it is usually possible to select the best of several available cross sections for the measurement.

Use the type AA or the pygmy meter for wading measurements. Table 2 lists the type of meter and velocity method to use for wading measurements for various depths.

If a type AA meter is being used in a cross section with an average depth greater than 1.5 feet, do not change to the pygmy meter for a few depths less than 1.5 feet or vice versa. Use 


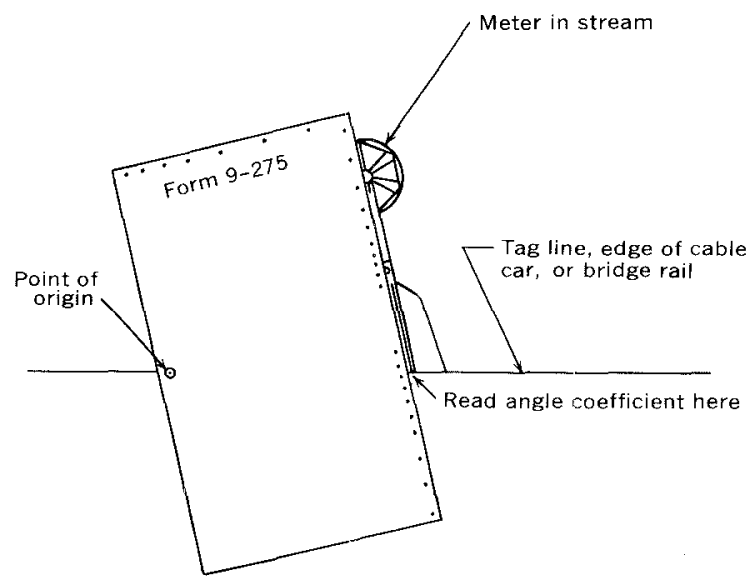

Figure 57.-Measurement of horizontal angles.

Table 2.-Current-meter and velocity-measurement method for various depths

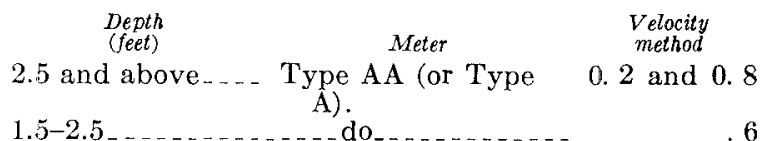

3-1.5_ Pygmy $1 . \ldots$

1 Used when velocities are less than $2.5 \mathrm{fps}$.

the type AA meter at depths as shallow as 0.5 foot. Its use is not recommended below depths of 1.0 foot because the registration of the meter is affected by its proximity to the water surface and to the streambed. Do not use the type AA meter or the pygmy meter in velocities less than 0.2 fps unless absolutely necessary.

Coefficients given by Pierce (1941) for the performance of current meters in water of shallow depth and low velocities are no longer

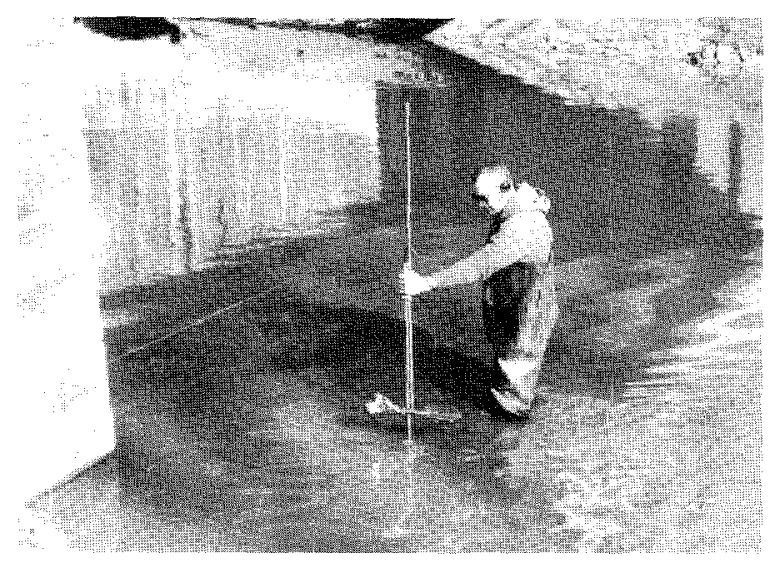

Figure 58.-Wading measurement using top-setting rod. recommended for use, at least until further investigation.

When natural conditions for measuring are in the range considered undependable, modify the measuring cross section, if practical, to provide acceptable conditions. Often it is possible to build dikes to cut off dead water and shallow flows in a cross section, or to improve the cross section by removing the rocks and debris within the section and from the reach of stream immediately upstream from it. After modifying a cross section, allow the flow to stabilize before starting the discharge measurement.

Stand in a position that least affects the velocity of the water passing the current meter. This position is usually obtained by facing the bank, with the water flowing against the side of the leg. Holding the wading rod at the tag line, stand from 1 to 3 inches downstream from the tag line and 18 inches or more from the wading rod. Avoid standing in the water if feet and legs would occupy a considerable percentage of the cross section of a narrow stream. In small streams where the width permits, stand on a plank or other support rather than in the water.

Keep the wading rod in a vertical position and the meter parallel to the direction of flow while observing the velocity. If the flow is not at right angles to the tag line, measure the angle coefficient carefully. 
During measurements of streams with shifting beds, the scoured depressions left by the hydrographer's feet can affect soundings or velocities. Generally, place the meter ahead of and upstream from the feet. Record an accurate description of streambed and water-surface configuration each time a discharge measurement is made in a sand-channel stream.

For discharge measurements of flow too small to measure with a current meter use a volumetric method, Parshall flume, or weir plate.

\section{Current-meter measurements from cableways}

The equipment assemblies for use on cableways are described on page 18 .

The size of the sounding weight used in current-meter measurements depends on the depth and velocity to be found in a cross section. A rule of thumb is that the size of the weight in pounds should be greater than the maximum product of velocity and depth in the cross section. If insufficient weight is used,

the sounding line will be dragged at an angte downstream. If debris or ice is flowing or if the stream is shallow and swift, use a heavier weight than the rule designates. The rule is not rigid but does provide a starting point for deciding on the size weight necessary. Examine notes of previous measurements at a site to help determine the size weight needed at various stages.

The Price type-AA current meter is generally used when making discharge measurements from a cableway. The depth is measured by using a sounding reel and the velocity is measured by setting the meter at the proper position in the vertical. (See table 3.) Table 3 is designed so that no velocity observations will be made with the meter closer than 0.5 foot to the water surface. In the zone from the water surface to a depth of 0.5 foot, the current meter is known to give erratic results.

Table 3.-Velocity-measurement method for various suspensions and depths

\begin{tabular}{|c|c|c|}
\hline \multirow[b]{2}{*}{ Suspension } & \multicolumn{2}{|c|}{ Minimum depth (feet) } \\
\hline & 0.6 method & $\begin{array}{c}0.2 \text { and } 0.8 \\
\text { method }\end{array}$ \\
\hline $15 \mathrm{C} .5,30 \mathrm{C} .5 \ldots$ & 1. 2 & 2. 5 \\
\hline $50 \mathrm{C} .55 \ldots$ & 1. 4 & 2.8 \\
\hline $50 \mathrm{C} \cdot 9_{-}$ & 2. 2 & 4. 5 \\
\hline $75 \mathrm{C} 1.0,100 \mathrm{C} 1.0,150 \mathrm{C} 1.0$ & 2.5 & 5. 0 \\
\hline $200 \mathrm{C} 1.5,300 \mathrm{C} 1.5 \ldots$ & 13.8 & 7. 5 \\
\hline
\end{tabular}

Some sounding reels are equipped with a computing depth indicator. To use the computing spiral, set the indicator at zero when the center of the current-meter rotor is at the water surface. Lower the sounding weight and meter until the weight touches the streambed. If a 30 C .5 suspension is used and the indicator reads 18.5 feet when the sounding weight touches the bottom, the depth would be 19.0 feet. To move the meter to the 0.8-depth position, merely raise the weight and the meter until the hand on the indicator is over the 19-foot mark on the graduated spiral (fig. 25); the hand will then be pointing to 15.2 feet on the main dial. To set the meter at the 0.2 -depth position, raise the weight and meter until the hand on the indicator is pointing to 3.8 feet on the main dial.

One problem found while observing velocities from a cableway is that the movement of the cable car from one station to the next makes the car oscillate for a short time after coming to a stop. Wait until this oscillation has dampened to a negligible amount before counting the revolutions.

Tags can be placed on the sounding line a known distance above the center of the meter cups as an aid in determining depth. (See fig. 36.) The tags, which are usually streamers of different colored binding tape, are fastened to the sounding line by solder beads or by small cable clips. Tags are used for determining depth in two ways:

Set the tag at the water surface and then set on the depth indicator the distance which that particular tag is above the center of the meter cups. Then continue as if the meter cups themselves had been set at the water surface. This is the preferred procedure. If debris or ice is flowing, this method prevents damage to the meter.

With the sounding weight on the streambed, determine the depth by raising the weight until the first tag below the water surface appears at the surface. The total depth is then the sum of (a) the distance the weight was raised to bring the tag to the water surface, (b) the distance the tag is above the center of the meter cups, and (c) the distance from the 
bottom of the weight to the center of the cups. This method is sometimes used with handlines.

By using tags, the meter can be kept under water at all times to prevent freezing the meter in cold air. 'Tags are also used in measurements of deep, swift streams. (See p. 47.)

If large amounts of debris are flowing in the stream, raise the meter up to the cable car several times during the measurement to be certain the pivot and rotor of the meter are free of debris. However, keep the meter in the water during the measurement if the air tem-. perature is considerably below freezing. Carry a pair of lineman's side-cutter pliers when making measurements from a cableway. If the weight and meter become caught on a submerged object or on floating debris and it is impossible to release them, cut the sounding line to insure safety. Sometimes the cable car can be pulled to the edge of the water and the debris can be released.

When measurements are made from cableways where the stream is deep and swift, measure the angle that the meter suspension cable makes with the vertical due to the drag. The vertical angle, measured by protractor p. 47), is needed to correct the soundings to obtain the actual vertical depth. (See p. 49.)

\section{Current-meter measurements from bridges}

When a stream cannot be waded, bridges may be used to obtain current-meter measurements. Many measuring sections under bridges are satisfactory for current-meter measurements, but cableway sections are usually better.

No set rule can be given for choosing between the upstream or downstream side of the bridge when making a discharge measurement.

The advantages of using the upstream side of the bridge are:

1. Hydraulic characteristics at the upstream side of bridge openings usually are more favorable.

2. Approaching drift can be seen and be more easily avoided.

3. The streambed at the upstream side of the bridge is not likely to scour as badly as at the downstream side.
The advantages of using the downstream side of the bridge are:

1. Vertical angles are more easily measured because the sounding line will move away from the bridge.

2. The flow lines of the stream may be straightened out by passing through a bridge opening with piers.

Whether to use the upstream side or the downstream side of a bridge for a current-meter measurement should be decided individually for each bridge after considering the factors mentioned above and the physical conditions at the bridge, such as location of the walkway, traffic hazards, and accumulation of trash on piles and piers.

Use either a handline, or a sounding reel supported by a bridge board or a portable crane to suspend the current meter and sounding weight from bridges.

Measure the velocity by setting the meter at the position in the vertical as indicated in table 3. Keep equipment several feet from piers and abutments if velocities are high. Estimate the depth and velocity next to the pier or abutment on the basis of the observations at the vertical nearest the pier.

If there are piers in the cross section, it is usually necessary to use more than $25-30$ partial sections to get results as reliable as those from a similar section without piers. Piers will of ten cause horizontal angles that must be carefully measured. Piers also cause rapid changes in the horizontal velocity distribution in the section.

Footbridges are sometimes used for measuring canals, tailraces, and small streams. Rod suspension can be used from many footbridges. The procedure for determining depth in low velocities is the same as for wading measurements. For higher velocities obtain the depth by the difference in readings at an index point on the bridge when the base plate of the rod is at the water surface and on the streambed. Measuring the depth in this manner will eliminate errors caused by the water piling up on the upstream face of the rod. Handlines, bridge cranes, and bridge boards are also used from footbridges.

When using a sounding reel measure the depth by methods described on page 40. To 
determine depth when using a handline, lower the sounding weight to the streambed, then raise the weight until one of the tags is at the water surface. Measure along the rubbercovered service cord with a steel or metallic tape or a graduated rod to determine the distance the weight is raised. The total depth of water is then the summation of (1) the distance the particular tag is above the meter cups, (2) the measured distance the meter and weight was raised, and (3) the distance from the bottom of the weight to the meter cups.

Another method of determining depths is to set the meter cups at the water surface and then lower the sounding weight to the streambed while measuring the amount of line that has been let out by one of the methods mentioned previously. This measured distance, plus the distance from the bottom of the sounding weight to the meter cups, is the depth of water. When using a handline, unwind enough cable from the handline reel to keep the reel out of water when the sounding weight is on the streambed at the deepest part of the cross section. If the bridge is high enough above the water surface, raise and lower the weight and meter by the rubber-covered cable rather than by the bare cable. When the meter is set for the velocity observation, stand on the rubbercovered cable or tie it to the handrail to hold the meter in place. This arrangement frees the hands to record the data.

The handline can be disconnected from the headphone wire and passed around a truss member with the sounding weight on the bottom. This eliminates the need for raising the weight and meter to the bridge each time a move is made from one vertical to another, and is the principal advantage of a handline.

\section{Current-meter measurements from ice cover}

Discharge measurements under ice cover are made under the most severe conditions (fig. 59) but are extremely important because a large part of the discharge record during a winter period may depend on one measurement.

Select the possible locations of the cross section to be used for a measurement from ice cover during the open-water season when channel conditions can be evaluated.

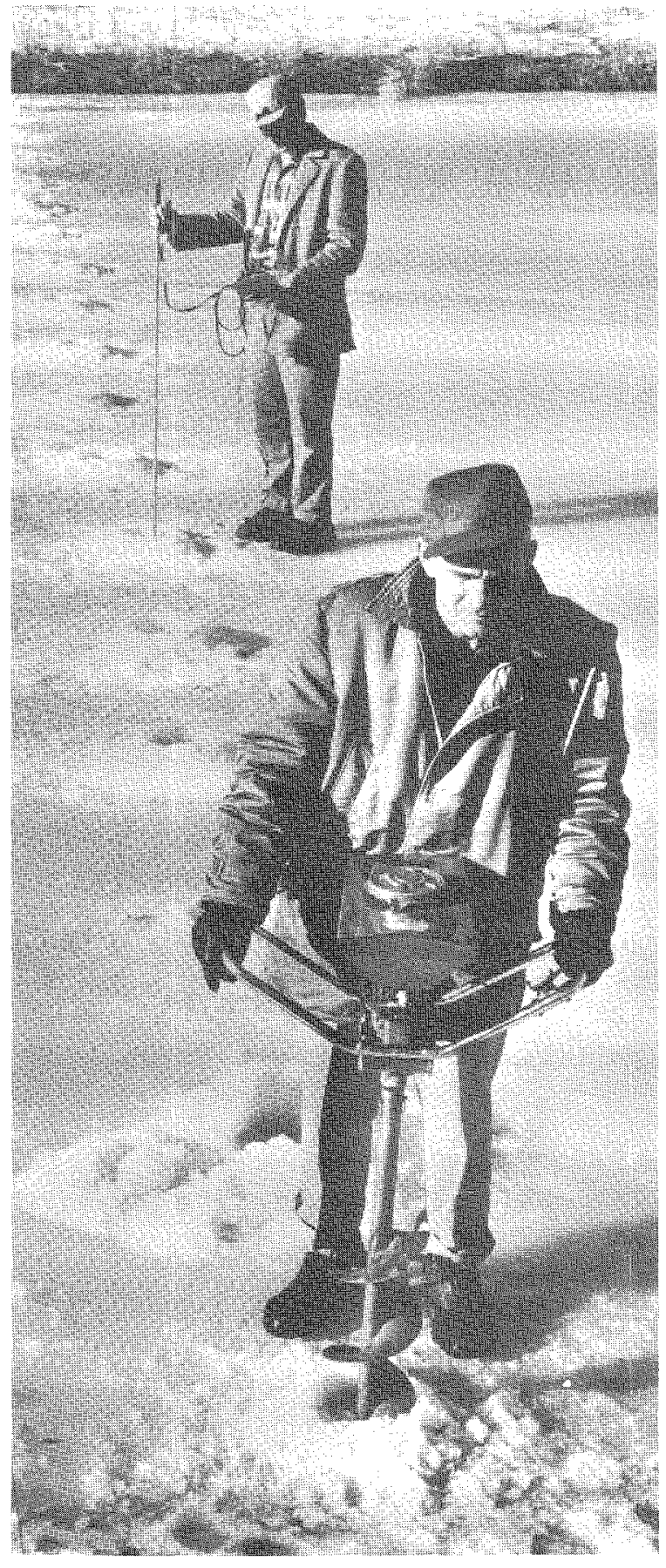

Figure 59.-Ice rod being used to support current meter for a discharge measurement, top; and ice drill being used to cut holes, bottom.

The equipment used for cutting or drilling the holes in the ice is described on page 27 .

Never underestimate the danger of working on ice-covered streams. When crossing, test 
the strength of the ice with solid blows using a sharp ice chisel. Ice thickness may be irregular, especially late in the season when a thick snow cover may act as an insulator. Water just above freezing can slowly melt the underside of the ice, creating thin spots. Ice bridged above the water may be weak, although thick.

Cut the first three holes in the selected cross section at the quarter points to detect the presence of slush ice or poor distribution of the flow in the measuring section. If poor conditions are found, investigate other sections to find one that is free of slush ice and that has good distribution of flow. Makke at least 20 holes in the ice for a current-meter measurement. Space the holes so that no partial section has more than 10 percent of the total discharge in it.

'The effective depth of the water (fig. 60) is the total depth of water minus the distance from the water surface to the bottom of the ice. The vertical pulsation of water in the holes in the ice sometimes causes difficulty in determining the depths. The total depth of water is usually measured with an ice rod or with a sounding weight and reel, depending on the depth.

Measure the distance from the water surface to the bottom of the ice with an ice-measuring stick. (See p. 27) If there is slush under the solid ice at a hole, the ice-measuring stick is not used. To find the depth at which the slush ice ends, suspend the current meter below the slush ice. with the meter rotor turning freely. Raise the meter slowly until the rotor stops. This point is used as the depth of the interface between water and slush.

After the effective depth of the water has been determined, compute the proper position of the meter in the vertical as shown in figure 60.

The vane ice meter is recommended for use under ice cover because the vanes do not become filled with slush ice as the cups of the Price meter often do, because the yoke of the vane meter will fit in the hole made by the ice drill, and because the yoke and ice rod can serve as an ice-measuring stick. The contact chamber of the vane meter can be rotated to any position, so the binding post is placed perpendicular to the axis of the yoke to avoid interference when using the top of the yoke to determine the underside of the ice.

The velocity distribution under ice cover is similar to that in a pipe with a lower velocity nearer the underside of the ice. (See fig. 61.) The 0.2- and 0.8-depth method is recommended for effective depths 2.5 feet or greater and the 0.6-depth method is recommended for effective depths less than 2.5 feet. It is recommend ed

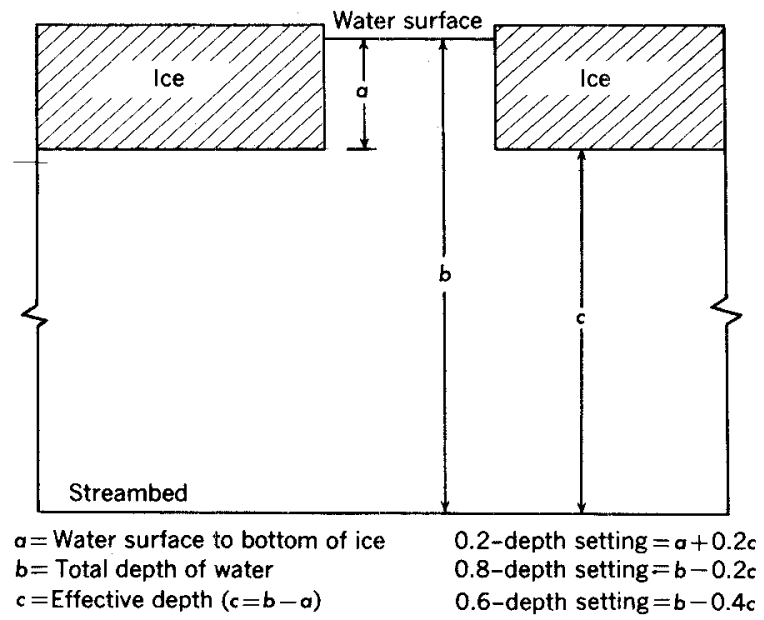

Figure 60.-Method of computing meter settings for measurements under ice cover. 


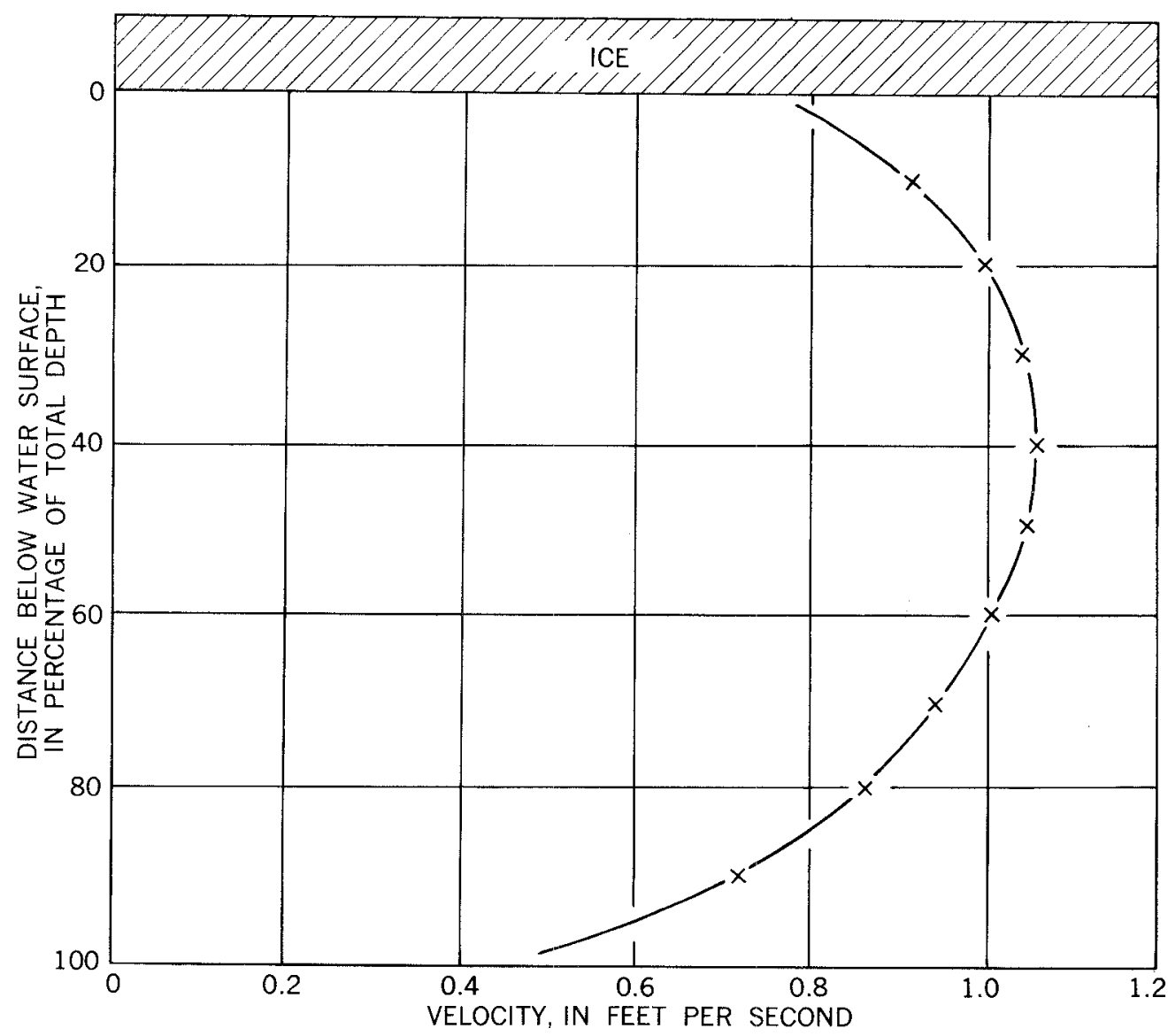

Figure 61.-Typical vertical-velocify curve under ice cover.

that two vertical-velocity curves be defined when ice measurements are made to determine whether any coefficients are necessary to convert the velocity obtained by the $0.2-$ and 0.8 depth method or the 0.6-depth method to the mean velocity. Normally the average of the velocities obtained by the 0.2 - and 0.8-depth method gives the mean velocity, but a coefficient of about 0.92 usually is applicable to the velocity obtained by the 0.6 -depth method.

When measuring the velocity, keep the meter as far upstream as possible to avoid any effect that the vertical pulsation of water in the hole might have on the meter. Eliminate as much as possible the exposure of the meter to the cold air during the measurement. The meter must be free of ice when the velocity is being observed.

If there is partial ice cover at a cross section, use the procedure described above where there is ice cover, and use open-water methods elsewhere.

A sample sheet of discharge-measurement notes under ice cover is shown in figure 62. In this measurement the vertical-velocity curves indicate that the 0.2- and 0.8-depth method gives the mean velocity and that the 0.6-depth method requires a coefficient of 0.92 .

\section{Current-meter measurements from boats}

Discharge measurements are made from boats where no cableways or suitable bridges are available and where the stream is too deep to wade. Personal safety is the limiting factor in the use of boats on streams having high velocity of flow.

String the tag line at the measuring section by unreeling the line as the boat moves across the stream. Some tag-line reels are equipped with brakes to control the line tension while 


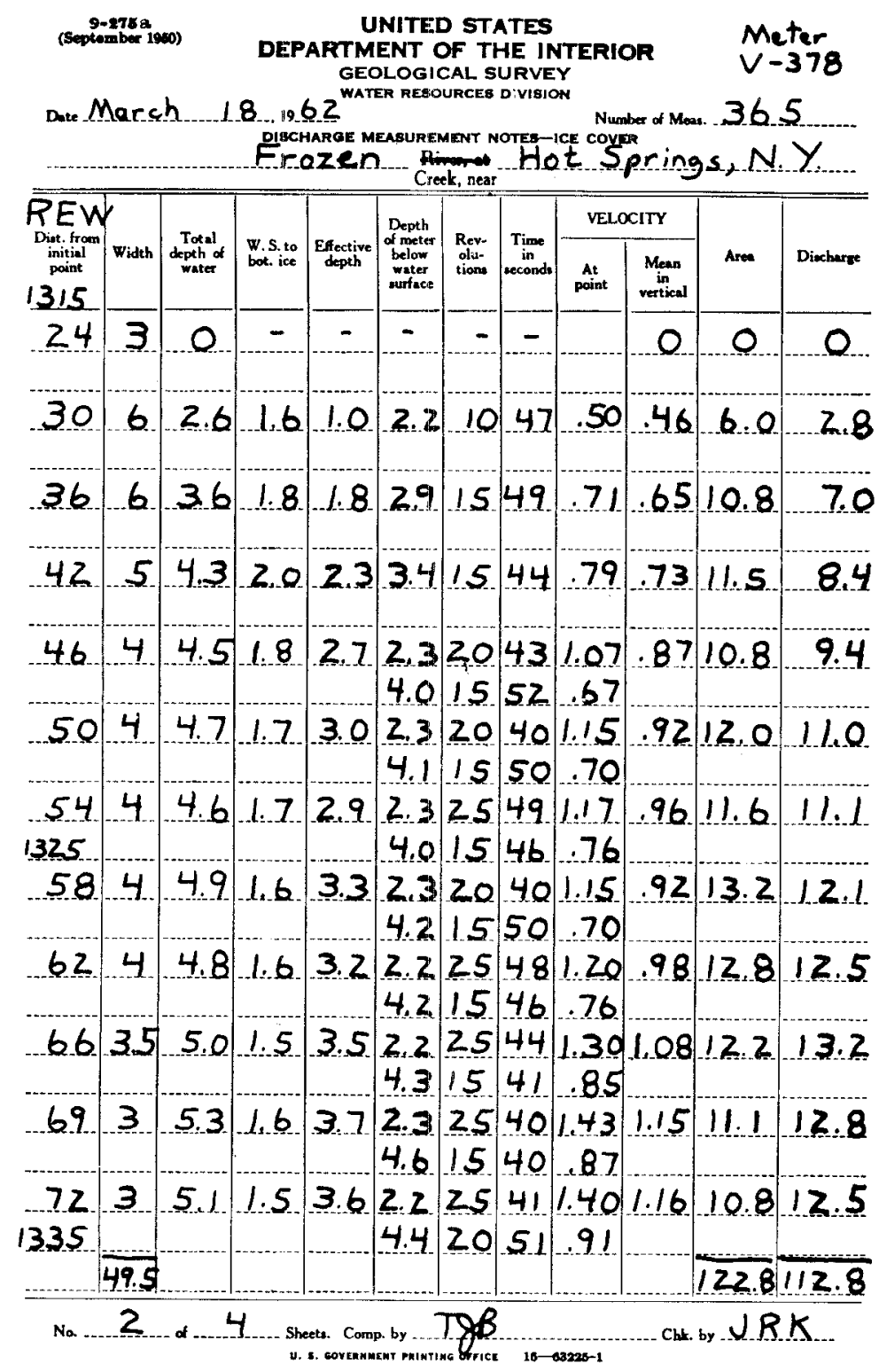

Figure 62.-Part of notes for discharge measurement under ice cover.

unreeling. (See p. 24.) After a tag line without a brake has been stretched across the stream, take up the slack by means of a block and tackle attached to the reel and to an anchored support on the bank. If there is traffic on the river one man must be stationed on the bank to lower and raise the tag line to allow the river traffic to pass. Place streamers on the tag line so that it may be seen by boat pilots. If there is a continual flow of traffic on the river, or if the width of the river is too great to stretch a tag line, other means will be needed to position the boat.

When no tag line is used, the boat can be kept in the cross section by lining up with flags positioned on each end of the cross section. (See fig. 63.) Flags on one bank would suffice but it is better to have them on both banks. The position of the boat in the cross section can be determined by a transit on the shore and a stadia rod held in the boat. (See fig. 63.) Another method of determining the position 


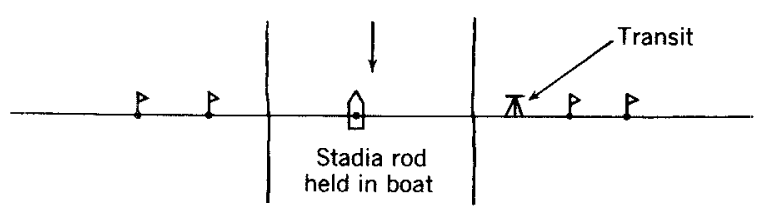

Figure 63.-Defermining position in the cross section, stadia method.

of the boat is by setting a transit on one bank some convenient known distance from and at right angles to the cross-section line. The position of the boat is computed by measuring the angle $\alpha$ to the boat. (See fig. 64.) A third method of determining the position of the boat is done with a sextant read from the boat. Position a flag on the cross-section line and another at a known distance perpendicular to the line. The boat position can be computed by measuring the angle $\beta$ with the sextant.

Unless anchoring is more convenient, the motor must hold the boat stationary when readings are being taken.

If the maximum depth in the cross section is less than 10 feet and the velocity is low, use a rod for measuring the depth and supporting the current meter. For greater depths, use a cable suspension with a reel and sounding weight.

Boat measurements are not recommended at velocities less than $1 \mathrm{fps}$ when the boat is subject to wave action. The up-and-down movement of the boat (and the meter) seriously affects the velocity observations.

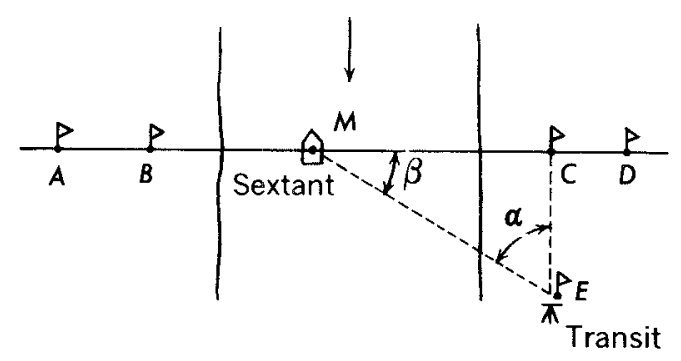

$$
\begin{aligned}
& M C=C E \tan \alpha \text { (transit) } \\
& M C=\frac{C E}{\tan \beta} \quad \text { (sextant) }
\end{aligned}
$$

Figure 64.-Determining position in the cross section, angular method.
The procedure for measuring from a boat using the boat boom and crosspiece is the same as that for measuring from a bridge or a cableway, once the special equipment has been set up and the method of positioning the boat has been established.

\section{Moving-boat measurements of discharge}

On large streams and estuaries the conventional methods of measuring discharge are frequently impractical and involve costly and tedious procedures. There may be no facilities at remote sites. Where facilities do exist, they may be inundated or inaccessible during floods. At some sites, unsteady flow conditions require that measurements be made as rapidly as possible. Measurements on tide-affected rivers must not only be made frequently but continually throughout a tidal cycle. The moving-boat technique is a method of measuring rapidly on large streams. It requires no fixed facilities, and it lends itself to the use of alternate sites if conditions make this desirable.

The moving-boat technique is described in detail by Smoot and Novak (1968). It is similar to the conventional current-meter measurement in that the velocity-area approach to determine discharge is used; the total discharge is the summation of the products of the partial areas of the stream cross section and their respective average velocities. During the traverse of a boat across a stream, a sonic sounder records the geometry of the cross section, and a continuously operating current meter senses the combined stream and boat velocities. Three men are required to operate the boat and equipment. The data they collect are converted to discharge quickly, efficiently, and inexpensively. Experience has shown that measurements obtained by the moving-boat technique compare within 5 percent of measurements obtained by conventional means.

\section{Networks of current meters}

Occasional special measurements require simultaneous velocities at several points in a cross section, distributed either laterally or vertically. For example, it may be necessary to measure a vertical-velocity profile quickly in unsteady flows and to check it frequently in 
order to determine the changes in shape of the vertical profile as well as the rates of these changes. In another example, for the measurement of tide-affected streams, it is desirable to measure the total discharge continuously during at least a full tidal cycle, approximately 13 hours. The need for so many simultaneous velocity determinations (one at each vertical in the cross section) for so long a period could be an expensive and laborious process using conventional techniques of discharge measurement.

A grouping of 21 current meters and special instrumentation has been devised by the Water Resources Division to facilitate measurements of the types just described. Only a few persons are required. The 21 meters are connected together so that the spacing between any two adjacent meters can be varied up to 200 feet. Furthermore, each meter has sufficient handline cable to be suspended vertically from a bridge as much as 200 feet. The meters have a uniform calibration. Revolutions of the rotors are recorded by electronic counters which are grouped compactly in one box at the center of the bank of meters. The operator, by flipping one switch, starts all 21 counters simultaneously, and after an interval of several minutes, stops all counters. The indicated number of revolutions for the elapsed time interval is converted to a velocity for each meter. The distance between meters is known; a record of stage is maintained to evaluate depth; prior information at the site is obtained to convert point velocities in the verticals to mean velocities in those verticals. All of the information necessary to compute discharge in the cross section is therefore available, and is tabulated for easy conversion to discharge.

\section{Measurement of deep, swift streams}

Discharge measurements of deep, swift streams present no serious problems when adequate sounding weights are used and when floating drift or ice is not excessive. Normal procedures must sometimes be altered, however, when measuring these streams. The four most common circumstances are:

1. Possible to sound, but weight and meter drift downstream.
2. Not possible to sound, but a standard cross section is available.

3. Not possible to sound, and a standard cross section is not available.

4. Not possible to put the meter in the water.

Procedures are described below for use during measurements made under these conditions. The procedures for items 2,3 , and 4 are used where there is a stable cross section. The procedure to be used in unstable channels must be determined by conditions at each location.

\section{Possible to sound; weight and meter drift downstream}

Where it is possible to sound but the weight and meter drift downstream, the depths measured by the usual methods are too large. (See fig. 65.) The correction for this error has two parts, the air correction and the wet-line correction. The air correction is shown in figure 65 as the distance $c d$. The wet-line correction in figure 65 is shown as the difference between the wet-line depth $d e$ and the vertical depth $d g$.

As shown in figure 65, the air correction depends on the vertical angle $P$ and the distance $a b$. The correction is computed as follows:

$$
\begin{aligned}
a b & =a c \\
\cos P & =\frac{a b}{a d}=\frac{a b}{a c+c d}=\frac{a b}{a b+c d} \\
a b+c b & =\frac{a b}{\cos P} \\
c d & =\frac{a b}{\cos P}-a b=a b\left[\frac{1}{\cos P}-1\right] .
\end{aligned}
$$

The air correction for even-numbered angles between $4^{\circ}$ and $36^{\circ}$ and vertical lengths between 10 and 100 feet is shown in table 4 . The correction is applied to the nearest tenth of a foot; hundredths are given to aid in interpolation.

The air correction may be nearly eliminated by using tags at selected intervals on the sounding line and using the tags to refer to the water surface. This practice is almost equivalent to moving the reel to a position just above the water surface. 


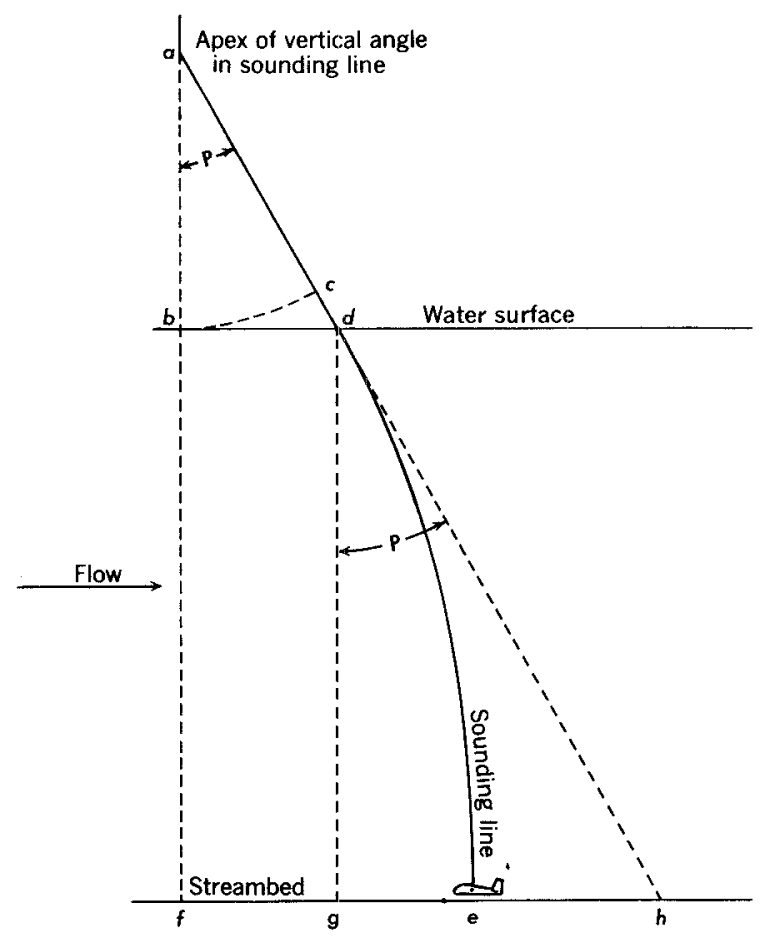

Figure 65.-Position of sounding weight and line in deep, swift water.

The correction for excess length of line below the water surface is obtained by using an elementary principle of mechanics. If a known horizontal force is applied to a weight suspended on a cord, the cord takes a position of rest at some angle with the vertical, and the tangent of the vertical angle of the cord is equal to the horizontal force divided by the vertical force owing to the weight. If several additional horizontal and vertical forces are applied to the cord, the tangent of the angle in the cord above any point is equal to a summation of the horizontal forces below that point, divided by the summation of the vertical forces below the point.

The distribution of total horizontal drag on the sounding line is in accordance with the variation of velocity with depth. The excess in length of the curved line over the vertical depth is the sum of the products of each tenth of depth and the function $\left(\frac{1}{\cos P}-1\right)$ of the corresponding angles derived for each tenth of depth by means of the tangent relation of the forces acting below any point.

The wet-line correction for even-numbered angles between $4^{\circ}$ and $36^{\circ}$ and wet-line depths between 10 and 100 feet is shown in table 5 . The correction is applied to the nearest tenth of a foot. The wet-line correction cannot be determined until the air correction has been deducted from the observed depth.

The following points concerning the wet-line correction should be kept in mind:

1. The weight will go to the bottom despite the force of the current.

2. The sounding is made when the weight is at the bottom but entirely supported by the line. 
Table 4.- Air-correction table, giving difference, in feet, between vertical length and slant length of sounding line above water surface for selected vertical angles

\begin{tabular}{|c|c|c|c|c|c|c|c|c|c|c|c|c|c|c|c|c|c|c|}
\hline \multirow{2}{*}{$\begin{array}{l}\text { Vertical } \\
\text { length } \\
\text { (feet) }\end{array}$} & \multicolumn{17}{|c|}{ Vertical angle of sounding line at protractor } & \multirow{2}{*}{$\begin{array}{l}\text { Vertical } \\
\text { length } \\
\text { (feet) }\end{array}$} \\
\hline & $4^{\circ}$ & $6^{\circ}$ & $8^{\circ}$ & $10^{\circ}$ & $12^{\circ}$ & $14^{\circ}$ & $16^{\circ}$ & $18^{\circ}$ & $20^{\circ}$ & $22^{\circ}$ & $24^{\circ}$ & $26^{\circ}$ & $28^{\circ}$ & $30^{\circ}$ & $32^{\circ}$ & $34^{\circ}$ & $36^{\circ}$ & \\
\hline $\begin{array}{l}10 \ldots \\
12 \ldots \\
14 \ldots \\
16 \ldots \\
18 \ldots\end{array}$ & $\begin{array}{r}0.02 \\
.03 \\
.03 \\
.04 \\
.04\end{array}$ & $\begin{array}{r}0.06 \\
.07 \\
.08 \\
.09 \\
.10\end{array}$ & $\begin{array}{r}0.10 \\
.12 \\
.14 \\
.16 \\
.18\end{array}$ & $\begin{array}{r}0.15 \\
.19 \\
.22 \\
.25 \\
.28\end{array}$ & $\begin{array}{l}0.22 \\
.27 \\
.31 \\
.36 \\
.40\end{array}$ & $\begin{array}{r}0.31 \\
.37 \\
.43 \\
.49 \\
.65\end{array}$ & $\begin{array}{l}0.40 \\
.48 \\
.56 \\
.64 \\
.73\end{array}$ & $\begin{array}{r}0.51 \\
.62 \\
.72 \\
.82 \\
.93\end{array}$ & $\begin{array}{r}0.64 \\
.77 \\
.90 \\
1.03 \\
1.16\end{array}$ & $\begin{array}{r}0.79 \\
.94 \\
1.10 \\
1.26 \\
1.41\end{array}$ & $\begin{array}{l}0.95 \\
1.14 \\
1.32 \\
1.51 \\
1.70\end{array}$ & $\begin{array}{l}1.13 \\
1.35 \\
1.58 \\
1.80 \\
2.03\end{array}$ & $\begin{array}{l}1.33 \\
1.59 \\
1.86 \\
2.12 \\
2.39\end{array}$ & $\begin{array}{l}1.55 \\
1.86 \\
2.17 \\
2.48 \\
2.78\end{array}$ & $\begin{array}{l}1.79 \\
2.15 \\
2.51 \\
2.87 \\
3.23\end{array}$ & $\begin{array}{l}2.06 \\
2.47 \\
2.89 \\
3.30 \\
\mathbf{3} .71\end{array}$ & $\begin{array}{l}2.36 \\
2.83 \\
3.30 \\
3.78 \\
4.25\end{array}$ & $\begin{array}{l}10 \\
12 \\
14 \\
16 \\
18\end{array}$ \\
\hline $\begin{array}{l}20 \ldots \\
22 \ldots \ldots \\
24 \ldots \\
26 \ldots \\
28 \ldots\end{array}$ & $\begin{array}{l}.05 \\
.05 \\
.06 \\
.06 \\
.07\end{array}$ & $\begin{array}{l}.11 \\
.12 \\
.13 \\
.14 \\
.15\end{array}$ & $\begin{array}{l}.20 \\
.22 \\
.24 \\
.26 \\
.28\end{array}$ & $\begin{array}{l}.31 \\
.34 \\
.37 \\
.40 \\
.43\end{array}$ & $\begin{array}{l}.45 \\
.49 \\
.54 \\
.58 \\
.63\end{array}$ & $\begin{array}{l}.61 \\
.67 \\
.73 \\
.80 \\
.86\end{array}$ & $\begin{array}{r}.81 \\
.89 \\
.97 \\
1.05 \\
1.13\end{array}$ & $\begin{array}{l}1.03 \\
1.13 \\
1.24 \\
1.34 \\
1.44\end{array}$ & $\begin{array}{l}1.28 \\
1.41 \\
1.54 \\
1.67 \\
1.80\end{array}$ & $\begin{array}{l}1.57 \\
1.73 \\
1.88 \\
2.04 \\
2.20\end{array}$ & $\begin{array}{l}1.89 \\
2.08 \\
2.27 \\
2.46 \\
2.65\end{array}$ & $\begin{array}{l}2.25 \\
2.48 \\
2.70 \\
2.93 \\
3.15\end{array}$ & $\begin{array}{l}2.65 \\
2.92 \\
3.18 \\
3.45 \\
3.71\end{array}$ & $\begin{array}{l}\text { 3. } 09 \\
3.40 \\
3.71 \\
4.02 \\
4.33\end{array}$ & $\begin{array}{l}3.58 \\
3.94 \\
4.30 \\
4.66 \\
5.02\end{array}$ & $\begin{array}{l}\text { 4. } 12 \\
4.54 \\
4.95 \\
5.36 \\
5.77\end{array}$ & $\begin{array}{l}4.72 \\
5.19 \\
5.67 \\
6.14 \\
6.61\end{array}$ & $\begin{array}{l}20 \\
22 \\
24 \\
26\end{array}$ \\
\hline $\begin{array}{l}30 \\
32 \ldots \\
34 \ldots \\
36 \ldots \\
38\end{array}$ & $\begin{array}{l}.07 \\
.08 \\
.08 \\
.09 \\
.09\end{array}$ & $\begin{array}{l}.17 \\
.18 \\
.19 \\
.20 \\
.21\end{array}$ & $\begin{array}{l}.29 \\
.31 \\
.33 \\
.35 \\
.37\end{array}$ & $\begin{array}{l}.46 \\
.49 \\
.52 \\
.56 \\
.59\end{array}$ & $\begin{array}{l}.67 \\
.71 \\
.76 \\
.80 \\
.85\end{array}$ & $\begin{array}{r}.92 \\
.98 \\
1.04 \\
1.10 \\
1.16\end{array}$ & $\begin{array}{l}1.21 \\
1.29 \\
1.37 \\
1.45 \\
1.53\end{array}$ & $\begin{array}{l}1.54 \\
1.65 \\
1.75 \\
1.85 \\
1.96\end{array}$ & $\begin{array}{l}1.93 \\
2.05 \\
2.18 \\
2.31 \\
2.44\end{array}$ & $\begin{array}{l}2.36 \\
2.51 \\
2.67 \\
2.83 \\
2.98\end{array}$ & $\begin{array}{l}2.84 \\
3.03 \\
3.22 \\
3.41 \\
3.60\end{array}$ & $\begin{array}{l}3.38 \\
3.60 \\
3.83 \\
4.05 \\
4.28\end{array}$ & $\begin{array}{l}3.98 \\
4.24 \\
4.51 \\
4.77 \\
5.04\end{array}$ & $\begin{array}{l}4.64 \\
4.95 \\
5.26 \\
5.57 \\
5.88\end{array}$ & $\begin{array}{l}5.38 \\
5.73 \\
6.09 \\
6.45 \\
6.81\end{array}$ & $\begin{array}{l}6.19 \\
6.60 \\
7.01 \\
7.42 \\
7.84\end{array}$ & $\begin{array}{l}\mathbf{7 . 0 8} \\
\mathbf{7 . 5 5} \\
\mathbf{8 . 0 3} \\
\mathbf{8 . 5 0} \\
\mathbf{8 . 9 7}\end{array}$ & 36 \\
\hline $\begin{array}{l}40 \\
42 \\
44-- \\
46 \\
48 .-\end{array}$ & $\begin{array}{l}.10 \\
.10 \\
.11 \\
.11 \\
.12\end{array}$ & $\begin{array}{l}.22 \\
.23 \\
.24 \\
.25 \\
.26\end{array}$ & $\begin{array}{l}.39 \\
.41 \\
.43 \\
.45 \\
.47\end{array}$ & $\begin{array}{l}.62 \\
.65 \\
.68 \\
.71 \\
.74\end{array}$ & $\begin{array}{r}.89 \\
.94 \\
.98 \\
1.03 \\
1.07\end{array}$ & $\begin{array}{l}1.22 \\
1.29 \\
1.35 \\
1.41 \\
1.47\end{array}$ & $\begin{array}{l}1.61 \\
1.69 \\
1.77 \\
1.85 \\
1.93\end{array}$ & $\begin{array}{l}2.06 \\
2.16 \\
2.26 \\
2.37 \\
2.47\end{array}$ & $\begin{array}{l}2.57 \\
2.70 \\
2.82 \\
2.95 \\
3.08\end{array}$ & $\begin{array}{l}\text { 3.14 } \\
\text { 3. 30 } \\
\text { 3.46 } \\
\text { 3.61 } \\
\text { 3.77 }\end{array}$ & $\begin{array}{l}3.79 \\
3.97 \\
4.16 \\
4.35 \\
4.54\end{array}$ & $\begin{array}{l}4.50 \\
4.73 \\
4.95 \\
5.18 \\
5.40\end{array}$ & $\begin{array}{l}5.30 \\
5.57 \\
5.83 \\
6.10 \\
6.36\end{array}$ & $\begin{array}{l}6.19 \\
6.50 \\
6.81 \\
7.12 \\
7.43\end{array}$ & $\begin{array}{l}7.17 \\
7.53 \\
7.88 \\
8.24 \\
8.60\end{array}$ & $\begin{array}{l}8.25 \\
8.66 \\
9.07 \\
9.49 \\
9.90\end{array}$ & $\begin{array}{r}9.44 \\
9.91 \\
10.39 \\
10.86 \\
11.33\end{array}$ & $\begin{array}{l}42 \\
44 \\
46 \\
48\end{array}$ \\
\hline $\begin{array}{l}50 \ldots \\
52 \ldots \\
54 \ldots \ldots \\
56 \ldots \ldots \\
58 \ldots \ldots\end{array}$ & $\begin{array}{l}.12 \\
.13 \\
.13 \\
.14 \\
.14\end{array}$ & $\begin{array}{l}.28 \\
.29 \\
.30 \\
.31 \\
.32\end{array}$ & $\begin{array}{l}.49 \\
.51 \\
.53 \\
.55 \\
.57\end{array}$ & $\begin{array}{l}.77 \\
.80 \\
.83 \\
.86 \\
.89\end{array}$ & $\begin{array}{l}1.12 \\
1.16 \\
1.21 \\
1.25 \\
1.30\end{array}$ & $\begin{array}{l}1.53 \\
1.59 \\
1.65 \\
1.71 \\
1.78\end{array}$ & $\begin{array}{l}2.02 \\
2.10 \\
2.18 \\
2.26 \\
2.34\end{array}$ & $\begin{array}{l}2.57 \\
2.68 \\
2.78 \\
2.88 \\
2.98\end{array}$ & $\begin{array}{l}3.21 \\
3.34 \\
3.47 \\
3.59 \\
3.72\end{array}$ & $\begin{array}{l}3.93 \\
4.08 \\
4.24 \\
4.40 \\
4.55\end{array}$ & $\begin{array}{l}4.73 \\
4.92 \\
5.11 \\
5.30 \\
5.49\end{array}$ & $\begin{array}{l}\mathbf{5 . 6 3} \\
\mathbf{5 . 8 6} \\
6.08 \\
\mathbf{6 . 3 1} \\
\mathbf{6 . 5 3}\end{array}$ & $\begin{array}{l}6.63 \\
6.89 \\
7.16 \\
7.42 \\
7.69\end{array}$ & $\begin{array}{l}7.74 \\
8.04 \\
8.35 \\
8.66 \\
8.97\end{array}$ & $\begin{array}{r}8.96 \\
9.32 \\
9.68 \\
10.03 \\
10.39\end{array}$ & $\begin{array}{l}10.31 \\
10.72 \\
11.14 \\
11.55 \\
11.96\end{array}$ & $\begin{array}{l}11.80 \\
12.28 \\
12.75 \\
13.22 \\
13.69\end{array}$ & $\begin{array}{l}50 \\
52 \\
54 \\
56 \\
58\end{array}$ \\
\hline $\begin{array}{l}60 \ldots . \\
62 \ldots \ldots \\
64 \ldots \ldots \\
66 \ldots \ldots \\
68 \ldots \ldots\end{array}$ & $\begin{array}{l}.15 \\
.15 \\
.16 \\
.16 \\
.17\end{array}$ & $\begin{array}{l}.33 \\
.34 \\
.35 \\
.36 \\
.37\end{array}$ & $\begin{array}{l}.59 \\
.61 \\
.63 \\
.65 \\
.67\end{array}$ & $\begin{array}{r}.93 \\
.96 \\
.99 \\
1.02 \\
1.05\end{array}$ & $\begin{array}{l}1.34 \\
1.39 \\
1.43 \\
1.47 \\
1.52\end{array}$ & $\begin{array}{l}1.84 \\
1.90 \\
1.96 \\
2.02 \\
2.08\end{array}$ & $\begin{array}{l}2.42 \\
2.50 \\
2.58 \\
2.66 \\
2.74\end{array}$ & $\begin{array}{l}\text { 3.09 } \\
\text { 3.19 } \\
\text { 3. } 29 \\
\text { 3.40 } \\
\text { 3.50 }\end{array}$ & $\begin{array}{l}3.85 \\
3.98 \\
4.11 \\
4.24 \\
4.36\end{array}$ & $\begin{array}{l}4.71 \\
4.87 \\
5.03 \\
5.18 \\
5.34\end{array}$ & $\begin{array}{l}5.68 \\
5.87 \\
6.06 \\
6.25 \\
6.44\end{array}$ & $\begin{array}{l}6.76 \\
6.98 \\
7.21 \\
7.43 \\
7.66\end{array}$ & $\begin{array}{l}7.95 \\
8.22 \\
8.48 \\
8.75 \\
9.01\end{array}$ & $\begin{array}{r}9.28 \\
9.59 \\
9.90 \\
10.21 \\
10.52\end{array}$ & $\begin{array}{l}10.75 \\
11.11 \\
11.47 \\
11.83 \\
12.18\end{array}$ & $\begin{array}{l}12.37 \\
12.79 \\
13.20 \\
13.61 \\
14.02\end{array}$ & $\begin{array}{l}14.16 \\
14.64 \\
15.11 \\
15.58 \\
16.05\end{array}$ & $\begin{array}{l}60 \\
62 \\
64 \\
66 \\
68\end{array}$ \\
\hline $\begin{array}{l}70 \ldots \ldots \\
72 \ldots \ldots \\
74 \ldots \\
76 \ldots- \\
78 \ldots\end{array}$ & $\begin{array}{l}.17 \\
.18 \\
.18 \\
.19 \\
.19\end{array}$ & $\begin{array}{l}.39 \\
.40 \\
.41 \\
.42 \\
.43\end{array}$ & $\begin{array}{l}.69 \\
.71 \\
.73 \\
.75 \\
.77\end{array}$ & $\begin{array}{l}1.08 \\
1.11 \\
1.14 \\
1.17 \\
1.20\end{array}$ & $\begin{array}{l}1.56 \\
1.61 \\
1.65 \\
1.70 \\
1.74\end{array}$ & $\begin{array}{l}2.14 \\
2.20 \\
2.27 \\
2.33 \\
2.39\end{array}$ & $\begin{array}{l}2.82 \\
2.90 \\
2.98 \\
3.06 \\
3.14\end{array}$ & $\begin{array}{l}3.60 \\
3.71 \\
3.81 \\
3.91 \\
4.01\end{array}$ & $\begin{array}{l}4.49 \\
4.62 \\
4.75 \\
4.88 \\
5.01\end{array}$ & $\begin{array}{l}5.50 \\
5.65 \\
5.81 \\
5.97 \\
6.13\end{array}$ & $\begin{array}{l}6.62 \\
6.81 \\
7.00 \\
7.19 \\
7.38\end{array}$ & $\begin{array}{l}7.88 \\
8.11 \\
8.33 \\
8.56 \\
8.78\end{array}$ & $\begin{array}{r}9.28 \\
9.55 \\
9.81 \\
10.08 \\
10.34\end{array}$ & $\begin{array}{l}10.83 \\
11.14 \\
11.45 \\
11.76 \\
12.07\end{array}$ & $\begin{array}{l}12.54 \\
12.90 \\
13.26 \\
13.62 \\
13.98\end{array}$ & $\begin{array}{l}14.44 \\
14.85 \\
15.26 \\
15.67 \\
16.09\end{array}$ & $\begin{array}{l}16.52 \\
17.00 \\
17.47 \\
17.94 \\
18.41\end{array}$ & $\begin{array}{l}70 \\
72 \\
74 \\
76 \\
78\end{array}$ \\
\hline $\begin{array}{l}80 \ldots \\
82 \ldots \\
84 \ldots \\
86 \ldots \\
88 . .\end{array}$ & $\begin{array}{l}.20 \\
.20 \\
.20 \\
.21 \\
.21\end{array}$ & $\begin{array}{l}.44 \\
.45 \\
.46 \\
.47 \\
.48\end{array}$ & $\begin{array}{l}.79 \\
.81 \\
.83 \\
.85 \\
.87\end{array}$ & $\begin{array}{l}1.23 \\
1.27 \\
1.30 \\
1.33 \\
1.36\end{array}$ & $\begin{array}{l}1.79 \\
1.83 \\
1.88 \\
1.92 \\
1.97\end{array}$ & $\begin{array}{l}2.45 \\
2.51 \\
2.57 \\
2.63 \\
2.69\end{array}$ & $\begin{array}{l}\text { 3. } 22 \\
\text { 3. } 30 \\
\mathbf{3 . 3 9} \\
\mathbf{3 . 4 7} \\
\mathbf{3 . 5 5}\end{array}$ & $\begin{array}{l}4.12 \\
4.22 \\
4.32 \\
4.43 \\
4.53\end{array}$ & $\begin{array}{l}5.13 \\
5.26 \\
5.39 \\
5.52 \\
5.65\end{array}$ & $\begin{array}{l}6.28 \\
6.44 \\
6.60 \\
6.75 \\
6.91\end{array}$ & $\begin{array}{l}7.57 \\
7.76 \\
7.95 \\
8.14 \\
8.33\end{array}$ & $\begin{array}{l}9.01 \\
9.23 \\
9.46 \\
9.68 \\
9.91\end{array}$ & $\begin{array}{l}10.61 \\
10.87 \\
11.14 \\
11.40 \\
11.67\end{array}$ & $\begin{array}{l}12.38 \\
12.69 \\
12.99 \\
13.30 \\
13.61\end{array}$ & $\begin{array}{l}14.33 \\
14.69 \\
15.05 \\
15.41 \\
15.77\end{array}$ & $\begin{array}{l}16.50 \\
16.91 \\
17.32 \\
17.73 \\
18.15\end{array}$ & $\begin{array}{l}18.89 \\
19.36 \\
19.83 \\
20.30 \\
20.77\end{array}$ & $\begin{array}{l}80 \\
82 \\
84 \\
86 \\
88\end{array}$ \\
\hline $\begin{array}{l}90 \ldots \\
92 \ldots \\
94 \ldots \\
96 \ldots \\
98 \ldots\end{array}$ & $\begin{array}{l}.22 \\
.22 \\
.23 \\
.23 \\
.24\end{array}$ & $\begin{array}{l}.50 \\
.51 \\
.52 \\
.53 \\
.54\end{array}$ & $\begin{array}{l}.88 \\
.90 \\
.92 \\
.94 \\
.96\end{array}$ & $\begin{array}{l}1.39 \\
1.42 \\
1.45 \\
1.48 \\
1.51\end{array}$ & $\begin{array}{l}2.01 \\
2.06 \\
2.10 \\
2.14 \\
2.19\end{array}$ & $\begin{array}{l}2.75 \\
2.82 \\
2.88 \\
2.94 \\
3.00\end{array}$ & $\begin{array}{l}\text { 3. } 63 \\
\text { 3. } 71 \\
3.79 \\
3.87 \\
3.95\end{array}$ & $\begin{array}{l}4.63 \\
4.73 \\
4.84 \\
4.94 \\
5.04\end{array}$ & $\begin{array}{l}5.78 \\
5.90 \\
6.03 \\
6.16 \\
6.29\end{array}$ & $\begin{array}{l}7.07 \\
7.22 \\
7.38 \\
7.54 \\
7.70\end{array}$ & $\begin{array}{l}8.52 \\
8.71 \\
8.90 \\
9.09 \\
9.27\end{array}$ & $\begin{array}{l}10.13 \\
10.36 \\
10.58 \\
10.81 \\
11.08\end{array}$ & $\begin{array}{l}11.93 \\
12.20 \\
12.46 \\
12.73 \\
12.99\end{array}$ & $\begin{array}{l}13.92 \\
14.23 \\
14.54 \\
14.85 \\
15.16\end{array}$ & $\begin{array}{l}16.13 \\
16.48 \\
16.84 \\
17.20 \\
17.56\end{array}$ & $\begin{array}{l}18.56 \\
18.97 \\
19.38 \\
19.80 \\
20.21\end{array}$ & $\begin{array}{l}21.25 \\
21.72 \\
22.19 \\
22.66 \\
23.13\end{array}$ & $\begin{array}{l}90 \\
92 \\
94 \\
96 \\
98\end{array}$ \\
\hline 100. & .24 & .55 & .98 & 1.54 & 2.23 & 3.06 & 4.03 & 5.15 & 6.42 & 7.85 & 9.46 & 11.26 & 13. 26 & 15.47 & 17.92 & 20.62 & 23.61 & 100 \\
\hline
\end{tabular}

3. Drag on the streamlined weight in the sounding position is neglected.

4. The table is general and can be used for any size sounding weight or line, provided they are designed to offer little resistance to the current.

If the direction of flow is not perpendicular to the measuring section, the angle in the measuring line as indicated by the protractor will be less than the actual angle in the line. The air correction and wet-line correction will then be too small. To correct for this the horizontal angle between the direction of flow and a perpendicular to the measuring section is measured by using a protractor or by determining the horizontal angle coefficient as described on page 38 .
If the horizontal angle of the direction of flow may be called $H$, the measured vertical angle $P$, and the actual vertical angle $X$, the relation between the angles is expressed by the formula

$$
\tan X=\frac{\tan P}{\cos H}(\text { fig. } 66) .
$$

Table 6 gives the amounts in tenths of degrees to be added to observed vertical angles to obtain the actual vertical angles for a range of horizontal angles between $8^{\circ}$ and $28^{\circ}$.

The conditions that cause error in sounding the depth also cause error in placing of the meter at selected depths.

The correction tables are not strictly applicable to the problem of placing the meter 
Table 5.-Wet-line table, giving difference, in feet, between wet-line length and vertical depth for selected vertical angles

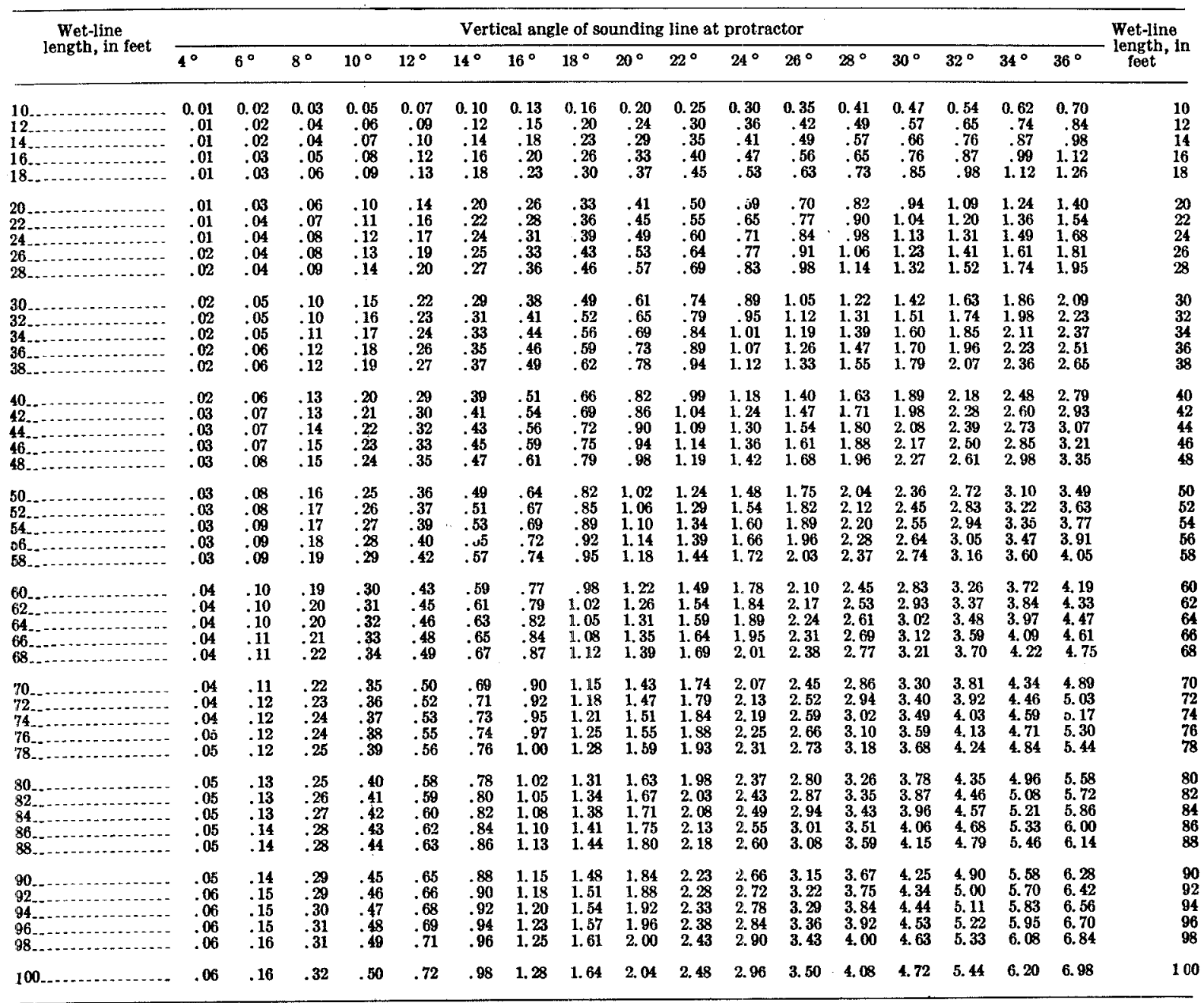

Table 6.-Degrees to be added to observed angles to obtain actual vertical angles

\begin{tabular}{|c|c|c|c|c|c|c|}
\hline \multirow{2}{*}{ Observed vertical angle } & \multicolumn{6}{|c|}{ Hortzontal angle } \\
\hline & $8^{8^{\circ}}=0.99$ & $\begin{array}{c}12^{\circ} \\
\cos =0.98\end{array}$ & $\begin{array}{c}16^{\circ} \\
\cos =0.96\end{array}$ & $\begin{array}{c}20^{\circ} \\
\cos =0.94\end{array}$ & $\begin{array}{c}24^{\circ} \\
\cos =0.91\end{array}$ & $\begin{array}{c}28^{\circ} \\
\cos =0.88\end{array}$ \\
\hline 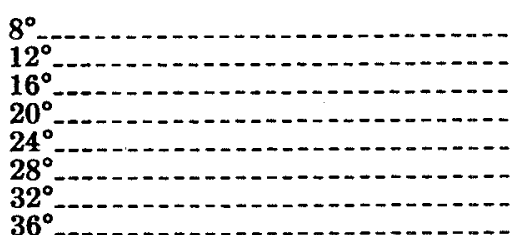 & $\begin{array}{r}0.1 \\
.1 \\
.1 \\
.2 \\
.2 \\
.2 \\
.2 \\
.2\end{array}$ & $\begin{array}{r}0.2 \\
.3 \\
.4 \\
.4 \\
.5 \\
.5 \\
.6 \\
.6\end{array}$ & $\begin{array}{r}0.3 \\
.5 \\
.6 \\
.7 \\
.8 \\
1.0 \\
1.0 \\
1.1\end{array}$ & $\begin{array}{r}0.5 \\
.8 \\
1.0 \\
1.2 \\
1.4 \\
1.5 \\
1.6 \\
1.7\end{array}$ & $\begin{array}{l}0.8 \\
1.1 \\
1.4 \\
1.7 \\
2.0 \\
2.2 \\
2.4 \\
2.5\end{array}$ & $\begin{array}{l}1.0 \\
1.5 \\
2.0 \\
2.4 \\
2.8 \\
3.0 \\
3.3 \\
3.4\end{array}$ \\
\hline
\end{tabular}

because of the increased pressure placed on the sounding weight by higher velocities when it is raised from the streambed. A meter placed in deep, swift water by the ordinary methods for observations at selected percentages of the depth will be too high in the water. The use of tables 4 and 5 will tend to eliminate this error in placement of the meter, and although not strictly applicable, their use for this purpose has become general.

For the 0.2-depth position; the curvature of the wet line is assumed to be negligible and 


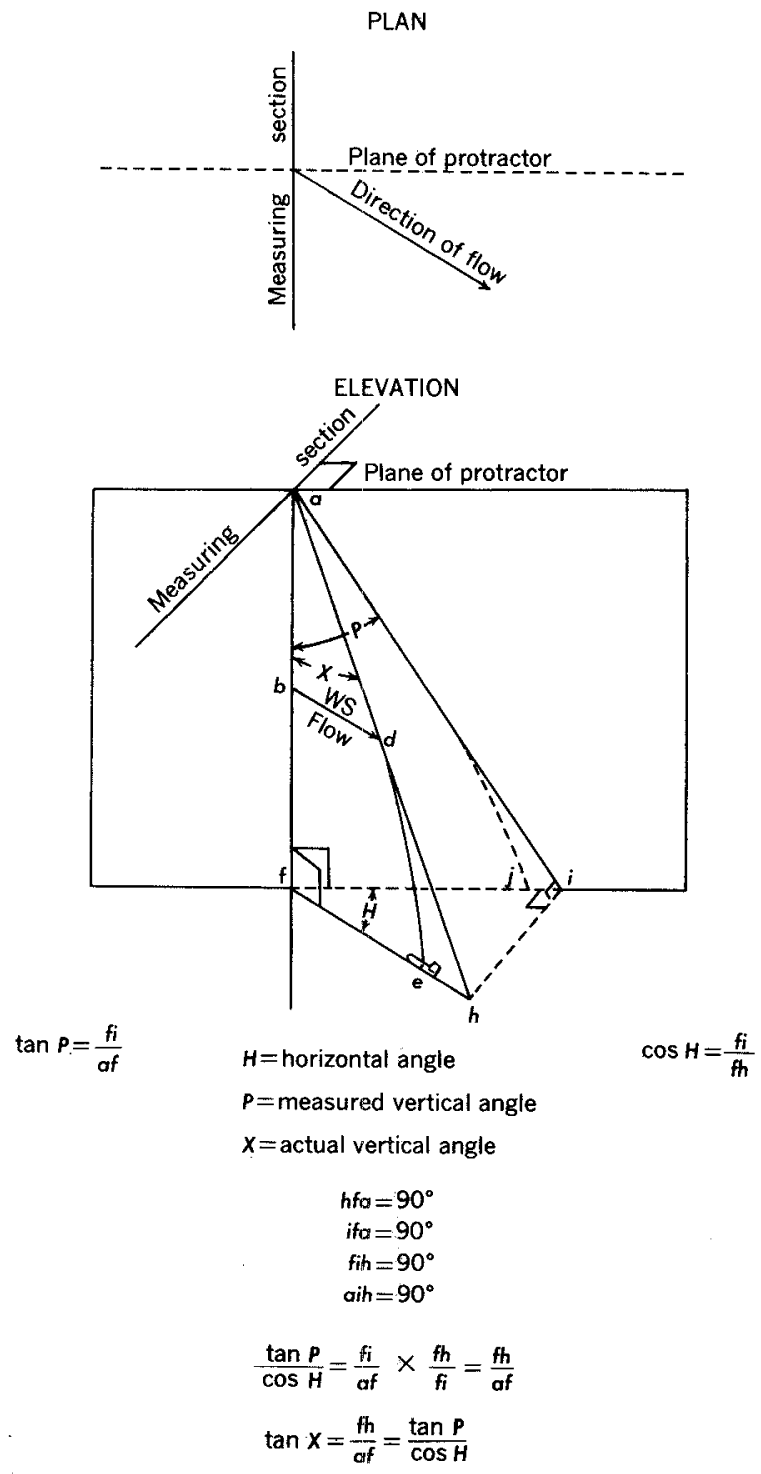

Figure 66.-Sketch of geometry of relationship of actual to measured vertical angle when flow direction is not normal to measuing section.

the length of sounding line from the apex of the vertical angle to the weight is considered a straight line. The method used to place the meter at the 0.2-depth position is:
1. Compute the 0.2 value of the vertica depth.

2. Lower the meter this depth into the water and read the vertical angle. 
3. Obtain the air correction from table 4. The vertical length used to obtain the air correction is the sum of 0.2 of the vertical depth, of the distance the apex of the angle is above water, and of the distance the meter is above the bottom of the weight.

4. Let out an additional amount of line equal to the air correction.

5. If the angle increases appreciably when the additional line is let out, let out more line until the total additional line, the angle, and the vertical distance are in agreement with figures in the air-correction table.

To place the meter at the 0.8 -depth position, a correction to the amount of line reeled in must be made for the difference, if any, between the air correction for the sounding position and that for the 0.8-depth position. This difference is designated as $m$ in table 7 . f the angle increases for the 0.8 -depth position, the meter must be lowered; if it decreases, the meter must be raised.

For the 0.8-depth position of the meter, the wet-line correction may require consideration if the depths are more than 40 feet and if the change in vertical angle is more than 5 percent. If the vertical angle remains the same or decreases, the wet-line correction (table 5) for the 0.8-depth position is less than the wet-line correction for the sounding position by some difference designated as $n$ in table 7 . If the vertical angle increases, the difference in correction $n$ diminishes until the increase in angle is about 10 percent; for greater increases in angle, the difference between corrections increases also. Table 7 summarizes the effect on air and wetline corrections caused by raising the meter from the sounding position to the 0.8-depth position.

For slight changes in the vertical angle, because of the differences $m$ and $n$ in the air and wet-line corrections, the adjustments to the wet-line length of the 0.8 -depth position are small and usually can be ignored. Table 7 indicates that the meter may be placed a little too deep if the adjustments are not made. Because of this possibility, the wet-line depth instead of the vertical depth is sometimes used as the basis for computing the 0.8 -depth position with no adjustments for the differences $m$ and $n$.

Not possible to sound; standard cross section available

When it is not possible to sound the bottom but a standard cross section is available, the procedure to follow is:

1. Determine the depths from the standard cross section.

2. Measure the velocity at 0.2 of the depth.

3 . Determine coefficients to adjust the $0.2-$ depth velocity to mean velocity on the basis of previous measurements at the site by the two-point method.

4. Compute the measurement in the normal manner using the depths from the standard cross section and the velocities measured.

The coefficient is then applied to the computed discharge.

Not possible to sound; standard cross section not available

When it is not possible to sound and a standard cross section is not available, the procedure to follow is:

1. Refer the water-surface elevation before and after the measurement to an elevation reference point on a bridge, on a driven stake, or on a tree at the water's edge.

Table 7.-Summary table for setting the meter at 0.8-depth position in deep, swift streams

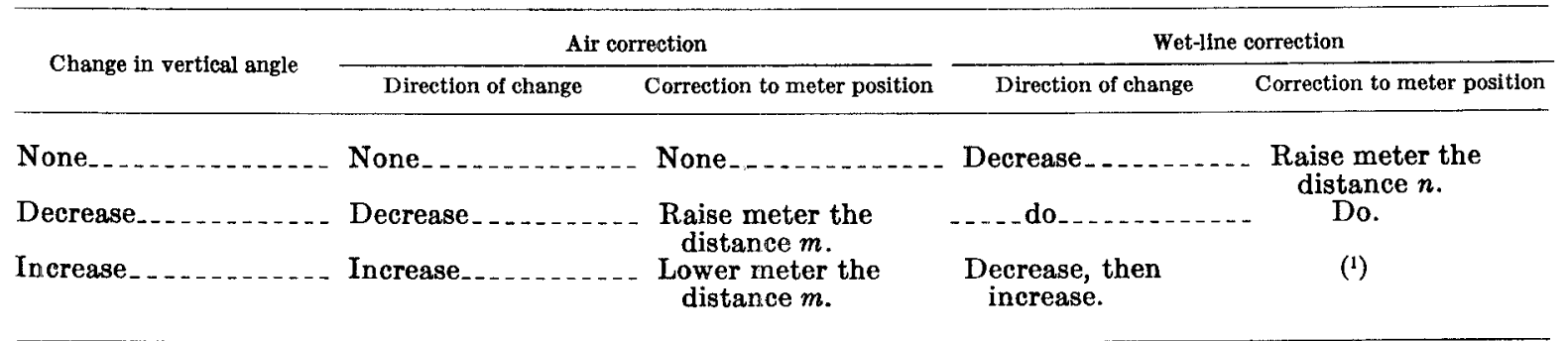

1 Raise meter the distance $n$ unless the increase in angle is greater than about 10 percent, then it is necessary to lower the meter the distance $n$. 
2. Estimate the depth and observe the velocity at 0.2 of the estimated depth. The meter should be at least 2.0 feet below the water surface. Record in the notes the actual depth the meter was placed below the water surface. If an estimate of the depth is impossible, place the meter 2.0 feet below the water surface and observe the velocity there.

3. Make a complete measurement at a lower stage, including some vertical-velocity curves.

4. Use the complete measurement and difference in stage between the two measurements to determine the cross section of the first measurement. To determine whether the streambed has shifted, the cross section should be compared with one taken for a previous measurement at that site.

5. Use vertical-velocity curves or the relationship between mean velocity and 0.2-depth velocity to adjust the velocities observed in step 2 to mean velocity.

6. Compute the measurement in the normal manner using the depths from step 4 and the velocities from step 5 .

Not possible to put meter in water

If it is impossible to keep the weight and meter in the water, the procedure to follow is:

1. Repeat step 1 for conditions when it is not possible to sound the bottom and a standard cross section is not available.

2. Measure surface velocities by timing floating drift, or by use of an optical flowmeter.

3. Repeat steps $3-6$ for conditions when it is not possible to sound the bottom and a standard cross section is not available.

An optical flowmeter has been described by Smith (1961). It is portable, battery operated, and requires no great skill for quick and accurate readings of the surface rate of flow. It is not immersed, so it does not disturb the flow, and it is in no danger of damage from floating debris or ice.

It is well to note that just after the crest, the amount of floating drift or ice is usually greatly reduced, and it may be possible to obtain velocity observations with a current meter.
Measurements during rapidly changing stage

During periods of rapidly changing stage, measurements should be made as quickly as possible to keep the change in stage to a minimum. This speed will minimize errors caused by shifting of flow patterns as the stage changes. The procedure to follow to speed up a measurement is:

1. Use the 0.6-depth method. The 0.2-depth method or the subsurface method could be used if placing the meter at the 0.6 depth creates vertical angles requiring time consuming corrections, or if the vertical angle increases because of drift collecting on the sounding line.

2. Reduce the velocity observation time to about 20-30 seconds.

3. Reduce the number of sections taken to about 15-18.

By incorporating all three of the above practices a measurement can be made in 15-20 minutes. If the subsurface method for observing velocities is used, then some vertical-velocity curves will be needed later to establish coefficients to convert observed velocity to mean velocity.

Carter and Anderson (1963) have shown that discharge measurements having 30 sections and using the two-point method of observation with a 45 -second period of observation will have a standard error of 2.2 percent. This means that two-thirds of the measurements made using this procedure would be in error by 2.2 percent or less. They have also shown that the standard error for a 25 -second period of observation and using the 0.6-depth method of velocity observations with depth and velocity observed at 16 sections is 4.2 percent. The error caused by using the shortcut method is generally less than the error that can be expected by shifting of flow patterns during periods of rapidly changing stage.

\section{Series of measurements during a peak of short duration}

The procedure to follow if a series of measurements is wanted during a peak of short duration is:

1. Take about 10 sections.

2. Take velocity observations at 0.6 depth. 
3. Repeat velocity and depth observations at the same 10 sections with corresponding stages as often as possible throughout the period of the flood wave.

4. Develop stage-velocity and stage-area curves for each of the 10 sections.

5. Compute the discharge corresponding to selected stages by summation of the partial discharges from the curves thus defined.

Mean gage height of discharge measurements

The mean gage height of a discharge measurement represents the mean height of the stream during the period the measurement was made and is referred to the datum of the gaging station.

The mean gage height for a discharge measurement is one of the coordinates used in plotting the measurements to establish the stage-discharge relation, often called the rating curve. An accurate determination of the mean gage height is therefore as important as an accurate measurement of the discharge to define the stage-discharge relationship.

The computation of the mean gage height presents no problem when the change in stage is 0.1 foot or less, for then the mean may be obtained by inspection. However, measurements must sometimes be made during floods or regulation regardless of how rapidly stage changes.

To obtain an accurate mean gage height, the gage must be read before and after the discharge measurement, and the recorder chart must be read at breaks in the slope of the gageheight graph during the measurement. If the station is equipped with a digital recorder, the gage-height readings punched during the measurement are to be read. At nonrecording stations the only way to obtain intermediate readings is for the stream gager to stop during the measurement once or twice to read the gage, or to have someone else do this for him.

If the change in stage is greater than 0.1 foot, the mean is obtained by weighting the gage-height readings rather than by inspection of the available readings.

The mean gage heights during periods of constant slope of the gage-height graph and the corresponding measured partial discharges are used to compute the mean gage height of the measurement. The formula used is:

$$
H=\frac{q_{1} h_{1}+q_{2} h_{2}+q_{3} h_{3} \ldots \ldots \ldots+q_{n} h_{n}}{Q}
$$

in which

$H=$ mean gage height, in feet, $Q=$ total discharge measured, in cubic feet per second $=$ $q_{1}+q_{2}+q_{3} \ldots \ldots+q_{n}$, $q_{1}, q_{2}, q_{3}, \ldots q_{n}=$ amount of discharged measured during time interval $1,2,3, . . . n$, in cubic feet per second,

$h_{1}, h_{2}, h_{3}, \ldots h_{n}=$ average gage height during time interval $1,2,3$, ... $n$, in feet.

Figure 67 shows the computation of a weighted mean gage height. The graph at the bottom is a reproduction of the gage-height graph during the discharge measurement. The discharges are taken from the current-meter measurement shown in figure 2. The upper computation of the mean gage height in figure 67 shows the computation using the given formula. The lower computation has been done by a shortcut method to eliminate the multiplication of large numbers. In this method, after the average gage height for each time interval has been computed, a base gage height, which is usually equal to the lowest average gage height, is chosen. Then, the difference between the base gage height and the average gage heights is used to weight the discharges. When the mean difference has been computed, the base gage height is added to it.

If a discharge measurement is made at a distance from the gage during a change in stage, the discharge passing the gage during the measurement will not be the same as the discharge at the measuring section because of the effects of channel storage between the measuring section and the gage.

Adjustment is made for channel storage by applying to the measured discharge a quantity obtained by multiplying the channel surface area by the average rate of change in stage in the reach. The formula is:

$$
Q_{G}=Q_{m} \pm W L \frac{\Delta h}{\Delta t}
$$




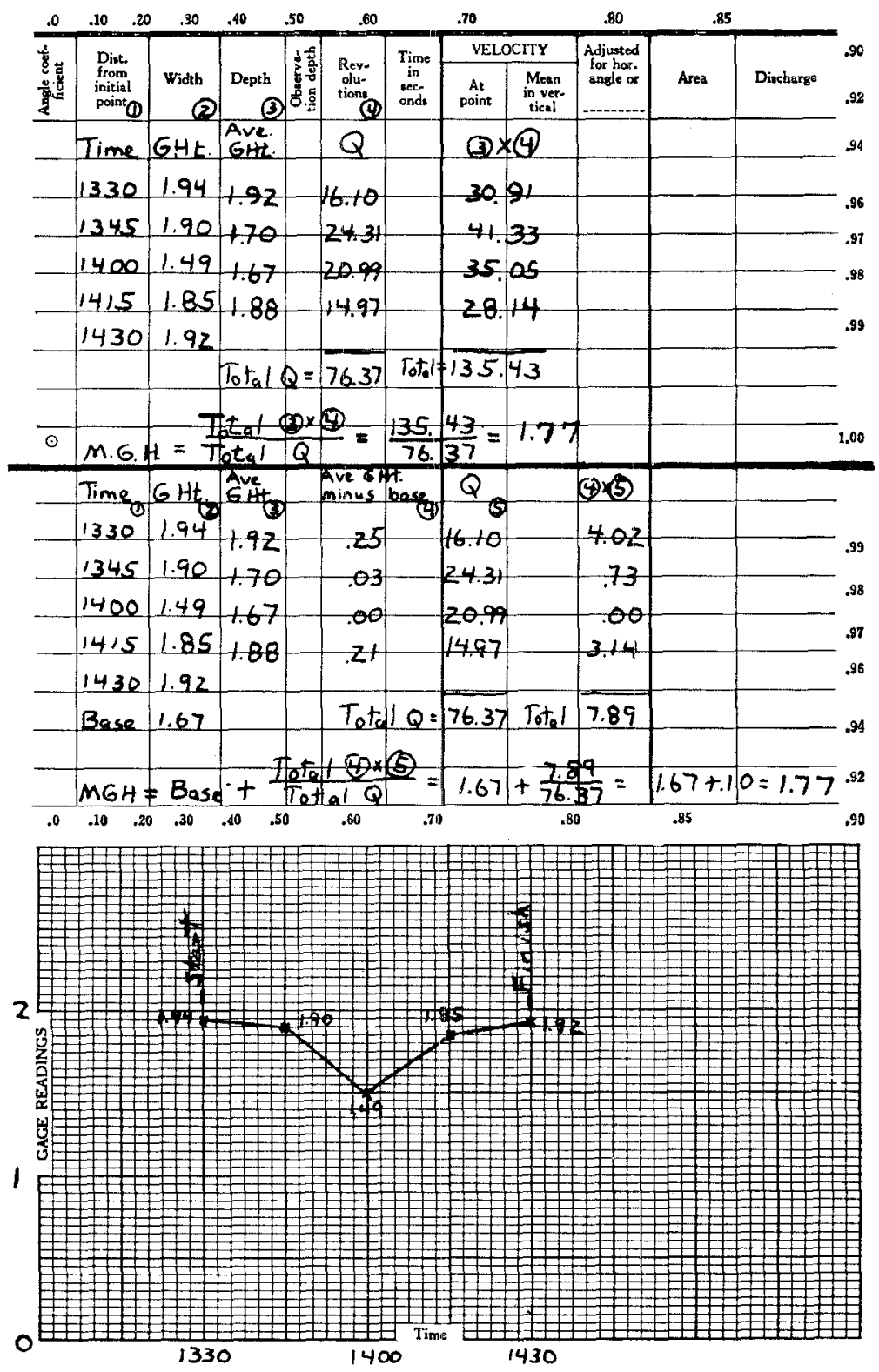

Figure 67.-Computation of weighted mean gage height.

in which

$Q_{G}=$ discharge going over the control, in cubic feet per second,

$Q_{m}=$ measured discharge, in cubic feet per second,

$W=$ average width of stream between measuring section and control, in feet,

$L=$ length of reach between measuring section and control, in feet,

$\Delta h=$ average change in stage in the reach $L$ during the measurement, in feet, and
$\Delta t=$ elapsed time during measurement, in seconds.

A reference point ( $R P)$ or a temporary gage is set at the measuring section if channel storage might be significant. The water-surface elevation at the section is determined before and after the measurement to compute $\Delta h$. If the measurement is made above the control, the adjustment will be plus for falling stages and minus for rising stages; if made below the con- 
trol, it will be minus for falling stages and plus for rising stages.

Figure 68 shows the front sheet of a measurement that has been made at a distance from the control during a period of changing stage. The computation of the adjustment for storage for the measurement shown in figure 68 follows:

Adjustment for measurement 264 on Big Creek near Dogwood, Va.

Measurement made 0.6 mile upstream $=3,170$ feet.
Average width between measuring section and control $=150$ feet.

Change in stage at control, 5.84-6.74 feet $=t=0.09$ foot. 4.90

Change in stage at measuring section, 12.72-13.74 feet $=+1.02$ feet. Readings taken at measuring section from a reference point before and after measurement.

Average change in stage $=(0.90+1.02)$ $\div 2=0.96$ foot.

\section{inen}

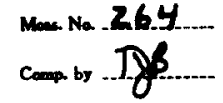

Sta. Na. $1-99.46 .5$

Big Creek near Degwesd Va Date Max 26,1962 Party $T$ J Buchanan width 14.0 Area 1.0 .40 vel. 8.07 G. H. 6.29. Dich" 8.390 Method 24.8 No. recs. $30 \quad$ G. H. change 1.9 .0 in 14 hro. Susp. 75C Method coef. I Hor. angle coef. Variess Susp. coef. 1.00 Meter No. 3684

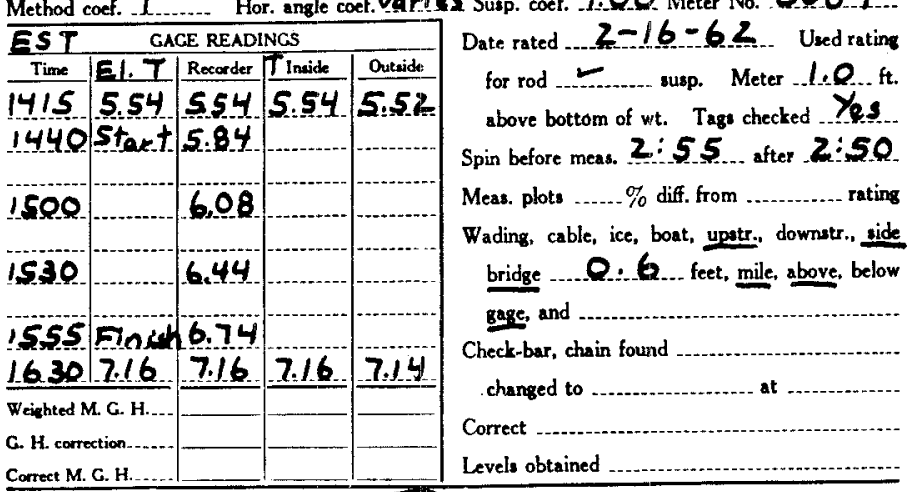
Meserrement rated excellent (2\%), rod (5\%) fair (8\%), poor (over 8\%), besed on following condition: Crous section Foirly even.j-stone and gravel bottom.

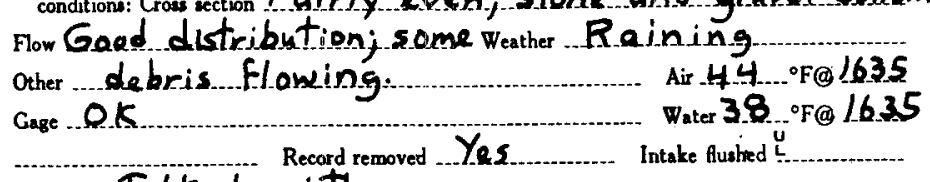
oberver Talked with

Control Clear. Remarks Discharse odjusted for storase effect
Qm $=8,494$

G. H. of zero flow it. Elev. $R P=30.00$ RP ro WS $1440=17.28 ; 30.00-17.28=12.72 \quad 10-70701-1$ RPt. Ws e $1555=16.26 ; 30.00-16.26=13.74$

Figure 68.-Discharge measurement notes with discharge adjusted for channel storage effect. 
Elapsed time during measurement $=1 \frac{1}{4}$ hours $=4,500$ seconds.

Measured discharge $=8,494 \mathrm{cfs}$ (cubic feet per second).

$$
\begin{aligned}
Q_{\mathrm{G}} & =8,494-150(3,170) \frac{0.96}{4,500} \\
& =8,494-101=8,393 \mathrm{cfs} \text {. Use } 8,390 \mathrm{cfs} .
\end{aligned}
$$

It is also possible to approximate the effect of storage by computing the time of travel of the flood wave between the measuring section and the control and then adjusting the gage height for the traveltime to correspond to the measured discharge. The flood-wave velocity is generally assumed to be 1.3 times the mean velocity for the measurement.

The traveltime is computed by the following formula:

$$
t=\frac{L}{1.3 V}
$$

in which

$t=$ time of travel of the flood wave between the measuring section and the control, in seconds,

$L=$ length of reach between measuring section and control in feet and

$V=$ mean velocity of measurement, in feet per second.

In applying the time adjustment, the time-oftravel adjustment is subtracted from the observed time at the gage-if the-measurement is mede either below the gage on a rising-stage, or above the gage on a falling stage, and the time-of-travel adjustment is added to the ob= served time at the gage if the meastrement is either below the gage on a falling stage, or above the gage on a rising stage. $]$

Figure 69 shows the front sheet for the same measurement used in figure 68 , but this time the storage adjustment has been made by adjusting the gage height. The computation of the traveltime is shown on the bottom of the front sheet. Figure 70 is an expanded plot of the gage-height graph during the time of the measurement. By applying the traveltime to the starting and finishing times of the measurement, the adjusted gage heights of 5.90 feet and 6.80 feet are obtained from figure 70 . The mean gage height is obtained by weighting as described previously.
The relationship between mean velocity and the velocity of the flood wave is uncertain in many instances. For this reason the adjustment method using change in channel storage is usually preferred.

The proper coordination of the gage height and the discharge because of the amount of change in stage is a separate and distinct problem from that of making adjustments owing to variable slopes caused by changing discharge. Therefore the relation of stage to discharge at the time a measurement is made should be determined before adjustments owing to variable slopes are made.

\section{Portable Weir Plates}

Current-meter measurements made in shallow depths and low velocities are usually inaccurate, if not impossible to obtain. Under these conditions a portable weir plate is a useful device for measuring the discharge.

A $90^{\circ} \mathrm{V}$-notch weir is suitable because of its favorable accuracy at low flows. A weir made of 10- to 16-gage galvanized sheet iron will produce a free-flowing nappe having the effect of a sharp-crested weir and will give satisfactory performance. The thickness of the plate should vary with the size of the weir. Refer to figure 71 for recommended proportions. Decreasing the plate thickness on larger weirs will help maintain portability. The notch is cut, without sharpening, leaving a flat, even edge. Framing, in the form of small angle irons, is required for medium and large sizes. Canvas attached on the downstream or upstream side prevents leakage under or around the weir. Eyebolts, properly placed, will secure rods driven in earth channels to stabilize the plate.

A staff gage should be placed far enough upstream from the weir opening so that it is not in the drawdown region and it should be related to the weir gage by means of a carpenter's level. At a distance greater than twice the head, the drawdown effect is negligible. The staff gage is used to obtain head on the weir.

Flows from 0.02 to $2.0 \mathrm{cfs}$ are measured with the large weir of figure 71 . Discharges can be measured within 3 percent accuracy if the weir

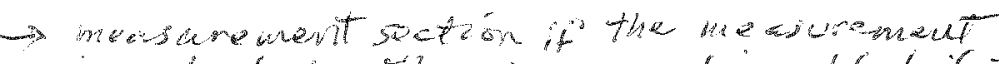

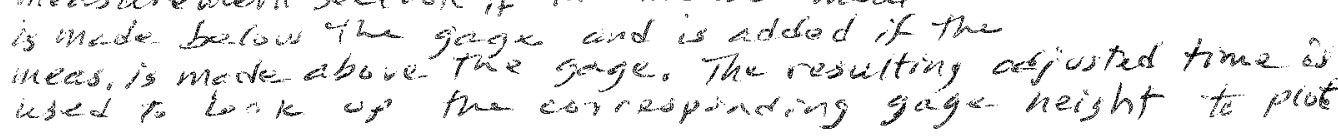

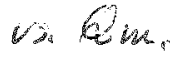




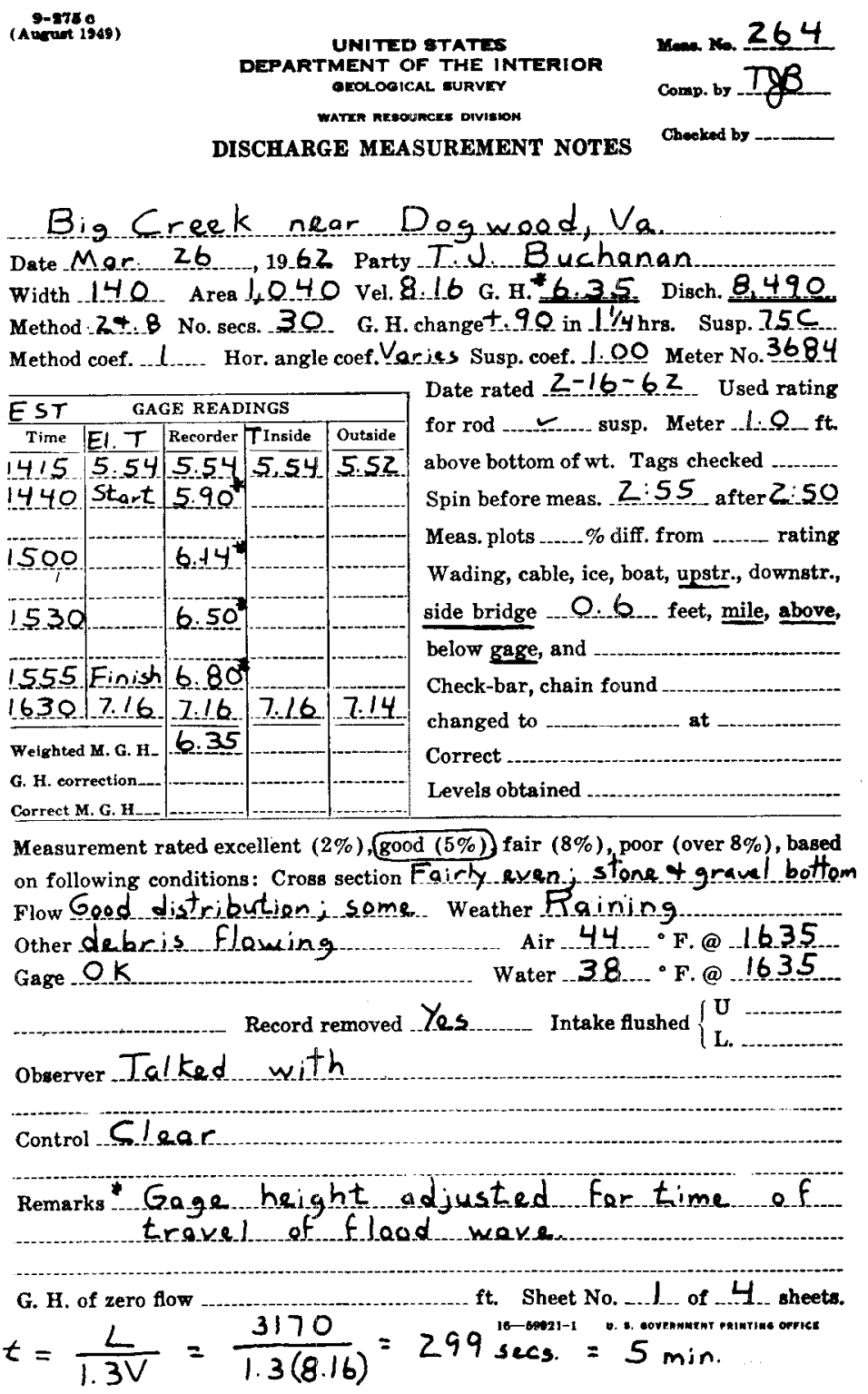

Figure 69.-Discharge measurement notes with mean gage height adjusted for time of travel of flood wave.

is not submerged. A weir is not submerged when there is free circulation of air on all sides of the nappe.

The general equation for flow over a sharpedged triangular weir with a $90^{\circ}$ notch is

$$
Q=C h^{5 / 2},
$$

where $Q$ is the discharge, $h$ is the static head, and $C$ is the coefficient of discharge. Each weir should be rated by determining the flow volumetrically. In the absence of such a rating a value of $C$ of 2.47 may be used.

To place the plate in a sand or silt channel, the only tools required are a carpenter's level and a shovel. The level is used to make the top of the plate horizontal and the plate plumb. Another way to level the plate is by fastening a staff gage or level bubble to each end of the weir. The staff gages are set at the same 


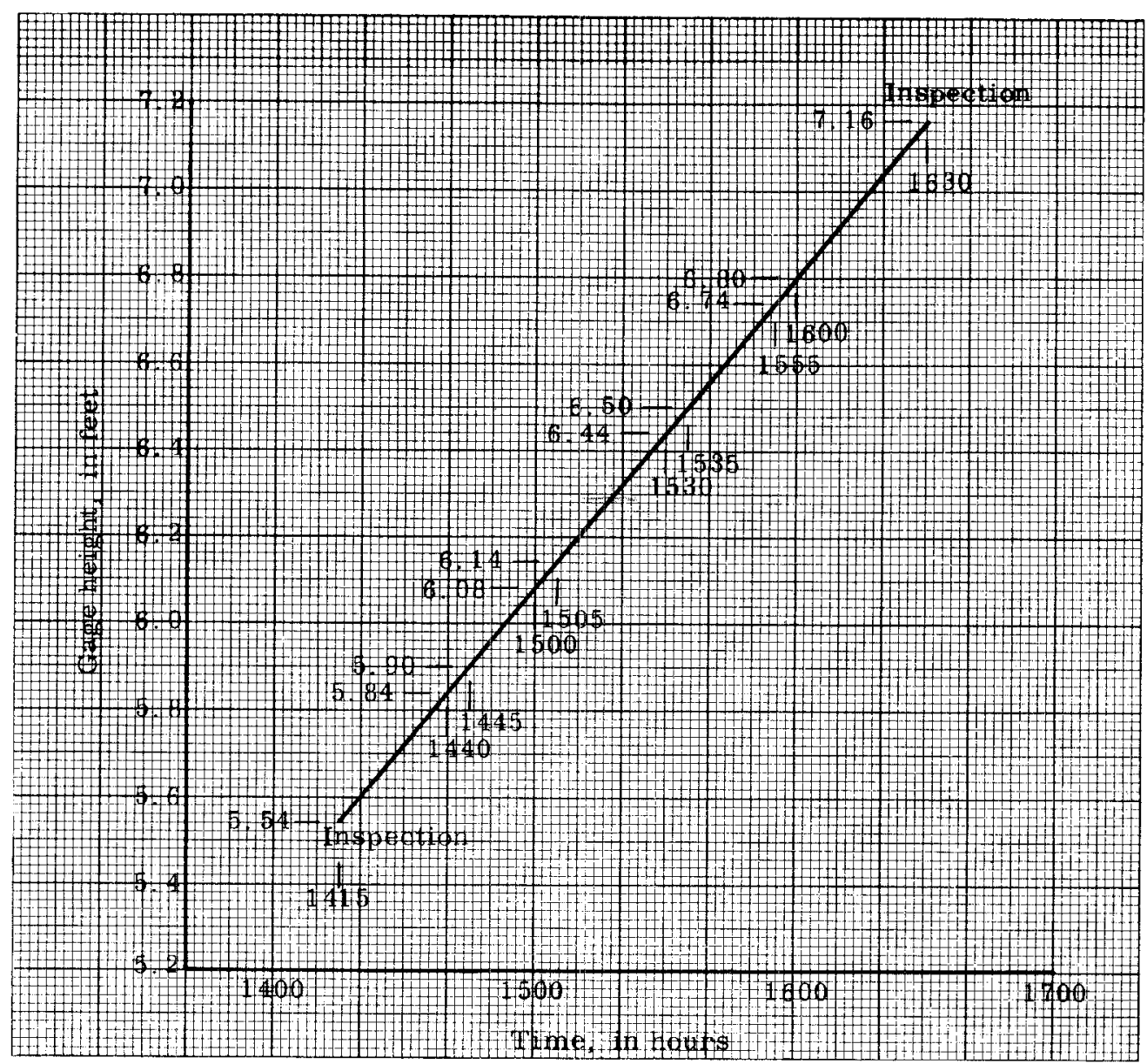

Figure 70.-Expanded plot of gage-height graph during measurement 26.4 at Big Creek near Dogwood, Va., March 26, 1962.

elevation. The plate is leveled by making the staff-gage readings identical or by using the level bubbles. The flow should be allowed to stabilize before making a measurement. The gage height should be read five or six times during a 3 -minute interval and a mean value should be used. Ordinarily a lone man can messure with a weir of this type.

\section{Portable Parshall Flumes, Description and Theory}

A portable Parshall measuring flume is useful for measuring discharge when the depths are shallow and the velocities are low. The flume has a converging section, a throat, and a diverging section. The floor of the converging, or upstream section is level both longitudinally and transversely when in place. The floor of the throat section slopes downward and the floor of the diverging or downstream section slopes upward.

The flume may be operated as a free-flow, single-head measuring device, or operated under submerged-flow conditions where two heads are measured. The head in the converging section and the head near the downstream end of the throat section are read on staff gages or in stilling wells. Both gages have their datum at the elevation of the floor of the converging section.

Free flow occurs when the ratio of the lower gage reading to the upper gage is less than 0.6. The discharge under this condition depends only on the length of crest (width of throat 


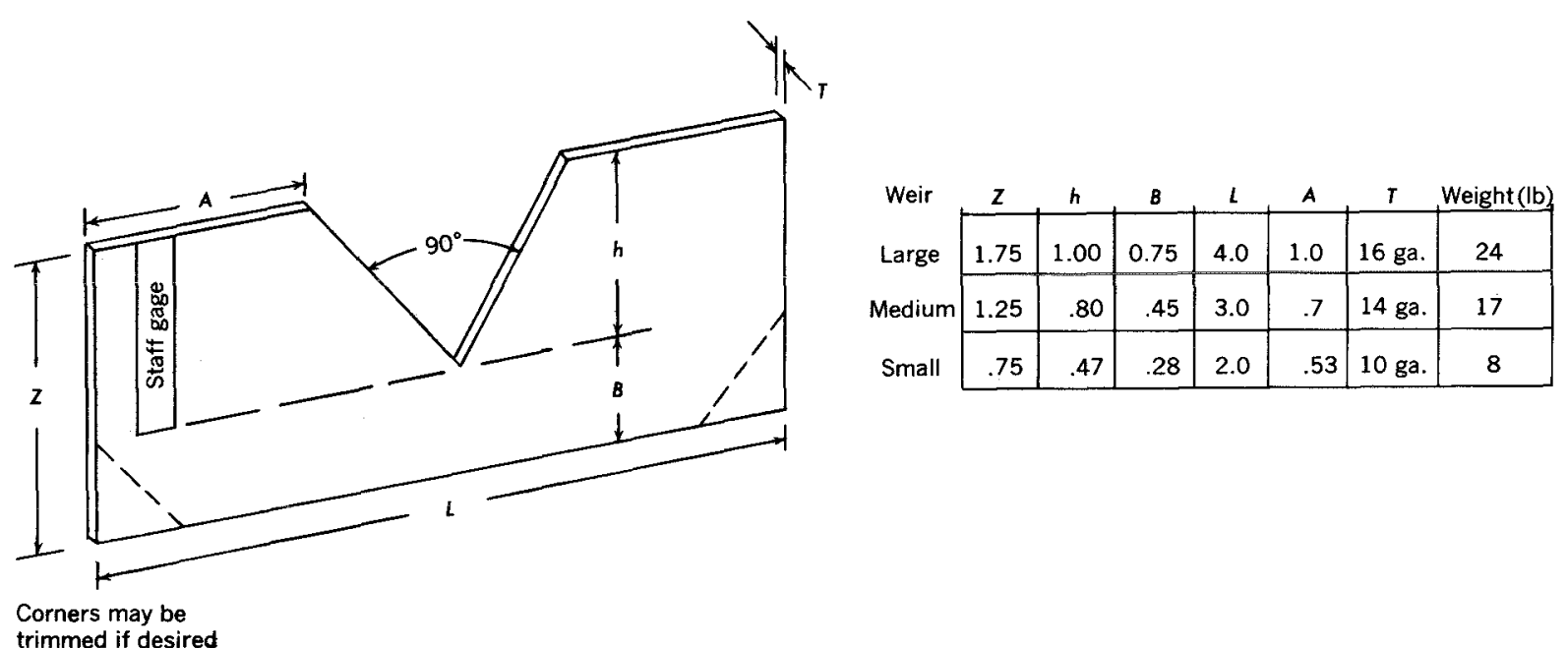

Figure 71. Portable weir plate sizes. 
section) and depth of water at the upper gage. Submerged flow occurs when the ratio of the lower gage reading to the upper gage reading exceeds 0.6. When this occurs, a reduction adjustment to the free-flow rating of the flume is needed.

A flume that is properly constructed has an accuracy of $2-3$ percent under free-flow conditions, but is less accurate during submerged flow.

A modified Parshall flume was designed by C. A. Taylor and H. C. Troxell in 1931 (fig. 72) and is virtually the same as the Parshall flume

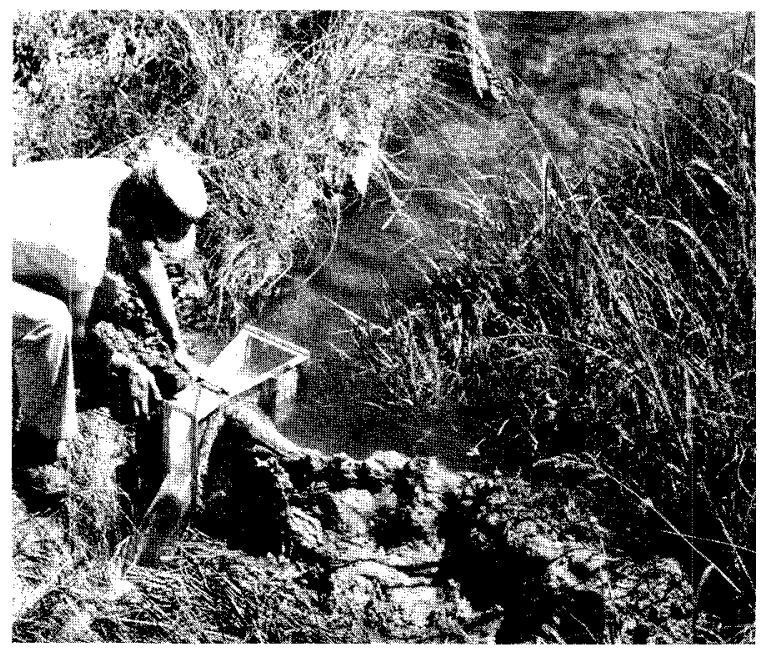

Figure 72.-Modified 3-inch Parshall flume made of sheet iron. except that it does not have a diverging section and is used only under free-flow conditions. The plans are shown in figure 73 and the rating is given in table 8 .

The modified Parshall flume is recommended for general use because of its simplicity, light weight, and ease of installation. However, the regular Parshall flume is also satisfactory.

The flume is installed by placing it in a hole dug in the channel and by filling in around it to prevent any water from bypassing it. A carpenter's level is used to set the floor of the converging section level. Some flumes are equipped with levels attached to the braces on the flume. After the flume is in place, the streamflow is allowed to stabilize before reading the gages. Gage readings indicate flow conditions. The discharge is determined by means of the flume rating.

\section{Volumetric Measurements}

The most accurate method of measuring small discharges is by observing the time required to fill a container of known capacity, or the time required to partly fill a calibrated container to a known volume. The basic equipment needed is a calibrated container and a stopwatch.

Calibration is done by weighing the container with varying amounts of water in it,

Table 8.- Rating fable for 3-inch modified Parshall flume as designed by C. A. Taylor and H. C. Troxell (1931)

\begin{tabular}{|c|c|c|c|c|c|}
\hline Gage height (ft) & Discharge (cfs) & Gage height (ft) & Discharge (cfs) & Gage height (ft) & Discharge (cfs) \\
\hline 0.01 & 0.0008 & 0.21 & 0.097 & 0.41 & 0.280 \\
\hline .02 & .0024 & .22 & .104 & .42 & .290 \\
\hline .03 & .0045 & .23 & .111 & .43 & .301 \\
\hline .04 & .0070 & .24 & .119 & 44 & .312 \\
\hline .05 & .010 & .25 & 127 & 45 & .323 \\
\hline .06 & .013 & 26 & .135 & 46 & .334 \\
\hline 07 & 017 & .27 & .144 & .47 & .345 \\
\hline 08 & 021 & .28 & .153 & .48 & .357 \\
\hline .09 & .025 & .29 & .162 & .49 & .368 \\
\hline .10 & 030 & .30 & 170 & .50 & 380 \\
\hline 11 & 035 & .31 & .179 & .51 & .392 \\
\hline .12 & 040 & .32 & .188 & .52 & .404 \\
\hline 13 & 045 & .33 & 198 & .53 & 417 \\
\hline 14 & 051 & 34 & .208 & .54 & .430 \\
\hline .15 & 057 & .35 & .218 & .55 & 443 \\
\hline .16 & 063 & .36 & .228 & .56 & .456 \\
\hline 17 & 069 & .37 & .238 & .57 & .470 \\
\hline .18 & 076 & .38 & 248 & .58 & .483 \\
\hline .19 & 083 & .39 & .259 & .59 & .497 \\
\hline 20 & 090 & 40 & 269 & & \\
\hline
\end{tabular}




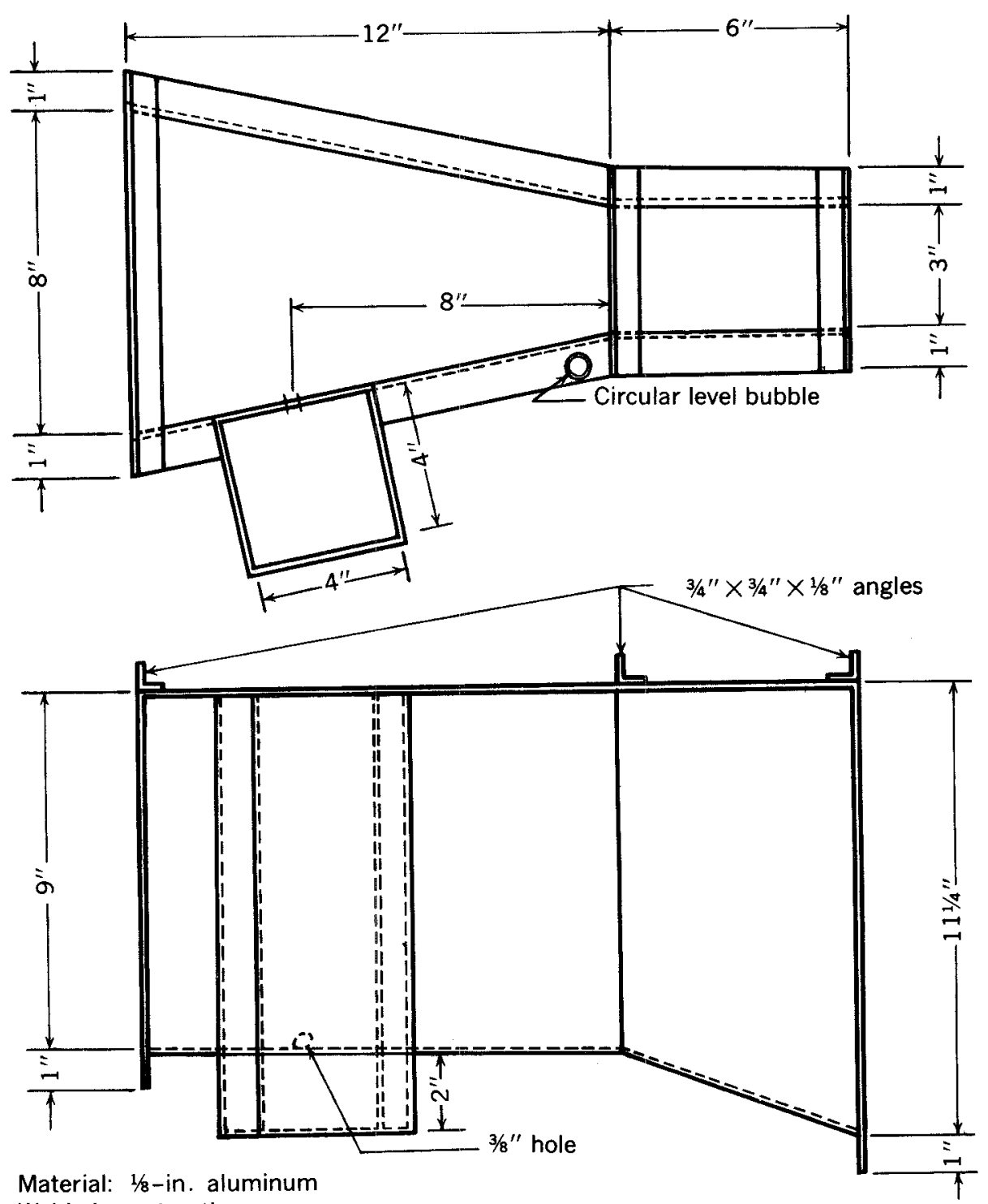

Welded construction

Note: This stilling well can accommodate

a 3 -in. float and be used with a recorder

if continuous measurement is desired for a period.

Figure 73.-Working drawing of modified 3-inch Parshall flume.

noting the depth of water in the container, and then using the following formula:

$$
V=\frac{W_{2}-W_{1}}{w}
$$

in which

$V=$ volume of water in container, in cubic feet,
$W_{2}=$ weight of container with water, in pounds,

$W_{1}=$ weight of container empty, in pounds, $w=$ unit weight of water, 62.4 lb per $\mathrm{cu} \mathrm{ft}$ (pounds per cubic foot).

Another way to calibrate a container is to add known volumes of water by increments and note the depth of water in the container. 
Volumetric measurer ents are made under two types of conditions:

1. When the flow is concentrated or can be concentrated so that all of it may be diverted into a container.

2. When the depth of water flowing over broad-crested weirs and dams is small and volumetric-increment samples can be obtained.

Measurements are made under the first condition at $V$-notch weirs, at artificial controls where all the flow is in a notch or catenary, and at places where an earth dam can be built and all the water can be diverted through a pipe of small diameter. Sometimes it is necessary to place a trough against the artificial control to carry the water from the control to the calibrated container. If a small dam is built, the stage behind the dam is allowed to stabilize before the measurement is begun. The measurement is made three or four times to be certain no errors have been made and to be sure the results are consistent.

Volumetric measurements are made under the second condition by catching a segment of the streamflow with a container having a known width of opening. Samples are taken at a number of locations across the dam or weir similar to procedures used for currentmeter measurements. The flow rate of each sample is increased by the ratio of the subsection width to the sampled width to obtain a discharge rate for each subsection. The total discharge of the stream is the summation of the discharge rates of each subsection.

\section{Floats}

Floats have very limited use in stream gaging, but there are two occasions when they prove useful. A float can be used where the velocity is too low to obtain reliable measurements with the current meter. They are also used where flood measurements are needed and the measuring structure has been destroyed or it is impossible to use a meter.

Both surface floats and rod floats are used. Surface floats may be almost anything that floats, such as wooden disks, bottles partly filled, or oranges. Rod floats are wooden rods weighted on one end so they will float upright in the stream. Rod floats must not touch the streambed. Floating debris or ice cakes may serve as natural floats.

Two cross sections are selected along a reach of straight channel for a float measurement. The cross sections should be far enough apart so that the time the float takes to pass from one cross section to the other can be measured accurately. A traveltime of at least 20 seconds is recommended, but a shorter time can be used on small streams with high velocities, where it is impossible to select an adequate length of straight channel.

The procedure for a float measurement is to distribute a number of floats uniformly over the stream width, noting the position of each. They should be allowed to reach a constant velocity before timing by stopwatch the interval each takes to travel between two cross sections. The distance of each float from the bank as it passes each cross section should also be noted.

The velocity of the float is equal to the distance between the cross sections divided by the time of travel. Care must be taken when measuring low velocities, that the floats are not being affected by wind. The mean velocity of flow in the vertical is equal to the float velocity multiplied by a coefficient which is based on the shape of the vertical-velocity profile and relative depth of immersion of the float. A coefficient of about 0.85 is commonly used to convert surface velocity to mean velocity. The coefficient for rod floats varies from 0.85 to 1.00 depending on the shape of the cross section and the velocity distribution.

The discharge in each partial section is computed by multiplying the average area of the partial section by the mean velocity in the vertical for that partial section. The total discharge is equal to the sum of the discharges for all the partial sections.

Float measurements can be made with an accuracy within 10 percent under good conditions and when a certain amount of care is exercised. If a poor reach is selected and not enough float runs are made, the results can be as much as 25 percent in error. 


\section{Indirect Discharge Measurements}

During floods, it is frequently impossible or impractical to measure the peak discharges when they occur, because of conditions beyond control. Roads may be impassable; structures from which current-meter measurements might have been made may be nonexistent, not suitably located, or destroyed; knowledge of the flood rise may not be available sufficiently in advance to permit reaching the site near the time of the peak; the peak may be so sharp that a satisfactory current-meter measurement could not be made even with an engineer present at the time; the flow of debris or ice may be such as to prevent use of a current meter; or limitations of personnel might make it impossible to obtain direct measurements of high-stage discharge at numerous locations during a short flood period. Consequently, many peak discharges must be determined after the passage of the flood by indirect methods such as slopearea, contracted-opening, flow-over-dam, or flow-through-culvert, rather than by direct current-meter measurement.

Detailed descriptions of the procedures used in collecting field data and in computing the discharge are given in Benson and Dalrymple (1967), Dalrymple and Benson (1967), Bodhaine (1968), Matthai (1967), and Hulsing (1967), which are book 3 , chapters A1-A5, of this series. The use of electronic computers in these computations is explained by Anderson and Anderson ${ }^{2}$ and by Somers and Selner. ${ }^{2}$

\section{Dye-Dilution Method of Measuring Discharge}

Measurement of discharge by this method depends on determination of the degree of dilution of an added tracer solution by the flowing water. A solution of a stable or radioactive chemical is injected into the stream at either a constant rate or all at once. The solution be-

\footnotetext{
Anderson, D. B., and Anderson, W. L., Computation of water-surface profiles in open channels: U.S. Geol. Survey Techniques Water-Resources Inv., unpub. data.

2 Somers, W. P., and Seiner, G. Y., Computation of stage-discharge relationships at culverts and Computer technique for slope-area measurements: U.S. Geal. Survey Techniques Water-Resources Inv., unpub, data.
}

comes diluted by the discharge of the stream. Measurement of the rate of injection, the concentration of the tracer in the injected solution, and the concentration of the tracer at a cross section downstream from the injection point permits the computation of stream discharge. The accuracy of the method critically depends upon complete mixing of the injected solution through the stream cross section before the sampling station is reached and upon no adsorption of the tracer on stream-bottom materials. The method is recommended only for those sites where conventional methods cannot be employed owing to shallow depths, extremely high velocities, or excessive turbulence. A detailed description of the procedures and equipment used in measuring discharge by a dyedilution method is given by Cobb and Bailey. ${ }^{3}$

\section{References}

Benson, M. A., and Dalrymple, Tate, 1967, General field and office procedures for indirect measurements: U.S. Geol. Survey Techniques WaterResources Inv., book 3, chap. A1, 30 p.

Bodhaine, G. L., 1968, Measurement of peak discharge at culverts by indirect methods: U.S. Geol. Survey Techniques Water-Resources Inv., book 3 , chap. A3, 60 p.

Carter, R. W., and Anderson, I. E., 1963, Accuracy of current-meter measurements: Am. Soc. Civil Engineers Jour., v. 89, no. HY 4, p. 105-115.

Dalrymple, Tate, and Benson, M. A., 1967, Measurement of peak discharge by the slope-area method: U.S. Geol. Survey Techniques Water-Resources Inv., book 3, chap. A2, 12 p.

Hulsing, Harry, 1967, Measurement of peak discharge at dams by indirect methods: U.S. Geol. Survey Techniques Water-Resources Inv., book 3, chap. A5, $29 \mathrm{p}$.

Matthai, H. F., 1967, Measurement of peak discharge at width contractions by indirect methods: U.S. Geol. Survey Techniques Water-Resources Inv., book 3, chap. A4, 44p.

Pierce, C. H., 1941, Investigations of methods and equipment used in stream gaging, part 1 , Performance of current meters in water of shallow depth: U.S. Geol. Survey Water-Supply Paper 868-A, 35 p.

1947, Structures for cableways: U.S. Geol. Survey Circular 17,38 p., 25 pl.

Rouse, Hunter, 1950, Engineering Hydraulics: New York, John Wiley and Sons, p. 222, 223.

3 Cobb, E. D., and Bailey, J. F., Measurement of discharge by dye dilution nethods: U.S. Geol. Survey Techniques Water- Resources Inv., unpub. data. 
Schubauer, G. B., and Mason, M. A., 1937, Performance characteristics of a water current meter in water and air: Natl. Bur. Standards Research Paper, RP 981.

Smith, Winchell, 1961, Optical current meter in Short papers in the geologic and hydrologic sciences: U.S. Geol. Survey Prof. Paper 424-B, Art. 424, p. D383-D384.

Smoot, G. F., and Novak, C. E., 1968, Calibration and maintenance of vertical-axis type current meters: U.S. Geol. Survey Techniques Water-Resources
Inv., book 8, chap. B2, 23 p.

1968, Measurement of discharge by the moving boat method: U.S. Geol. Survey Techniques of Water-Resources Inv., book 3, chap. A11, 22 p.

Townsend, F. W., and Blust, F. A., 1960, A comparison of stream velocity meters: Am. Soc. Civil Engineers Jour., v. 86 , no. HY 4, p. 11-19.

Young, K. B., 1950, A comparative study of meansection and mid-section methods for computation of discharge measurements: U.S. Geol. Survey open-file report, $52 \mathrm{p}$. 